\title{
Talarodrides A-F, Nonadrides from Antarctic Sponge-Derived Fungus Talaromyces sp. HDN1820200
}

Yi Zhao, ${ }^{\perp, \dagger}$ Chunxiao Sun, ${ }^{\perp, \dagger}$ Luyao Huang, ${ }^{\dagger}$ Xiao Zhang, ${ }^{\dagger}$ Guojian Zhang, ${ }^{\dagger, \ddagger}$ Qian Che, ${ }^{\dagger}$ Dehai $\mathrm{Li}^{\dagger,+, \S,{ }^{*}}$ and Tianjiao $\mathrm{Zhu}^{\dagger, *}$

${ }^{\dagger}$ Key Laboratory of Marine Drugs, Chinese Ministry of Education, School of Medicine and Pharmacy, Ocean University of China, Qingdao 266003, P. R. China;

${ }^{\ddagger}$ Laboratory for Marine Drugs and Bioproducts of Qingdao National Laboratory for Marine Science and Technology, Qingdao, 266237, People’s Republic of China;

$\S$ Open Studio for Druggability Research of Marine Natural Products, Pilot National Laboratory for Marine Science and Technology, Qingdao, 266237, P. R. China

${ }^{\perp}$ The authors contributed equally to this paper. 


\section{List of supporting Information}

1. Spectral data for compound 1 Figures S1-S10

2. Spectral data for compound 2 Figures S11-S21

3. Spectral data for compound 3 Figures S22-S31

4. Spectral data for compound 4 Figures S32-S41

5. Spectral data for compound 5 Figures S42-S51

6. Spectral data for compound 6 Figures S52-S61

7. Spectral data for compound 6 Figures S52-S61

8. Spectral data for compound $2 \mathbf{g}$ Figures S62-S65

9. Key NOESY correlations of compound 2g Figure S66

10. Computational data of compounds 1-6 Figures S67-S70 and Tables S1-S12

11. The experimental ECD spectra for compound 5 and the calculated ones using the truncated model compounds (5a and $\mathbf{5 b}$ ) Figure S71

12. ITS rRNA gene sequence of HDN1820200 Figure S72

13. HPLC-UV profile of Talaromyces sp. HDN1820200 Figure S73 


\section{List of supporting Information}

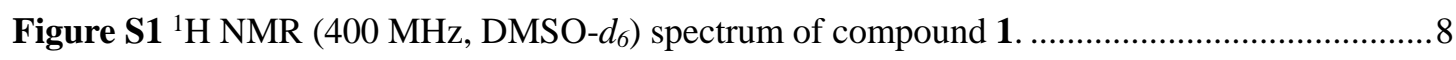

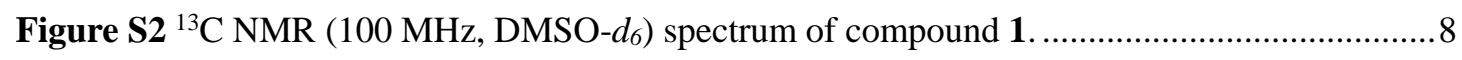

Figure S3 DEPT (100 MHz, DMSO-d 6 ) spectrum of compound 1...........................................

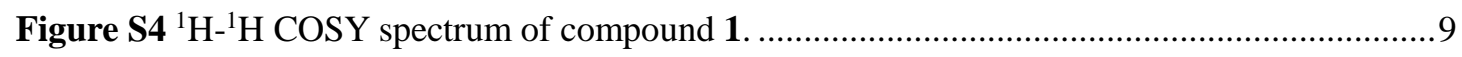

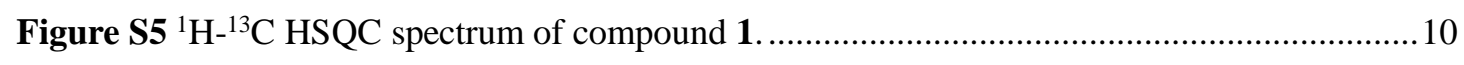

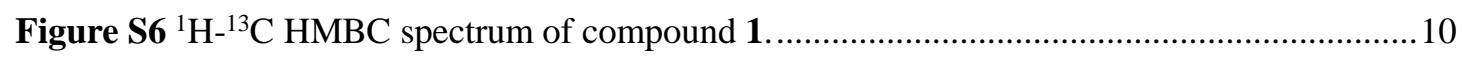

Figure S7 NOESY spectrum of compound 1 .....................................................................

Figure S8 HRESIMS spectrum of compound 1.................................................................... 11

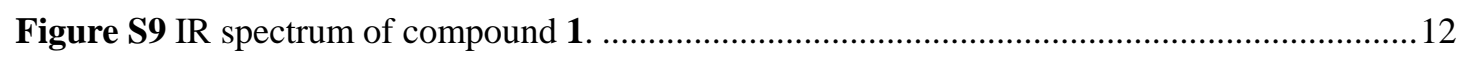

Figure S10 UV spectrum of compound 1 ...........................................................................12

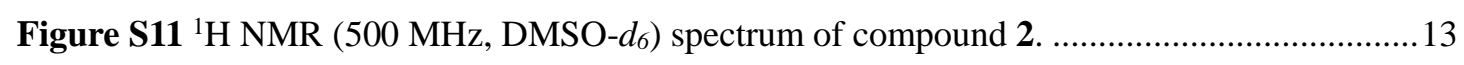

Figure S12 ${ }^{13} \mathrm{C}$ NMR $\left(125 \mathrm{MHz}\right.$, DMSO-d $\left.\mathrm{d}_{6}\right)$ spectrum of compound 2 .....................................13

Figure S13 DEPT (125 MHz, DMSO-d $d_{6}$ ) spectrum of compound 2........................................14

Figure S14 ${ }^{1} \mathrm{H}-{ }^{1} \mathrm{H}$ COSY spectrum of compound 2. ................................................................

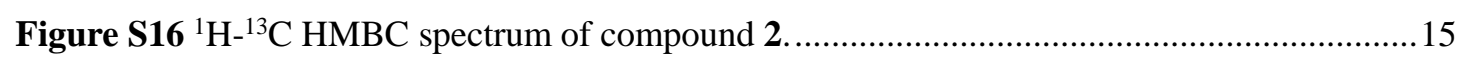

Figure $\mathbf{S 1 7}{ }^{1} \mathrm{H}_{-13} \mathrm{C}$ HSQMBC spectrum of compound 2.........................................................

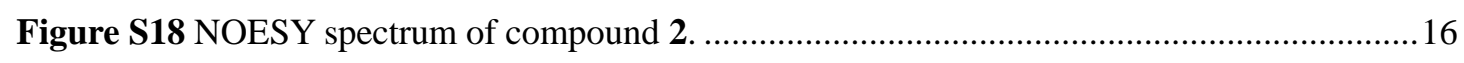

Figure S19 HRESIMS spectrum of compound 2 ………....................................................

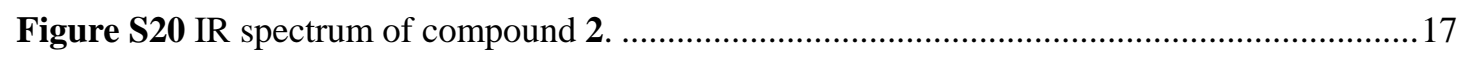

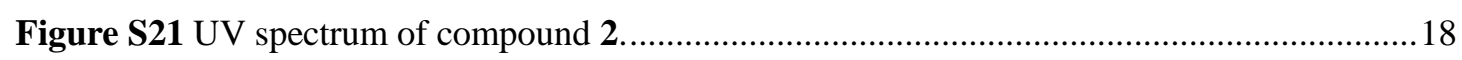


Figure S22 ${ }^{1} \mathrm{H}$ NMR (500 MHz, DMSO-d $)$ spectrum of compound 3.

Figure S23 ${ }^{13} \mathrm{C}$ NMR (125 MHz, DMSO- $\left.d_{6}\right)$ spectrum of compound 3.....................................19

Figure S24 DEPT (125 MHz, DMSO- $d_{6}$ ) spectrum of compound 3......................................20

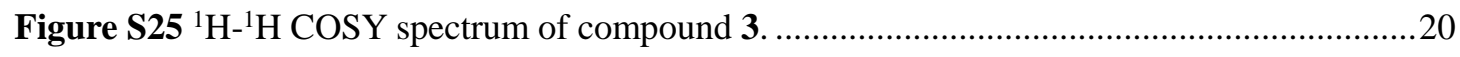

Figure S26 ${ }^{1} \mathrm{H}-{ }^{13} \mathrm{C}$ HSQC spectrum of compound 3..........................................................21

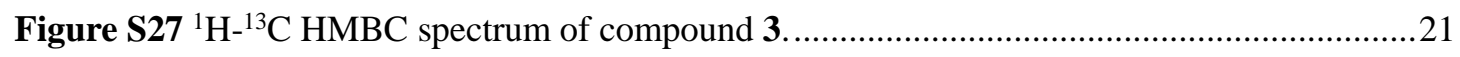

Figure S28 NOESY spectrum of compound 3. ..............................................................22

Figure S29 HRESIMS spectrum of compound 3. .............................................................22

Figure S30 IR spectrum of compound 3. ......................................................................23

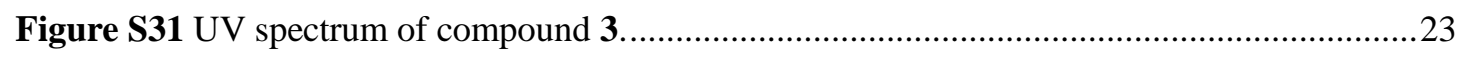

Figure S32 ${ }^{1} \mathrm{H}$ NMR (400 MHz, DMSO-d $)$ spectrum of compound 4. ...................................24

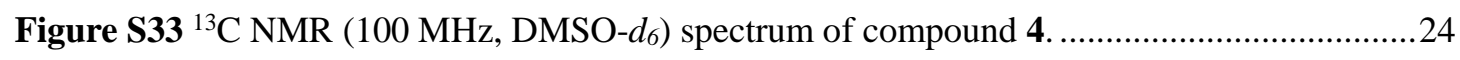

Figure S34 DEPT (100 MHz, DMSO-d $d_{6}$ ) spectrum of compound 4.......................................25

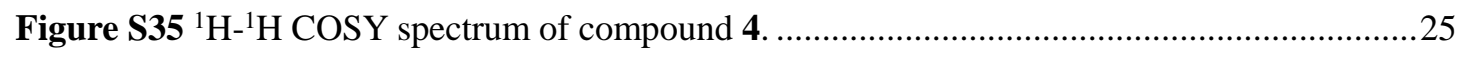

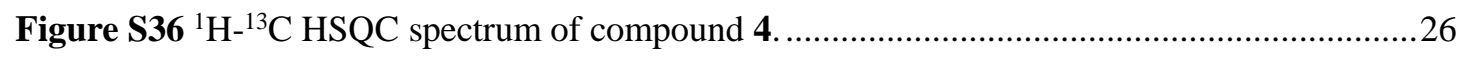

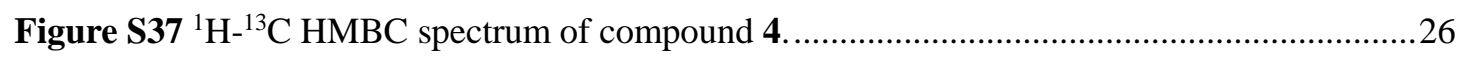

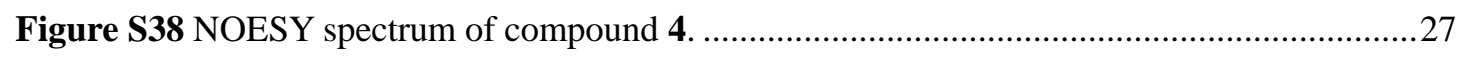

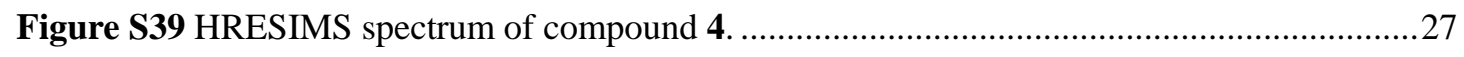

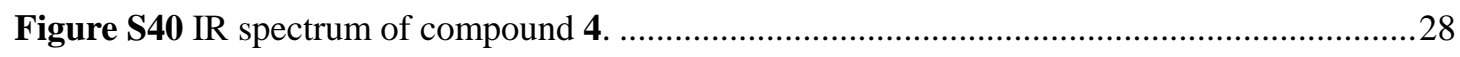

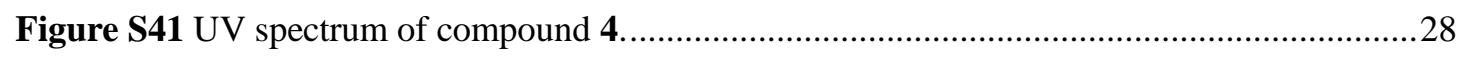

Figure S42 ${ }^{1} \mathrm{H}$ NMR (500 MHz, DMSO-d $)$ spectrum of compound 5.....................................29

Figure S43 ${ }^{13} \mathrm{C}$ NMR $\left(125 \mathrm{MHz}\right.$, DMSO- $\left.d_{6}\right)$ spectrum of compound 5...................................29 
Figure S44 DEPT (125 MHz, DMSO-d $)$ spectrum of compound 5.

Figure $\mathbf{5 4 5}{ }^{1} \mathrm{H}-{ }^{1} \mathrm{H}$ COSY spectrum of compound 5. 30

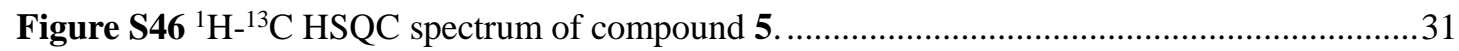

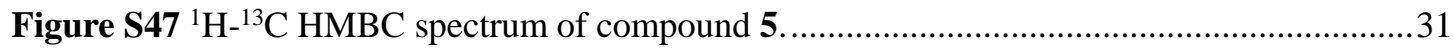

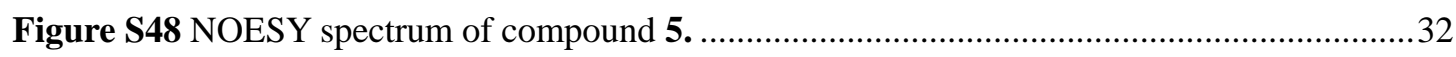

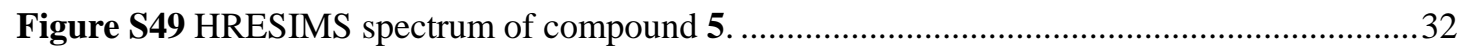

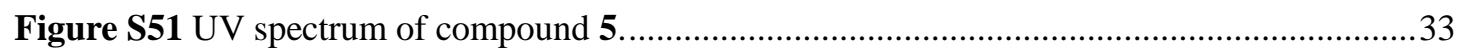

Figure S52 ${ }^{1} \mathrm{H}$ NMR (600 MHz, DMSO-d $d_{6}$ spectrum of compound 6. ....................................34

Figure S53 ${ }^{13} \mathrm{C}$ NMR $\left(150 \mathrm{MHz}\right.$, DMSO- $\left.d_{6}\right)$ spectrum of compound 6.................................34

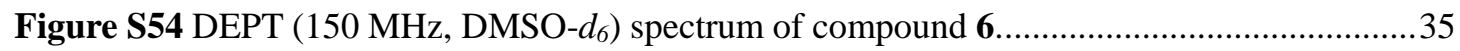

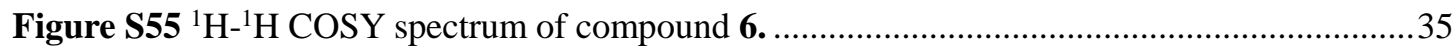

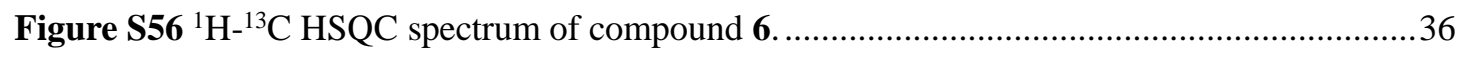

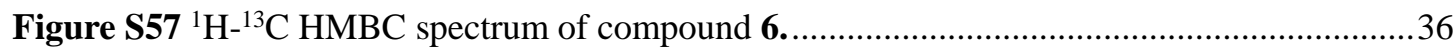

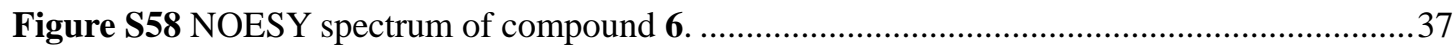

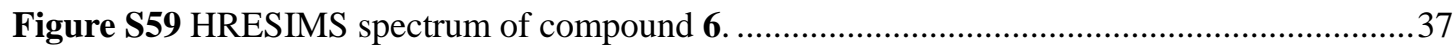

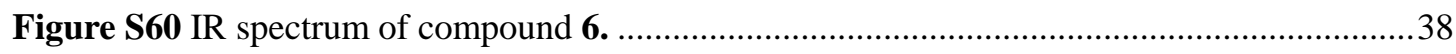

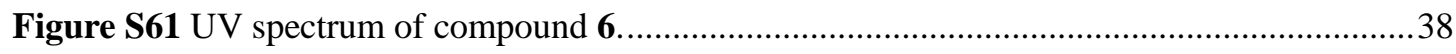

Figure S62 ${ }^{1} \mathrm{H}$ NMR (400 MHz, DMSO- $\left.d_{6}\right)$ spectrum of compound 2g. .................................39

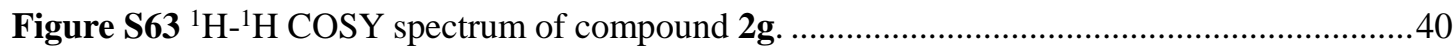

Figure S64 NOESY spectrum of compound 2 g. ............................................................ 40

Figure S65 HRESIMS spectrum of compound 2g. ................................................................ 41

Figure S66 Key NOESY correlations of compound 2g. ......................................................4 
Figure S67. DFT-optimized structures for low-energy conformers of $(7 R, 8 R, 12 R, 15 R, 22 S)$-1a at B3LYP/6-31+G(d) level in methanol (CPCM) (Conformer populations were calculated using the Gibbs free energy and Boltzmann population at $298 \mathrm{~K}$ estimated thereof). .42

Table S1. Harmonic frequencies $\left(\mathrm{cm}^{* *-1}\right)$ of $1 \mathrm{~A}$. .42

Table S2. Important thermodynamic parameters (a.u.) and Boltzmann distributions of the optimized 1a at B3LYP/6-31G+(d) level of theory with PCM solvent model for MeOH. .42

Table S3. Cartesian coordinates of the low-energy reoptimized conformers of $(7 R, 8 R, 12 R, 15 R$, 22S)-1a calculated at B3LYP/6-31+G(d) level of theory with PCM solvent model for MeOH. ....43 Figure S68. DFT-optimized structures for low-energy conformers of $(7 R, 8 R, 12 R, 15 R, 16 R, 18 R$, 22S)-4a at B3LYP/6-31+G(d) level in methanol (CPCM) (Conformer populations were calculated using the Gibbs free energy and Boltzmann population at $298 \mathrm{~K}$ estimated thereof). .44

Table S5. Important thermodynamic parameters (a.u.) and Boltzmann distributions of the optimized 4a at B3LYP/6-31G+(d) level of theory with PCM solvent model for MeOH. .44

Table S6. Cartesian coordinates of the low-energy reoptimized conformers of $(7 R, 8 R, 12 R, 15 R$, $16 R, 18 R, 22 S)-4 a$ calculated at B3LYP/6-31+G(d) level of theory with PCM solvent model for $\mathrm{MeOH}$. .45

Figure S69. DFT-optimized structures for low-energy conformers of ( $7 R, 8 R, 12 R, 15 R, 16 R, 18 R)$ 5a at B3LYP/6-31+G(d) level in methanol (CPCM) (Conformer populations were calculated using the Gibbs free energy and Boltzmann population at $298 \mathrm{~K}$ estimated thereof). .46

Table S7. Harmonic frequencies $\left(\mathrm{cm}^{* *-1}\right)$ of 5 A. .47

Table S8. Important thermodynamic parameters (a.u.) and Boltzmann distributions of the optimized 5a at B3LYP/6-31G+(d) level of theory with PCM solvent model for MeOH. .47 
Table S9. Cartesian coordinates of the low-energy reoptimized conformers of $(7 R, 8 R, 12 R, 15 R$, 16R, 18R)-5a calculated at B3LYP/6-31+G(d) level of theory with PCM solvent model for MeOH.

Figure S70. DFT-optimized structures for low-energy conformers of (7R, $8 R, 12 S, 15 R, 16 R, 18 R)$ 6a at B3LYP/6-31+G(d) level in methanol (CPCM) (Conformer populations were calculated using the Gibbs free energy and Boltzmann population at $298 \mathrm{~K}$ estimated thereof). ...............................50

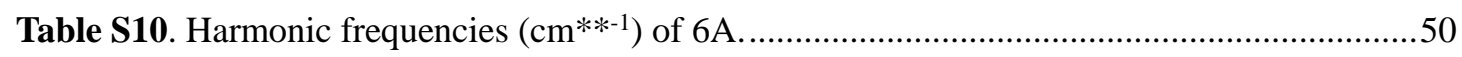

Table S11. Important thermodynamic parameters (a.u.) and Boltzmann distributions of the optimized 6a at B3LYP/6-31G+(d) level of theory with PCM solvent model for MeOH. .50

Table S12. Cartesian coordinates of the low-energy reoptimized conformers of $(7 R, 8 R, 12 S, 15 R$, 16R, 18R)-6a calculated at B3LYP/6-31+G(d) level of theory with PCM solvent model for MeOH.

Figure S71. The experimental ECD spectra for compound $\mathbf{5}$ and the calculated ones using the truncated model compounds (5a and $\mathbf{5 b}$ ). . .52

Figure S72. ITS rRNA gene sequence of HDN1820200. .52

Figure S73. HPLC-UV profile of Talaromyces sp. HDN1820200. .53 
Figure S1 ${ }^{1} \mathrm{H}$ NMR (400 MHz, DMSO- $d_{6}$ ) spectrum of compound 1.

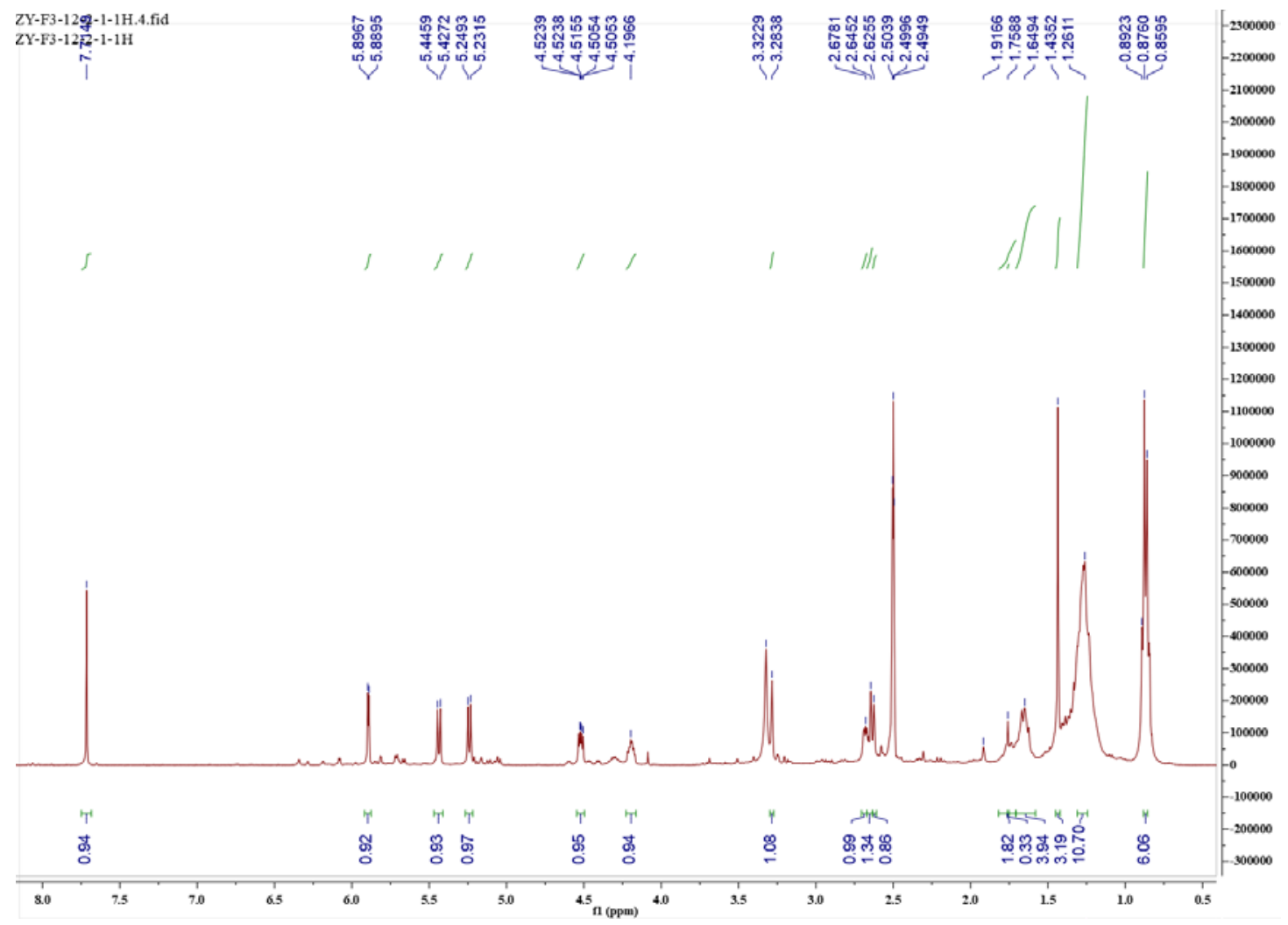

Figure S2 ${ }^{13} \mathrm{C}$ NMR (100 MHz, DMSO- $d_{6}$ ) spectrum of compound $\mathbf{1}$.

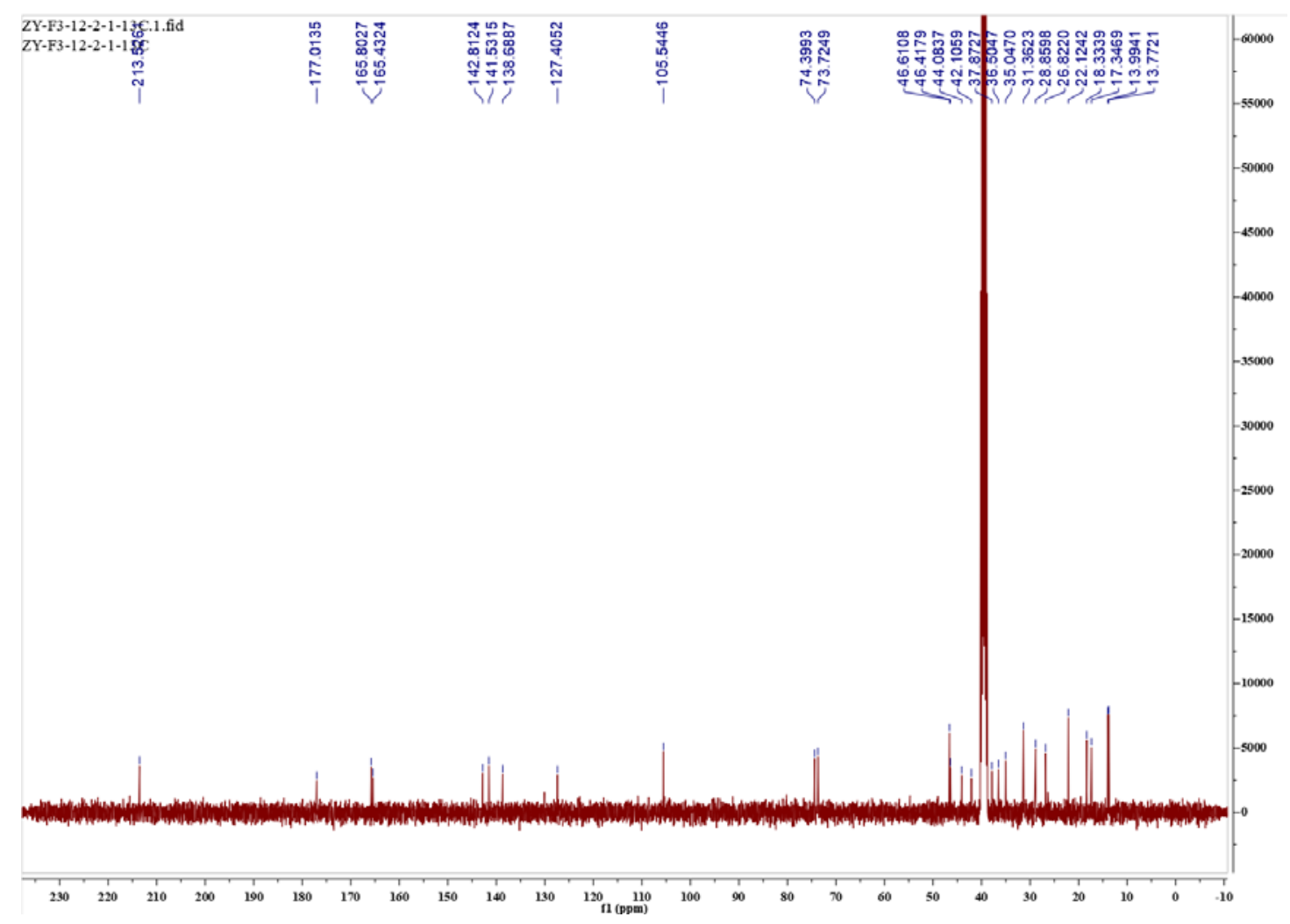


Figure S3 DEPT (100 MHz, DMSO-d $d_{6}$ ) spectrum of compound 1.

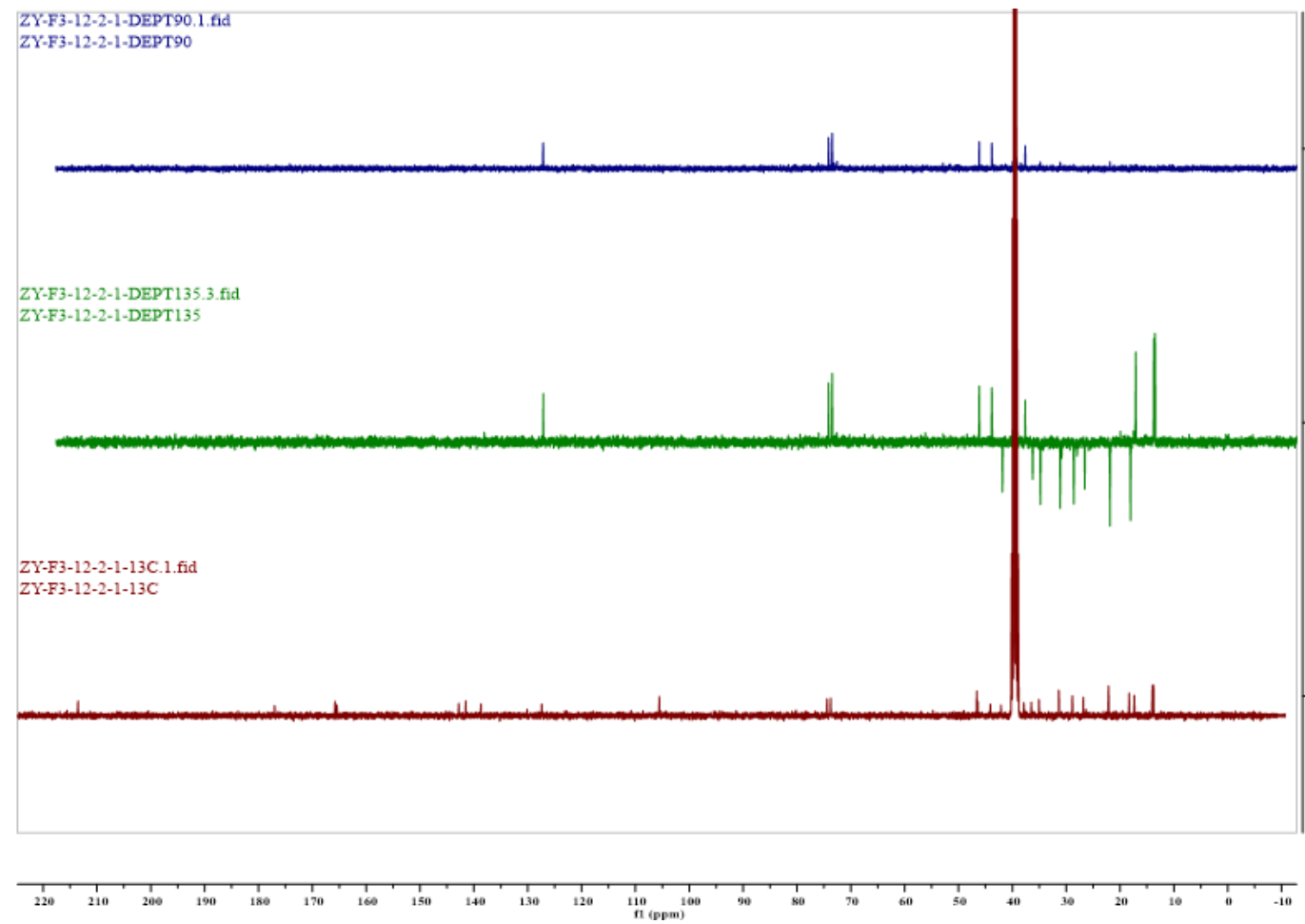

Figure S4 ${ }^{1} \mathrm{H}-{ }^{1} \mathrm{H}$ COSY spectrum of compound 1 .

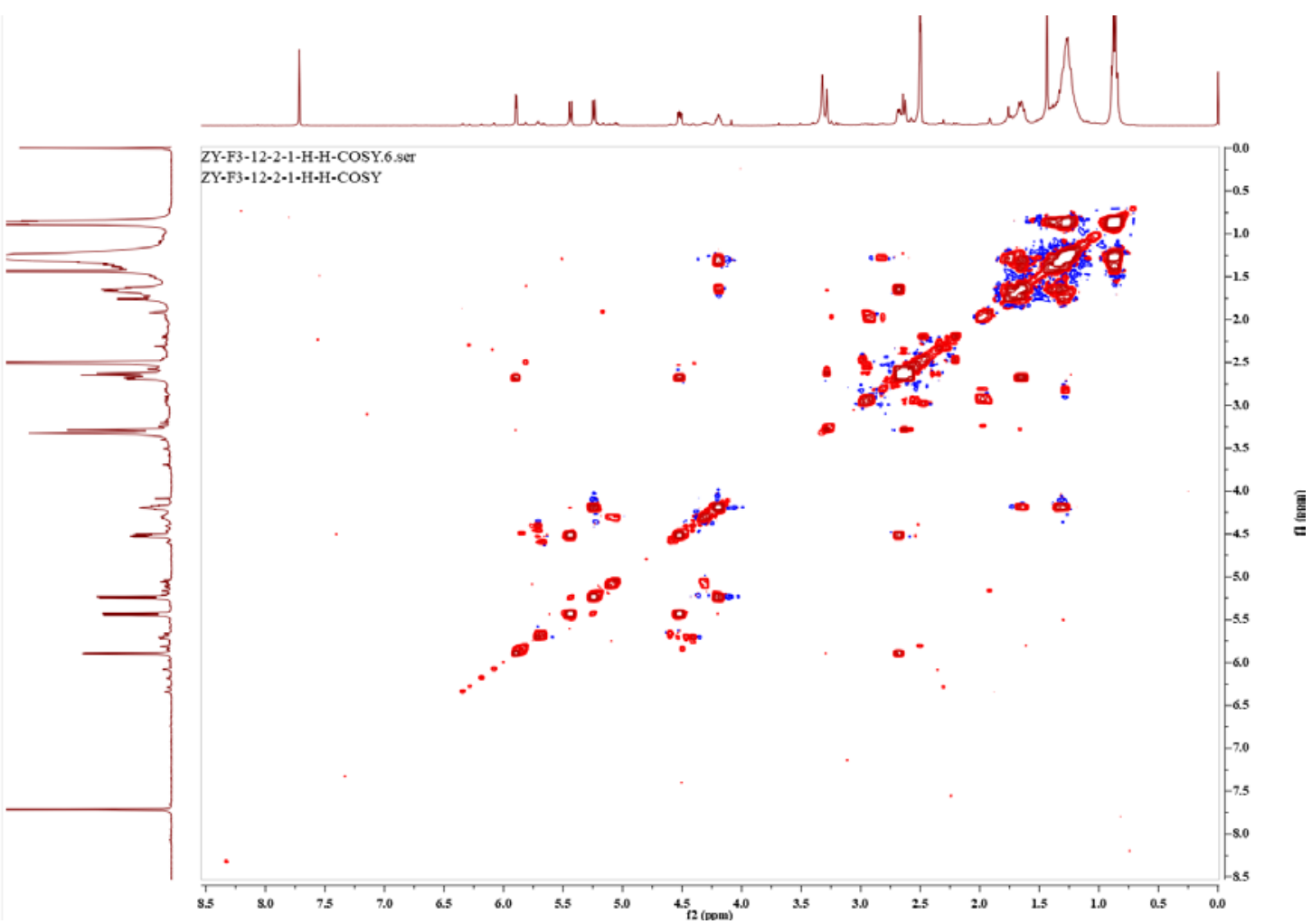


Figure S5 ${ }^{1} \mathrm{H}^{13} \mathrm{C}$ HSQC spectrum of compound 1.

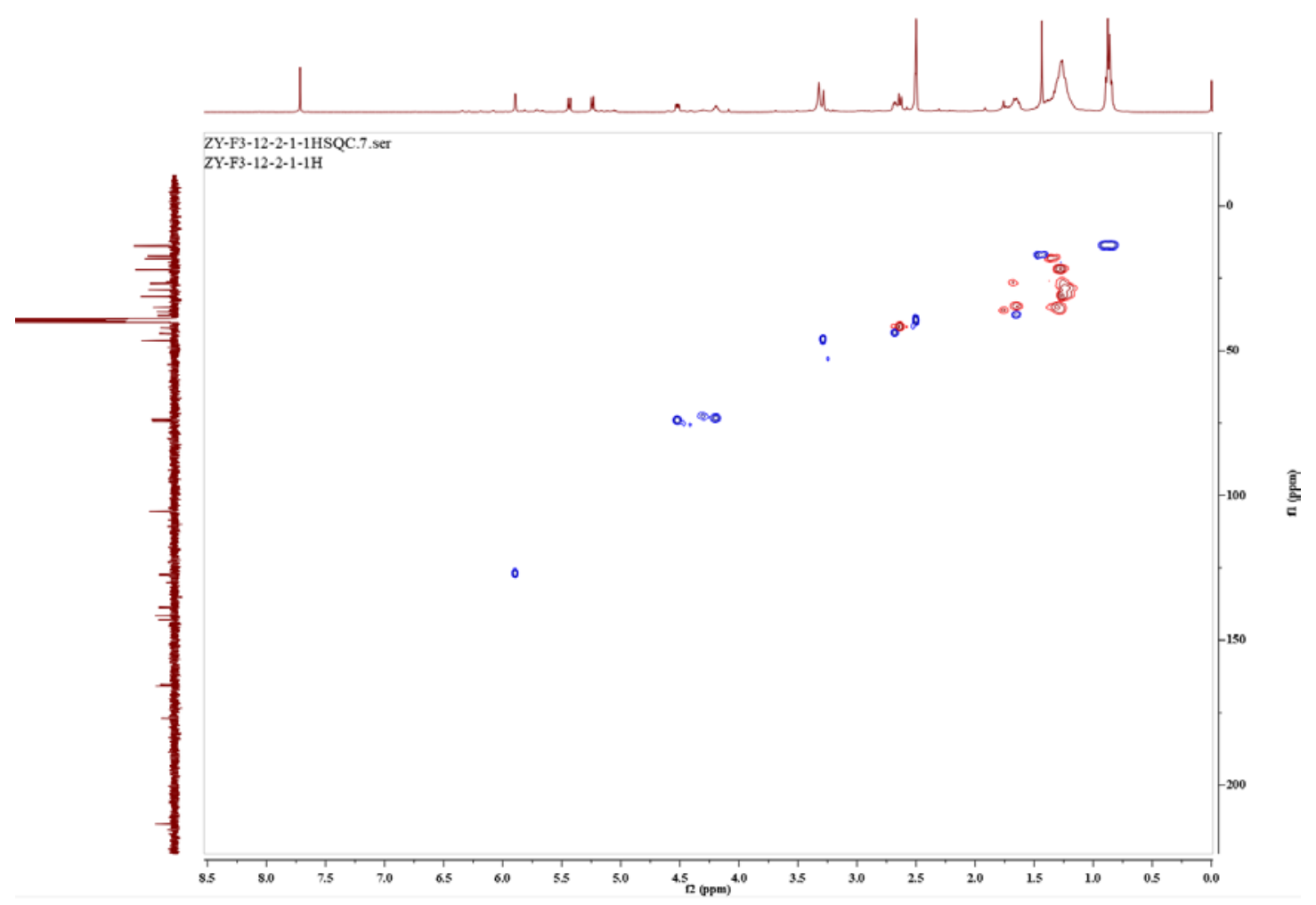

Figure S6 ${ }^{1} \mathrm{H}_{-}{ }^{13} \mathrm{C}$ HMBC spectrum of compound 1.

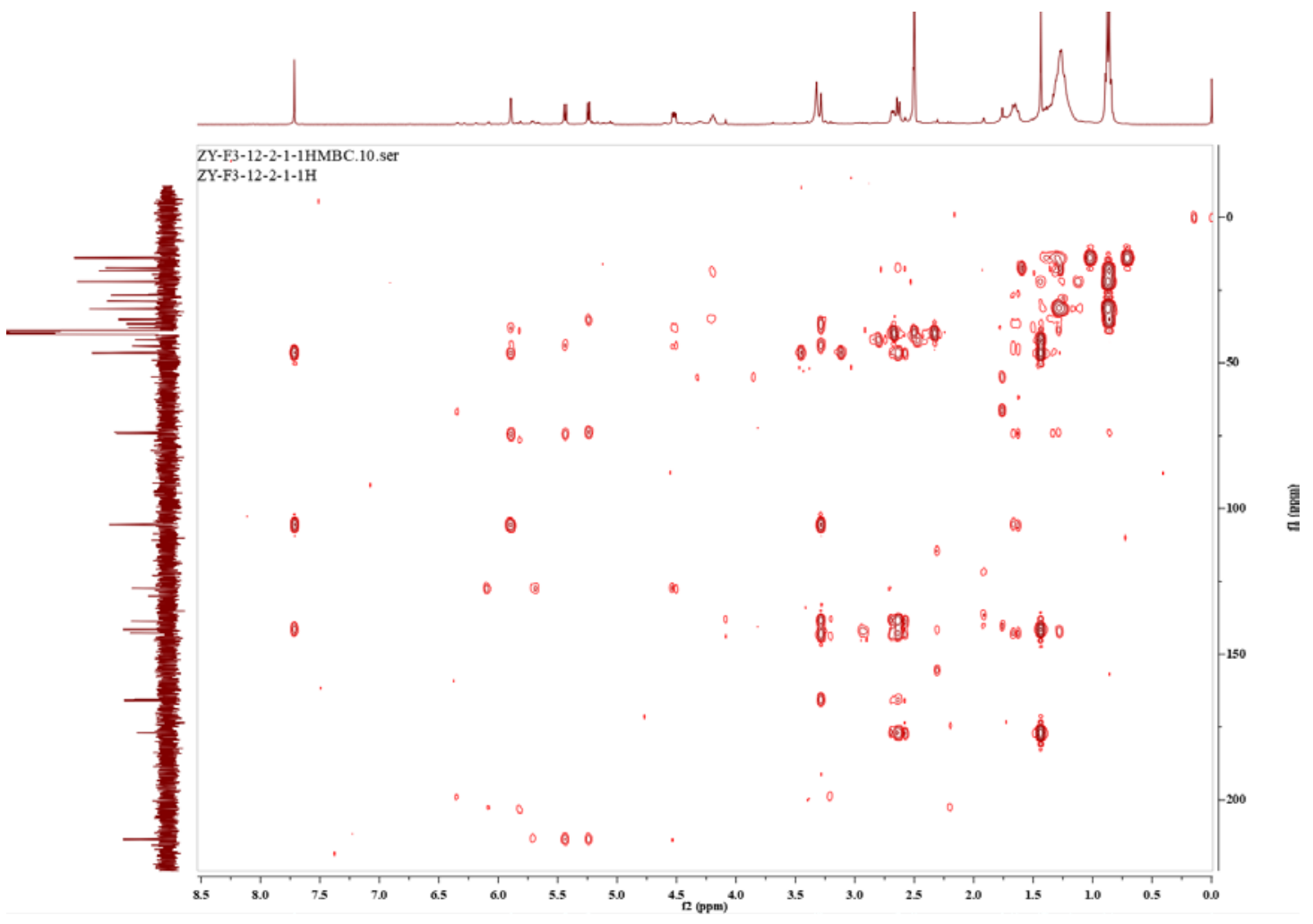

10 
Figure S7 NOESY spectrum of compound 1.

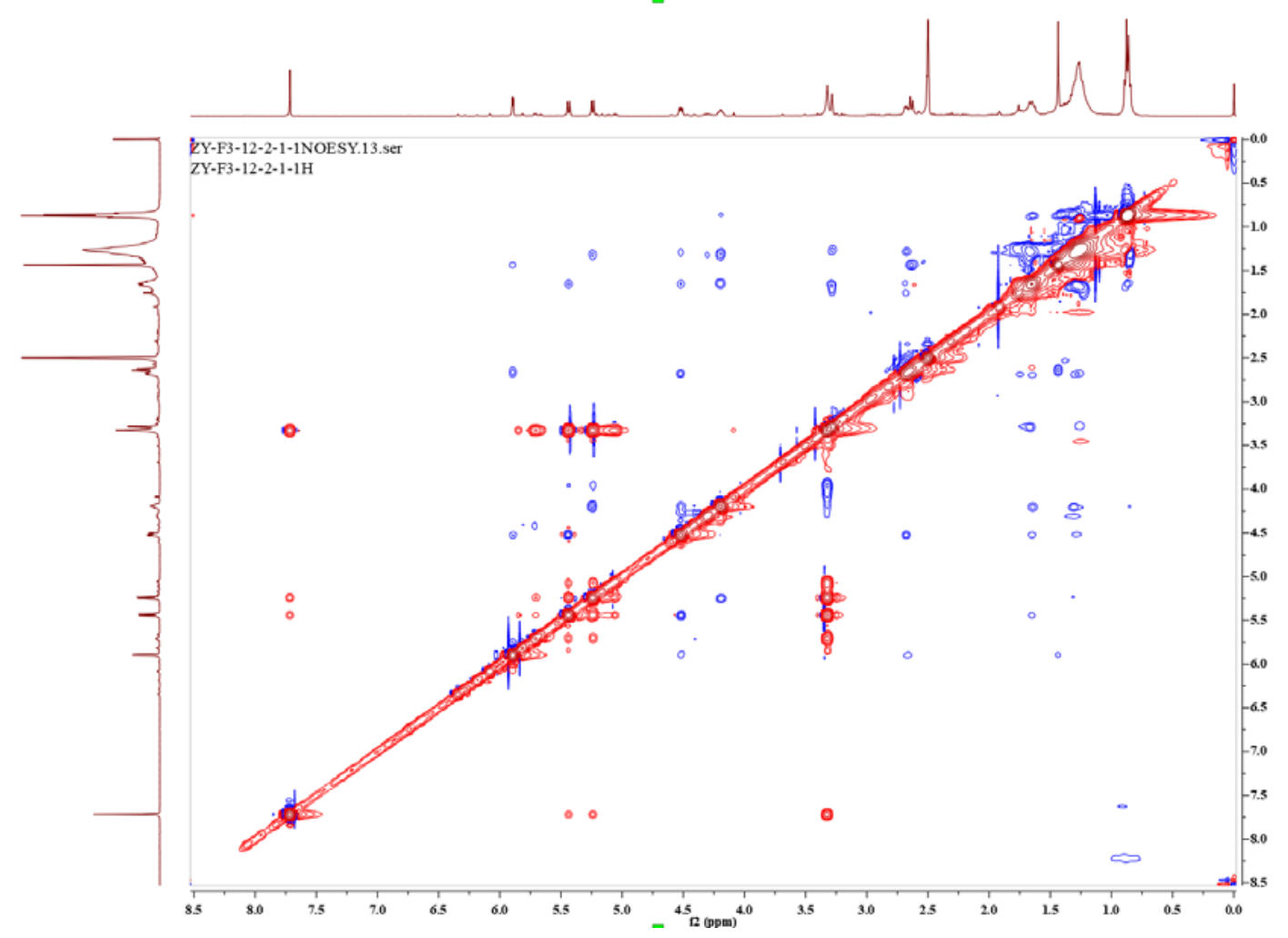

Figure S8 HRESIMS spectrum of compound 1.

20191030-ZY-F3-3-20-1_191030073932

10/30/2019 7:39:33 AM

ZY-F3-3-20-1

20191030-ZY-F3-3-20-1_191030073932 \#77-78 RT: 1.72-1.74 AV: 2 SB: 16 0.16-0.50 NL: 2.95E3 T: FTMS - p ESI Full ms [150.00-2000.00]

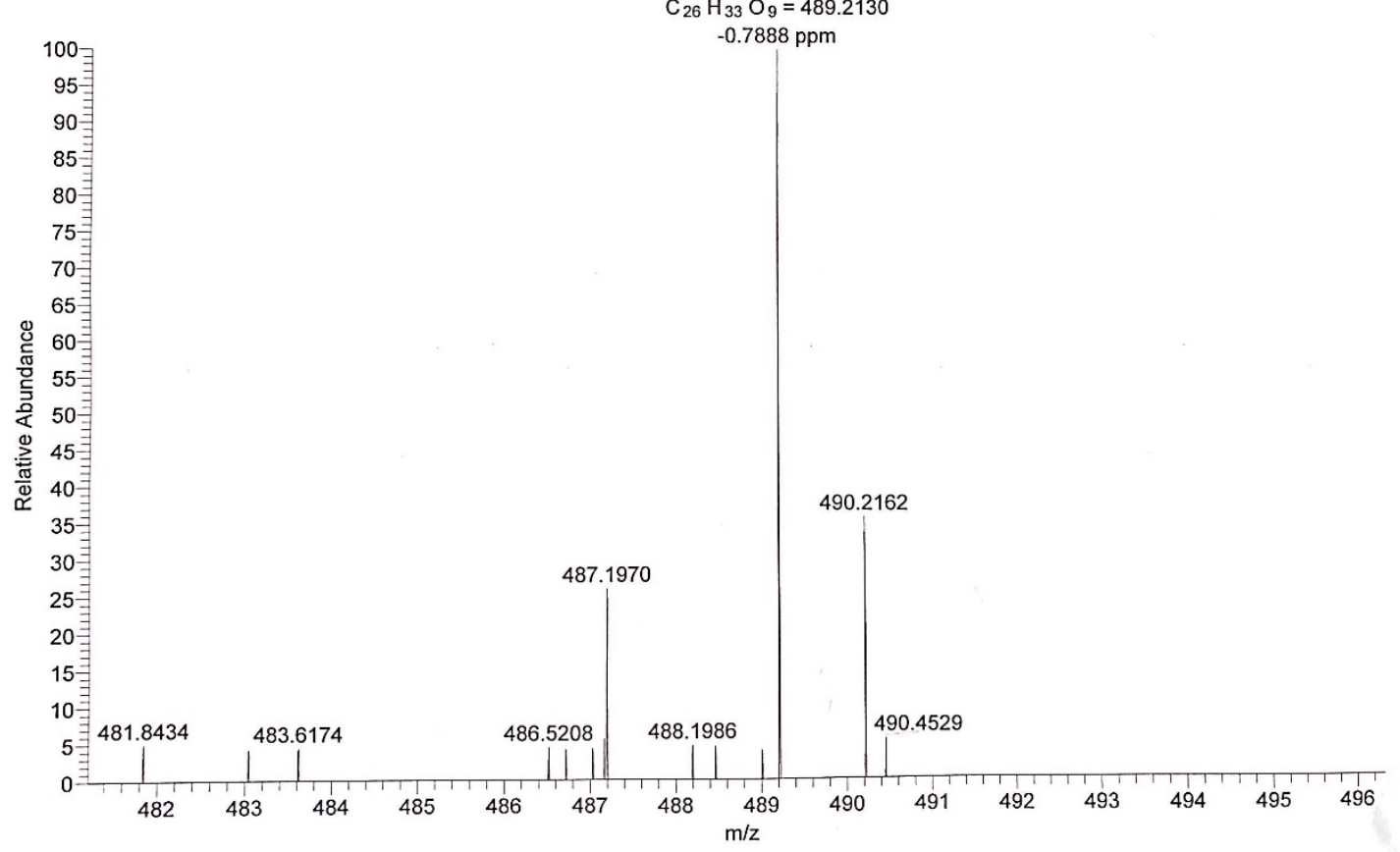


Figure S9 IR spectrum of compound 1.

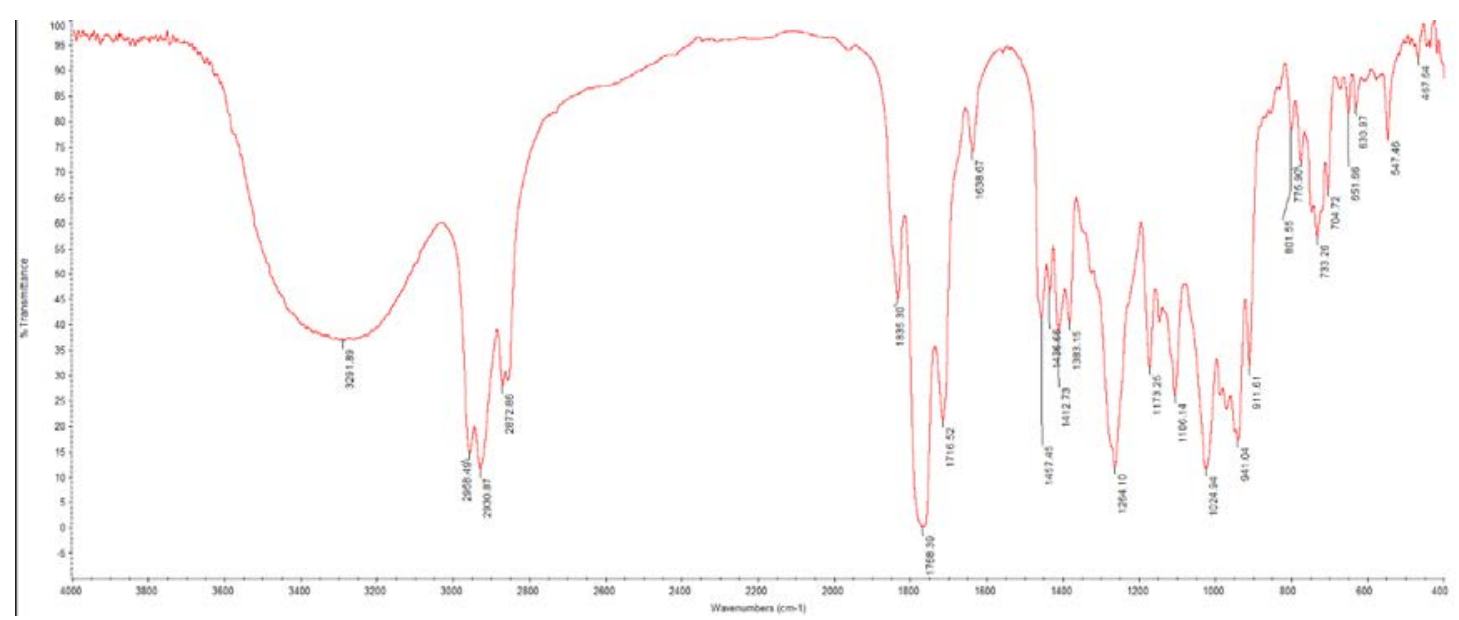

Figure S10 UV spectrum of compound 1.

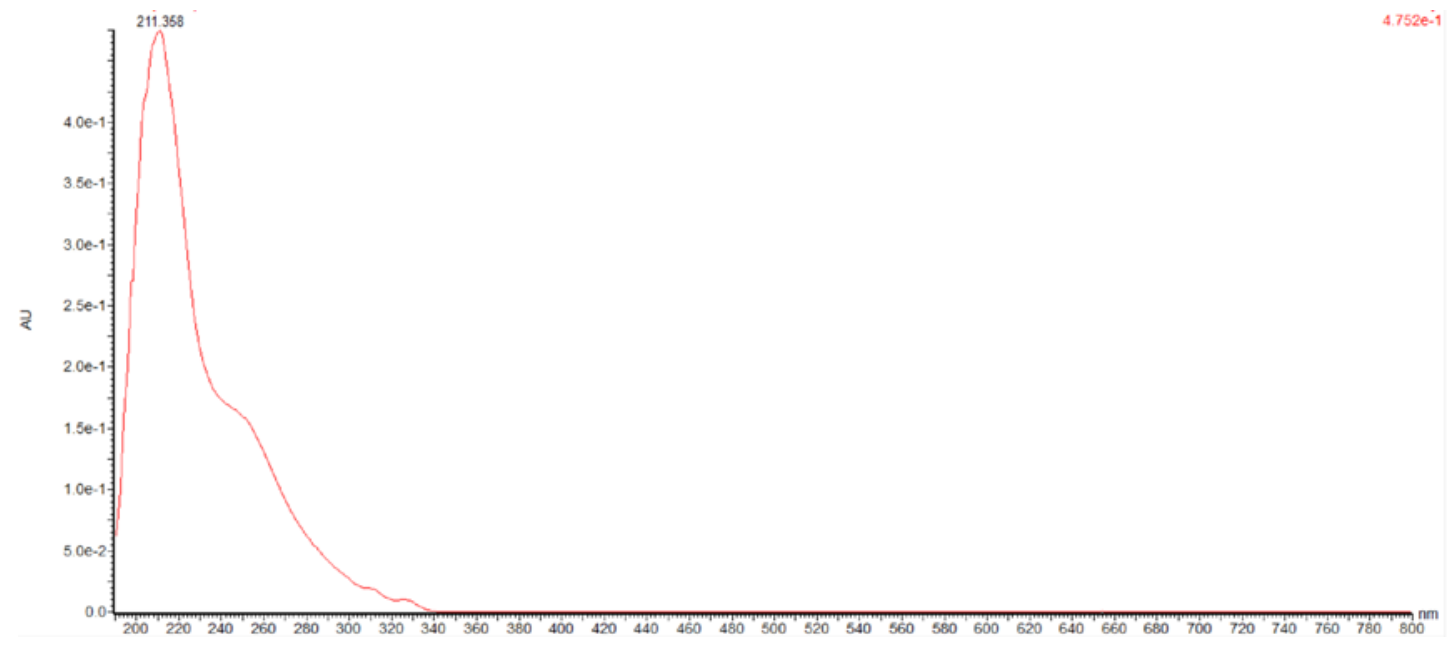


Figure S11 ${ }^{1} \mathrm{H}$ NMR (500 MHz, DMSO- $d_{6}$ ) spectrum of compound 2.

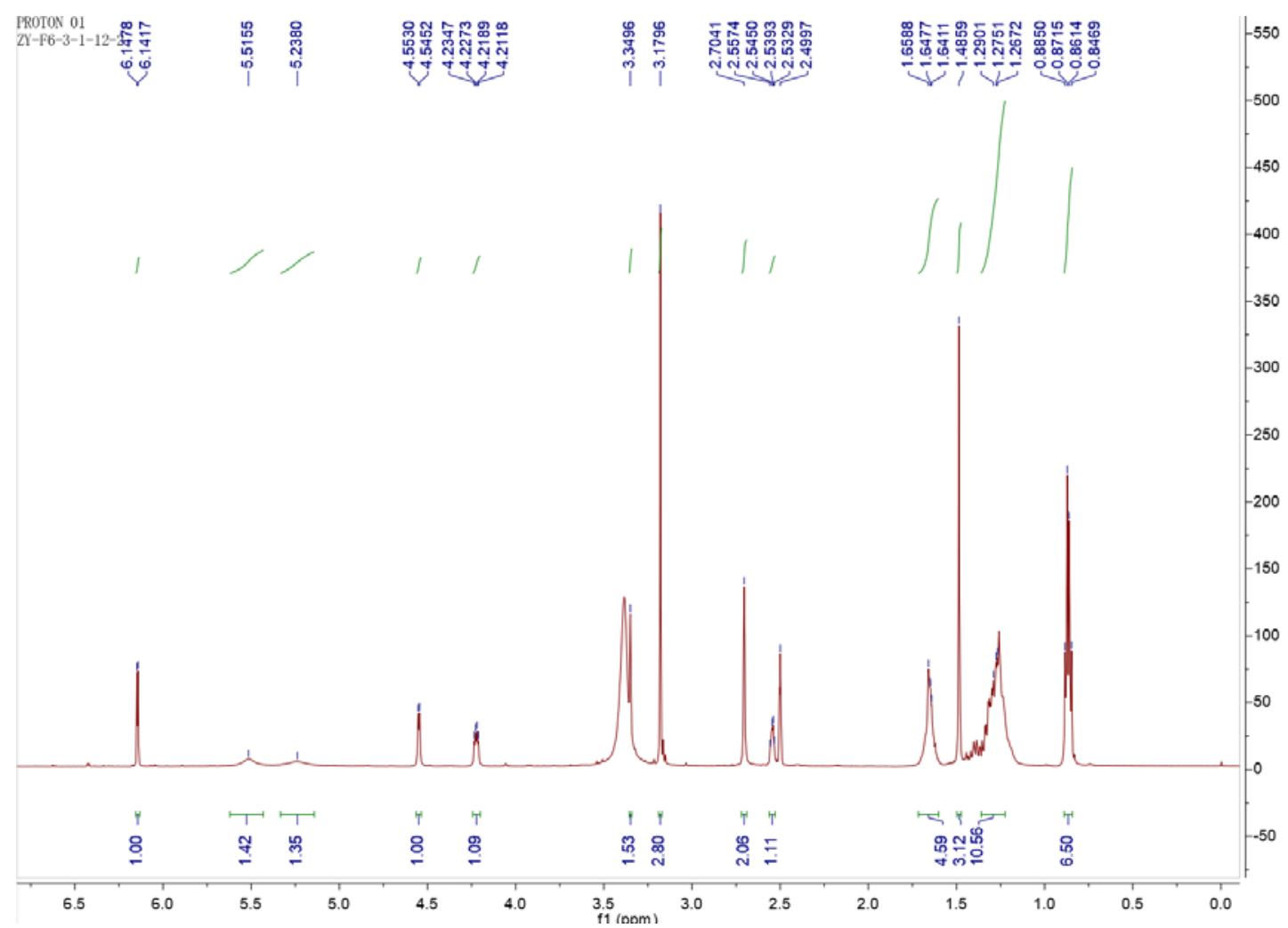

Figure S12 ${ }^{13} \mathrm{C}$ NMR (125 MHz, DMSO- $\left.d_{6}\right)$ spectrum of compound 2.

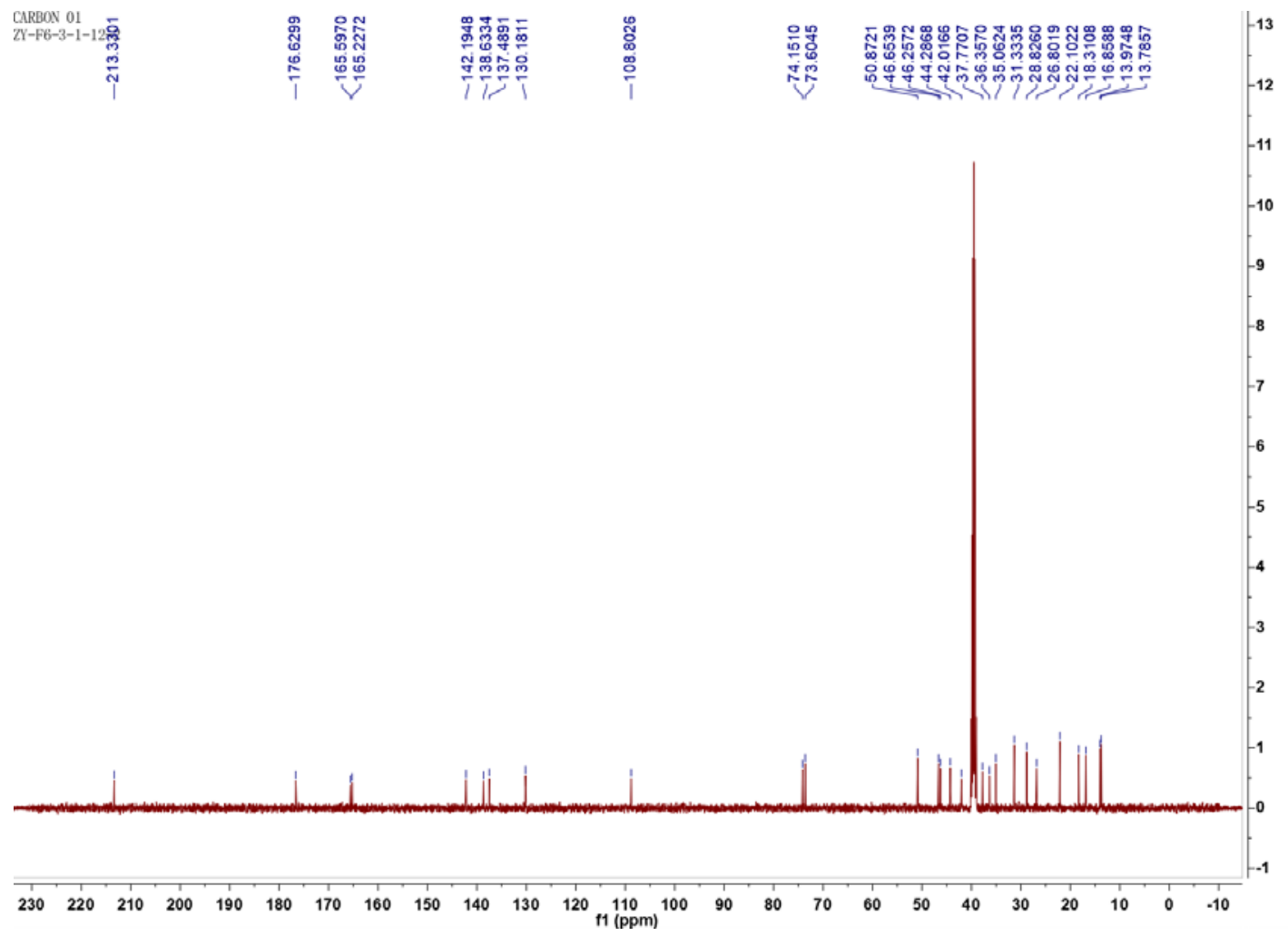


Figure S13 DEPT (125 MHz, DMSO- $d_{6}$ ) spectrum of compound 2.

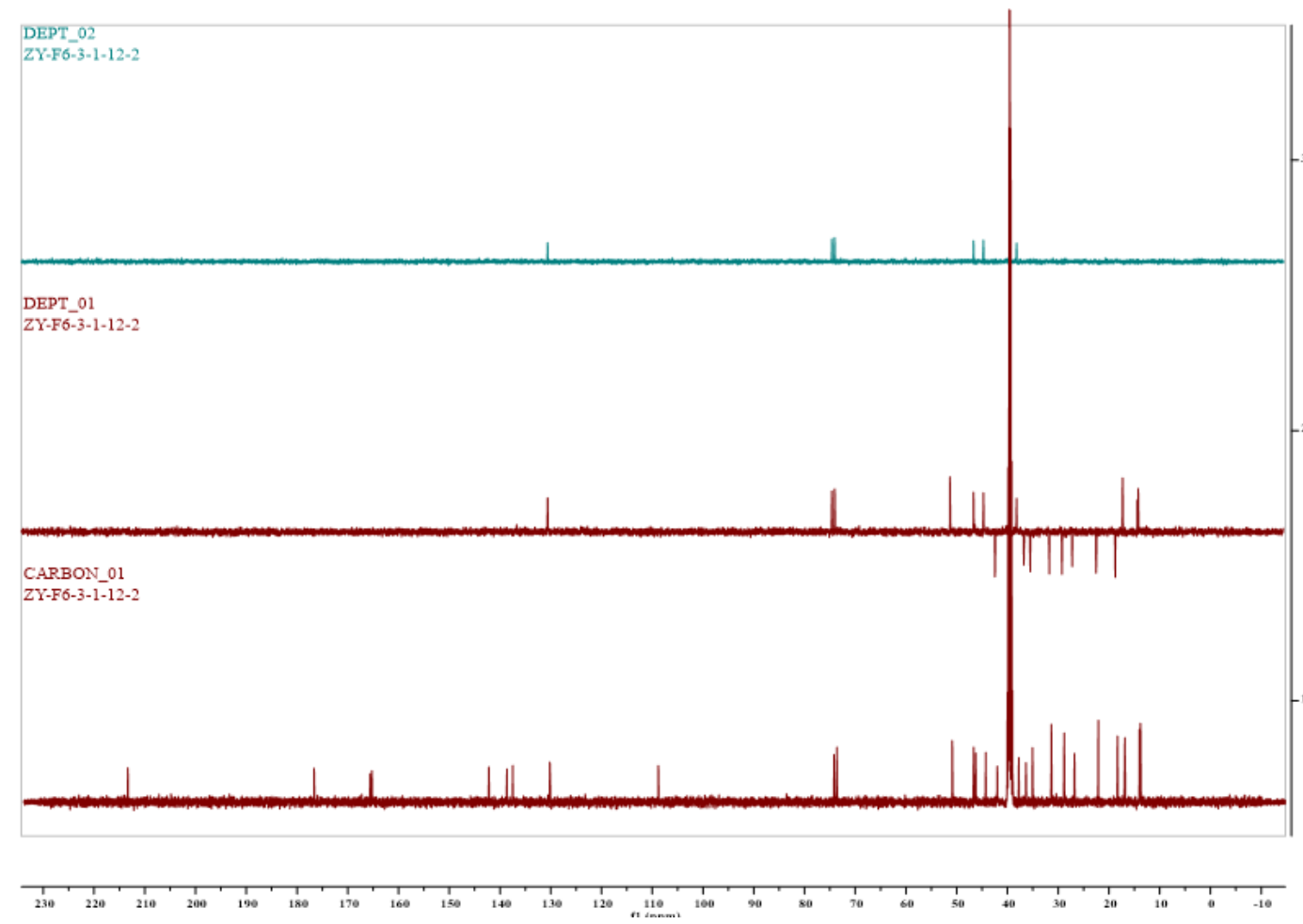

Figure S14 ${ }^{1} \mathrm{H}-{ }^{1} \mathrm{H}$ COSY spectrum of compound 2 .

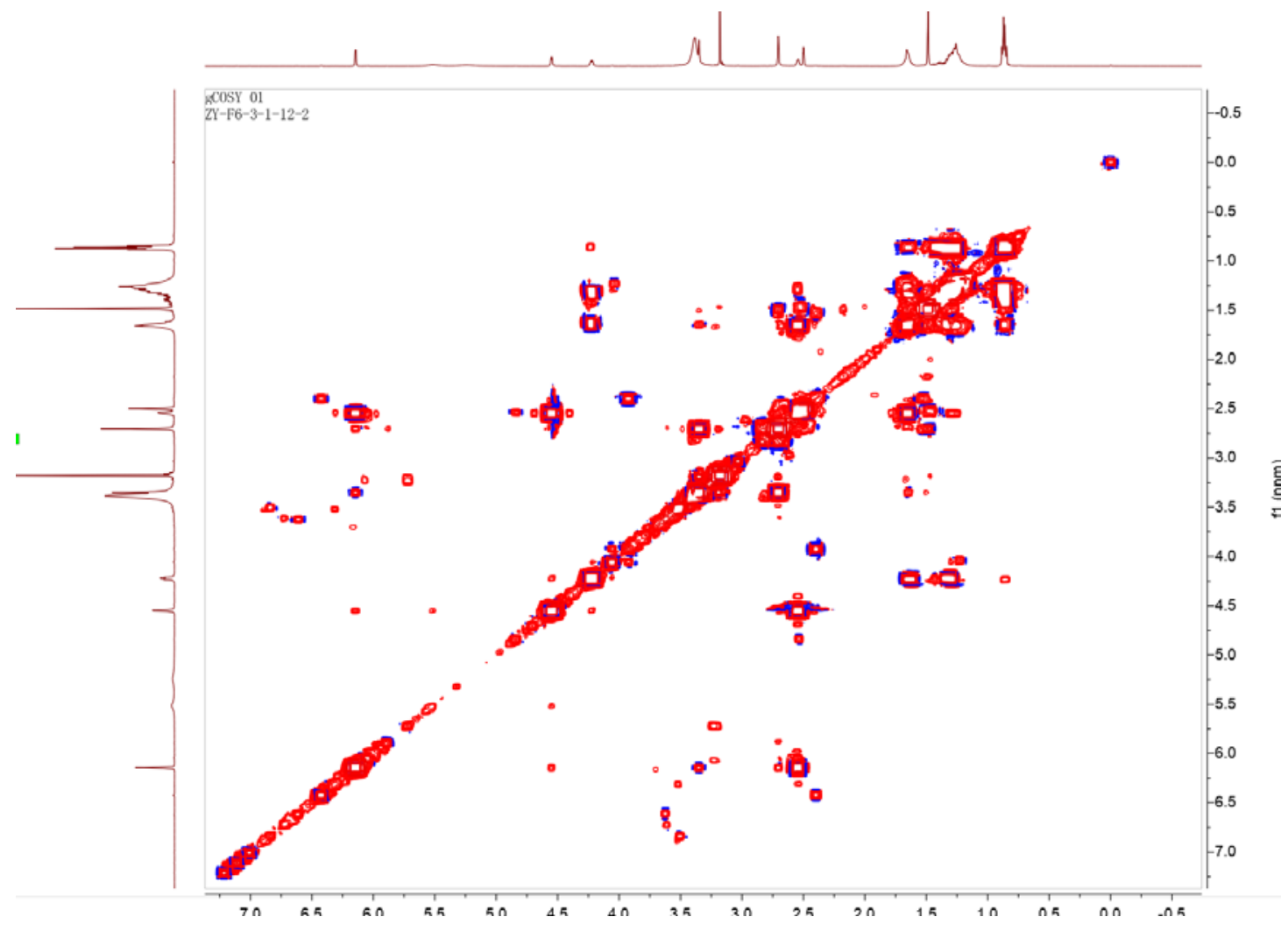


Figure S15 ${ }^{1} \mathrm{H}-{ }^{13} \mathrm{C}$ HSQC spectrum of compound 2 .

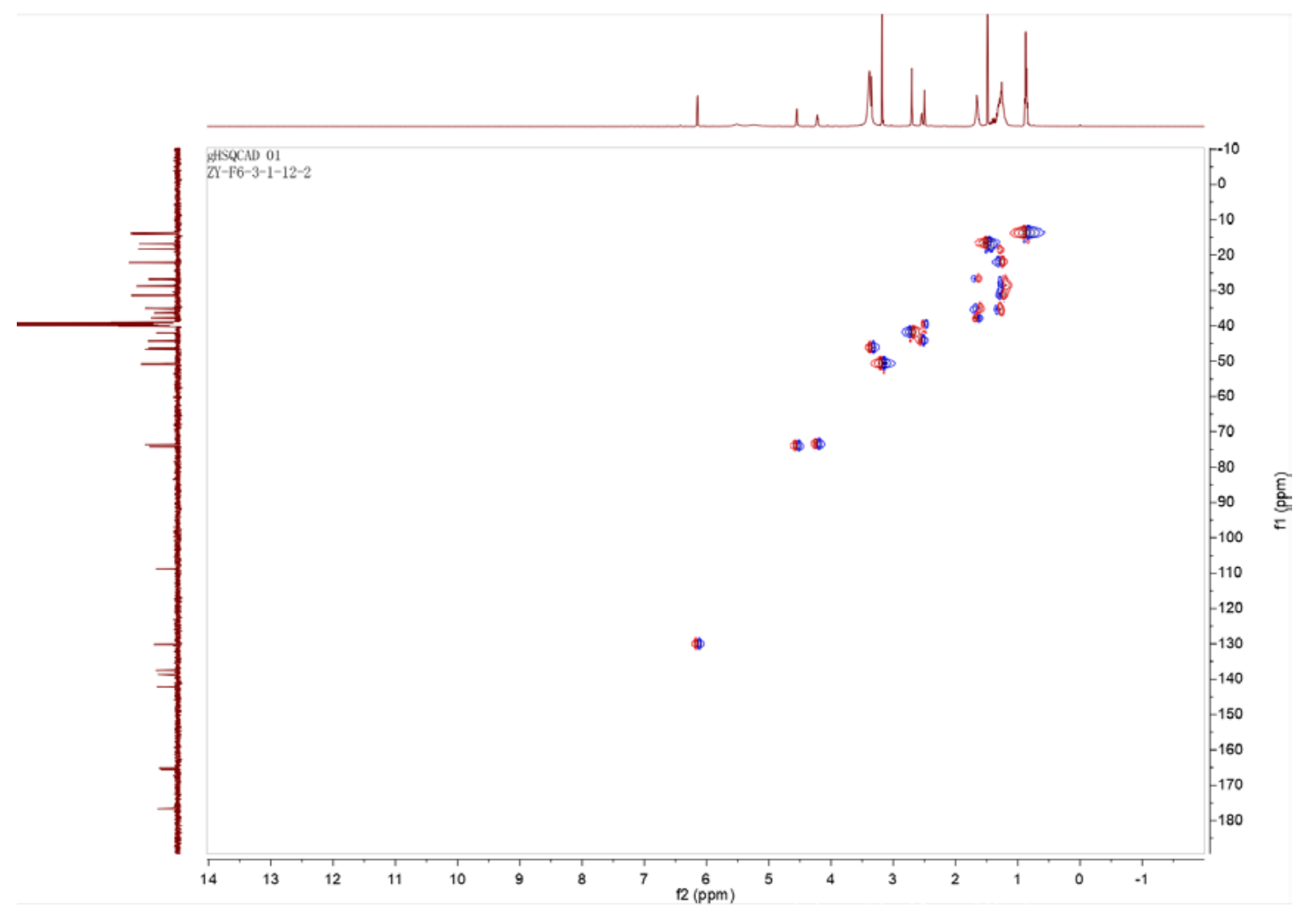

Figure S16 ${ }^{1} \mathrm{H}^{13} \mathrm{C}$ HMBC spectrum of compound 2.

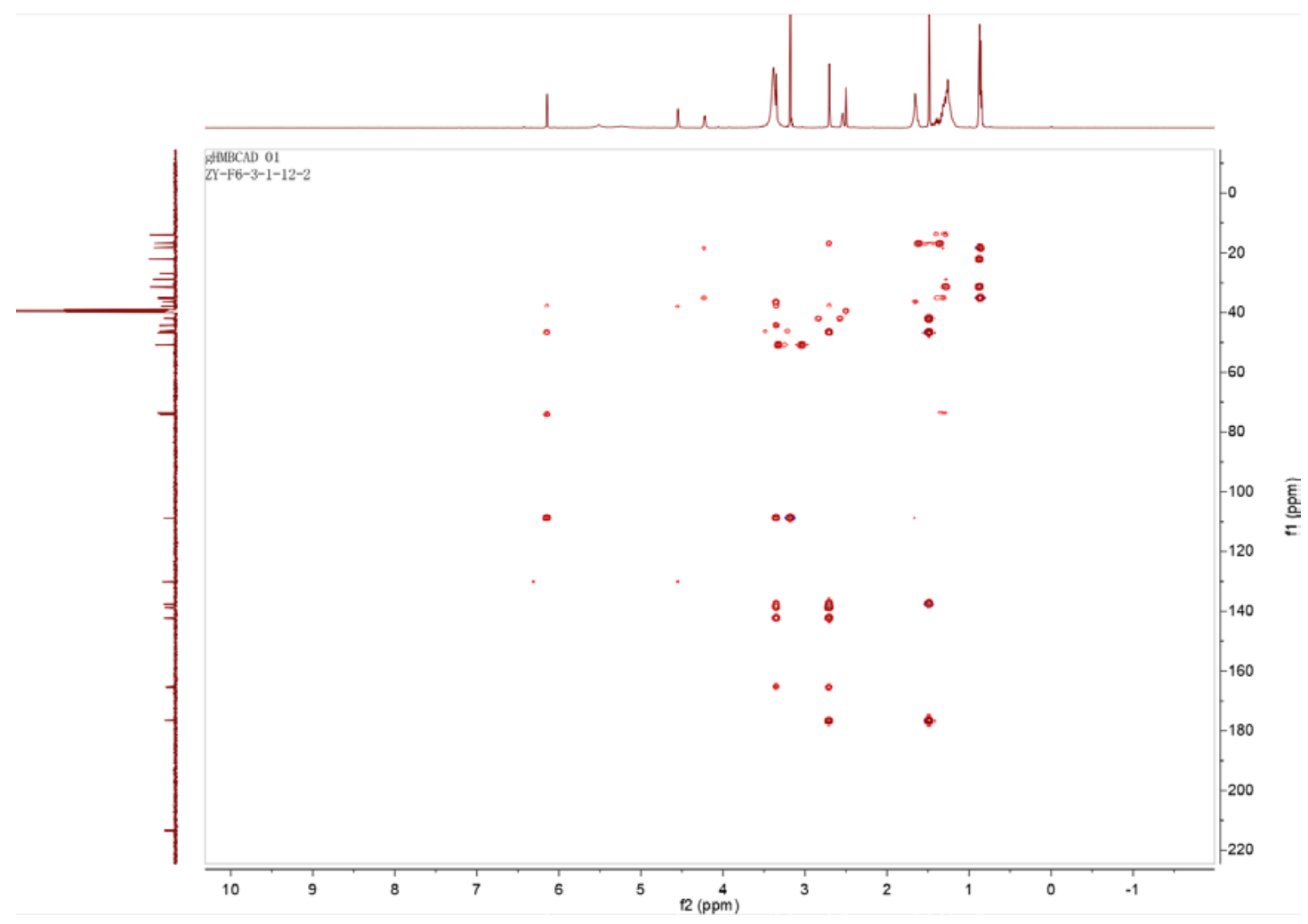


Figure $\mathbf{S 1 7}{ }^{1} \mathrm{H}_{-}{ }^{13} \mathrm{C}$ HSQMBC spectrum of compound 2.

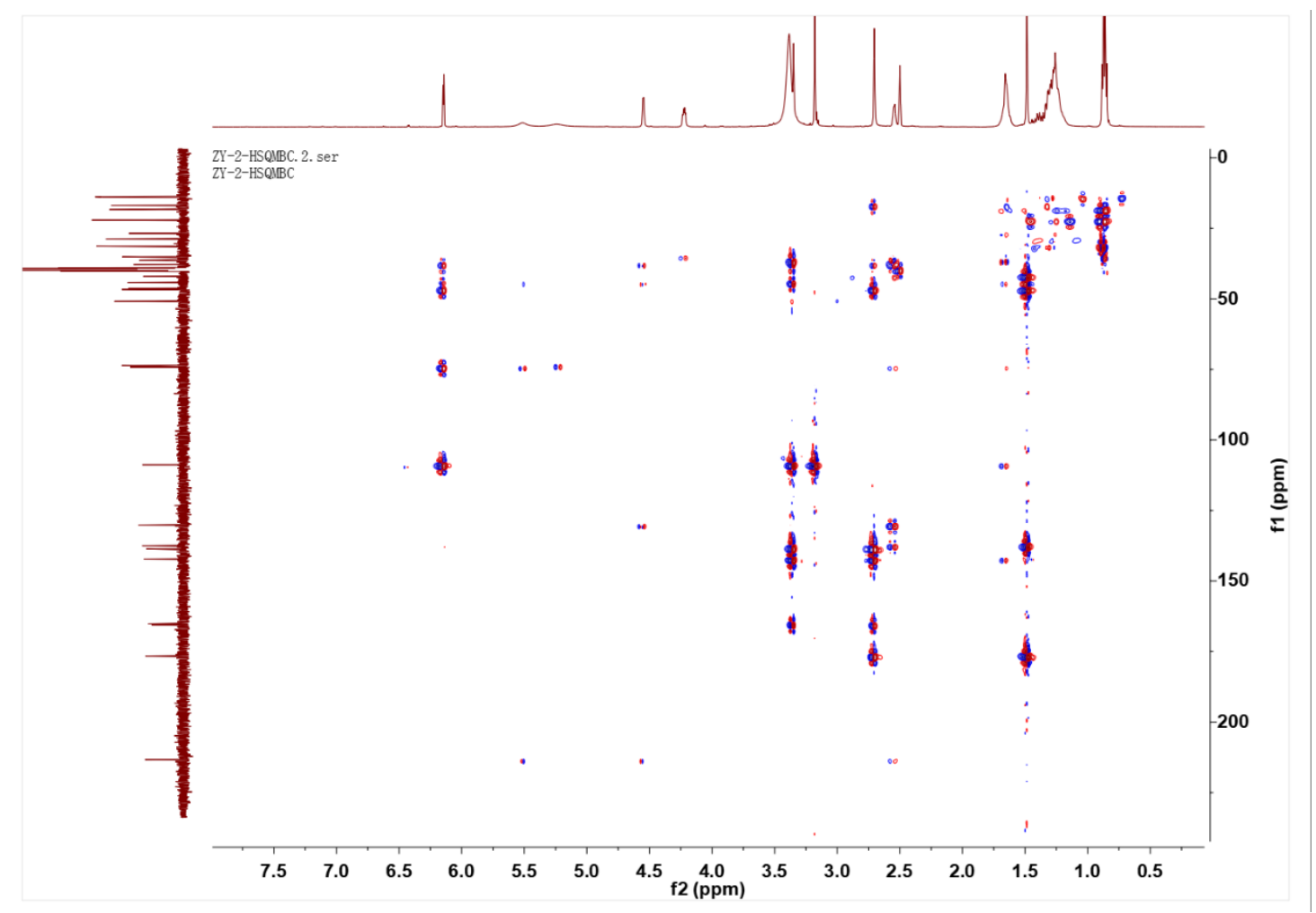

Figure S18 NOESY spectrum of compound 2.

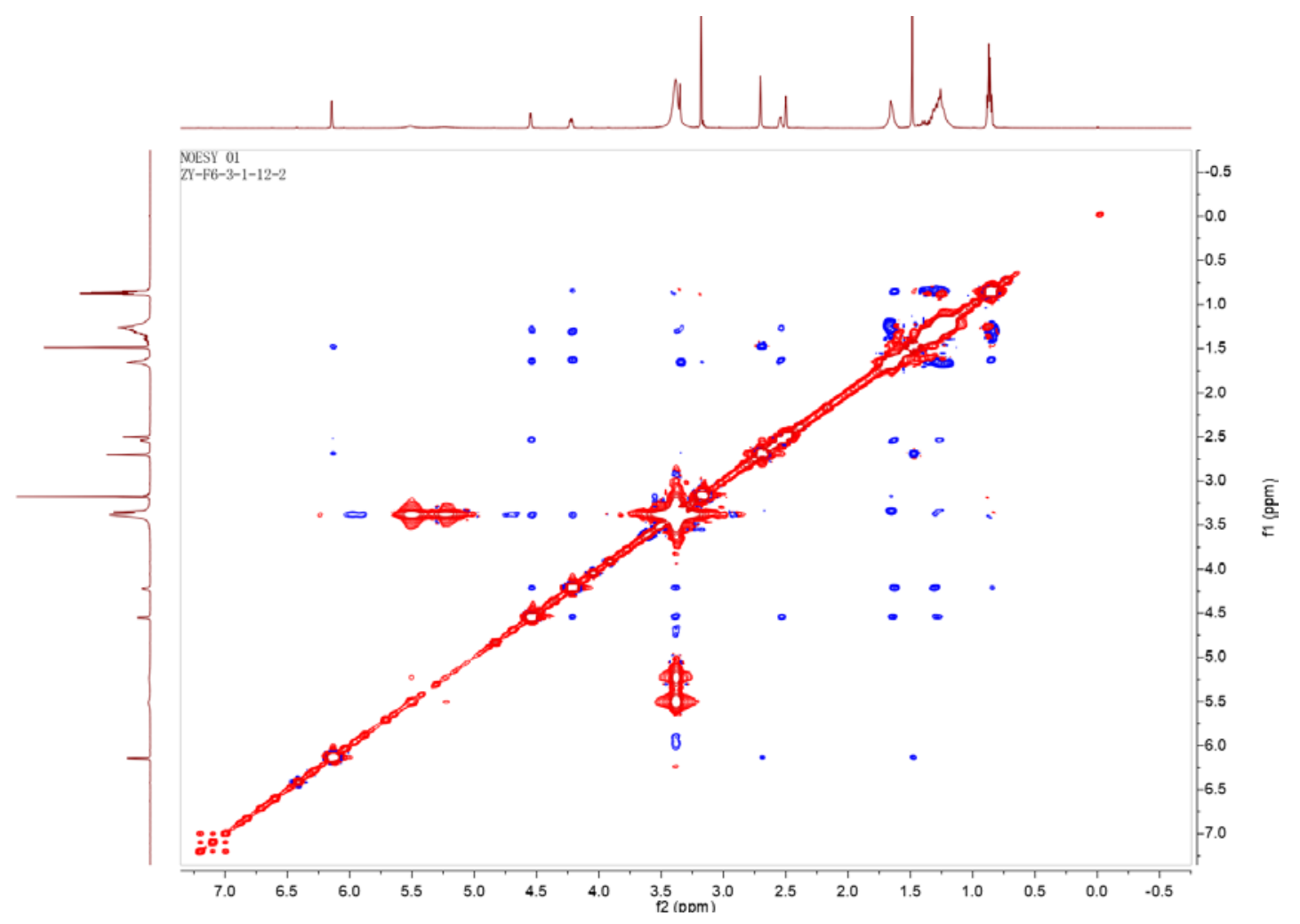


Figure S19 HRESIMS spectrum of compound 2.

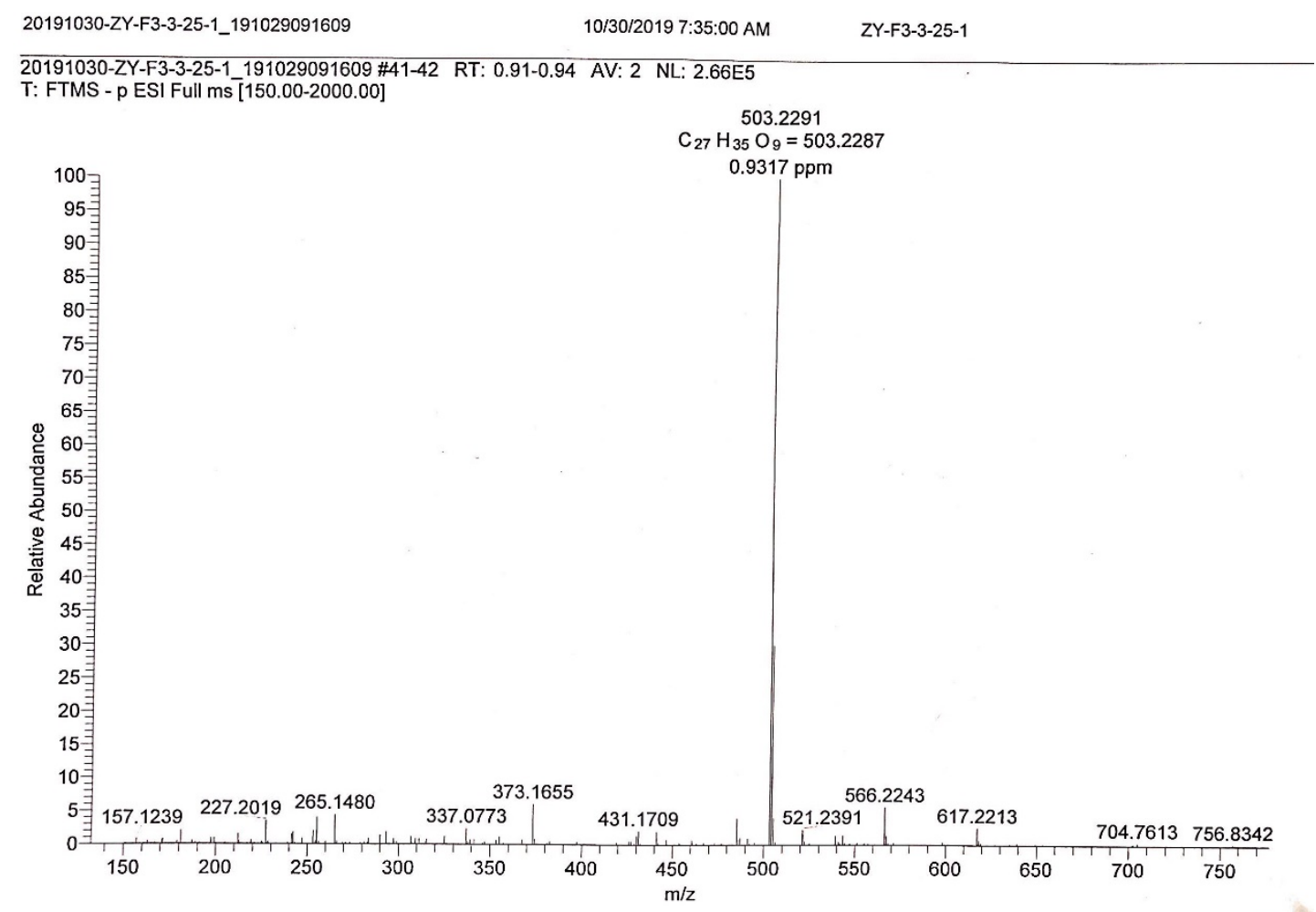

Figure S20 IR spectrum of compound 2.

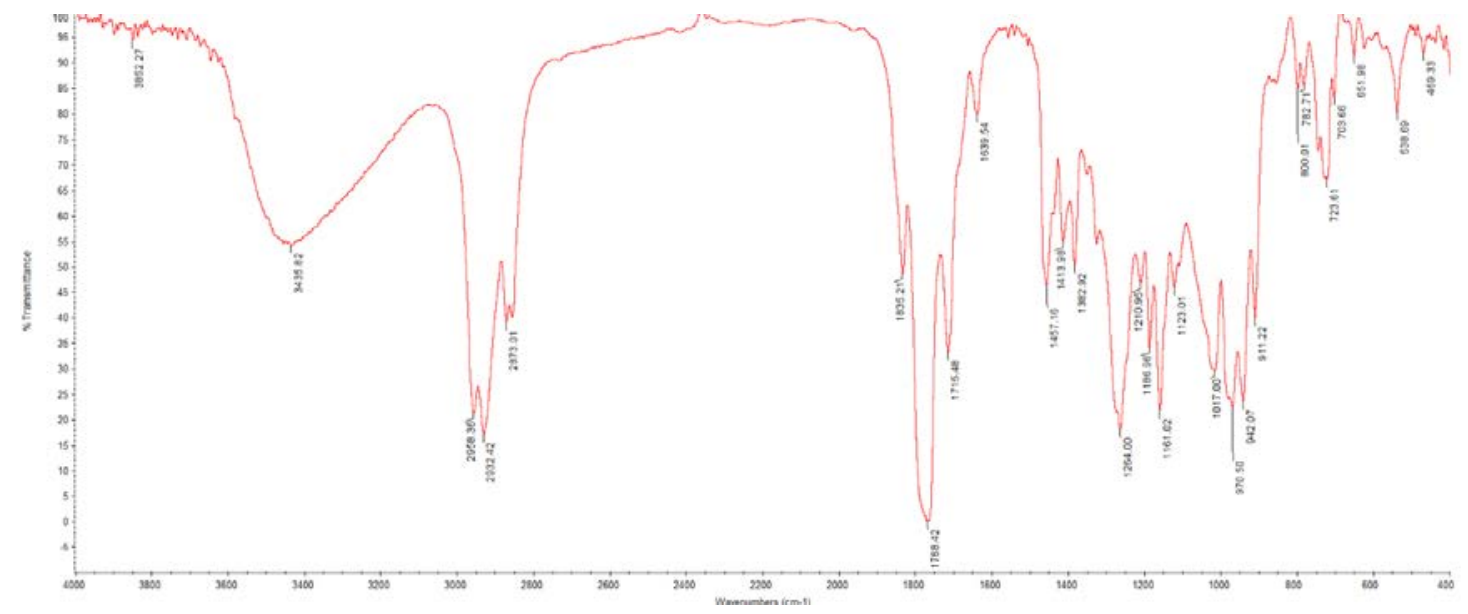


Figure S21 UV spectrum of compound 2.

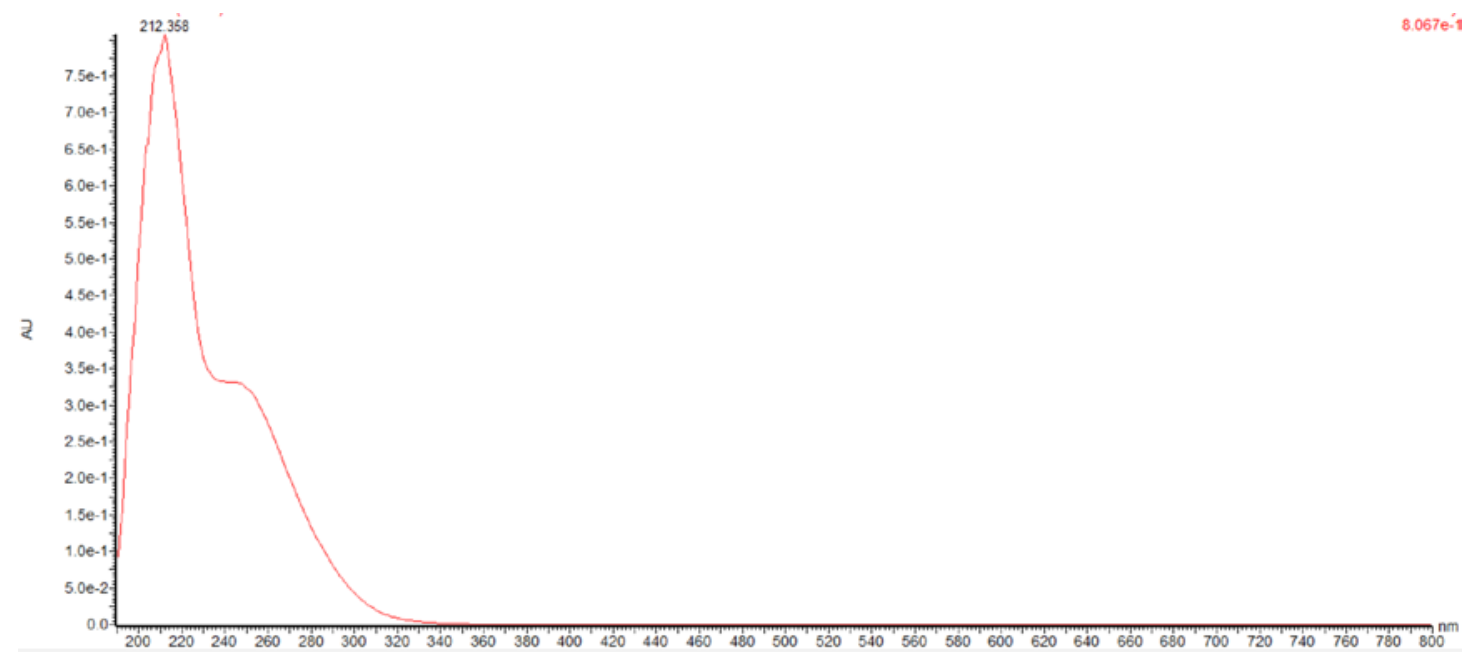


Figure S22 ${ }^{1} \mathrm{H}$ NMR (500 MHz, DMSO- $d_{6}$ ) spectrum of compound 3.

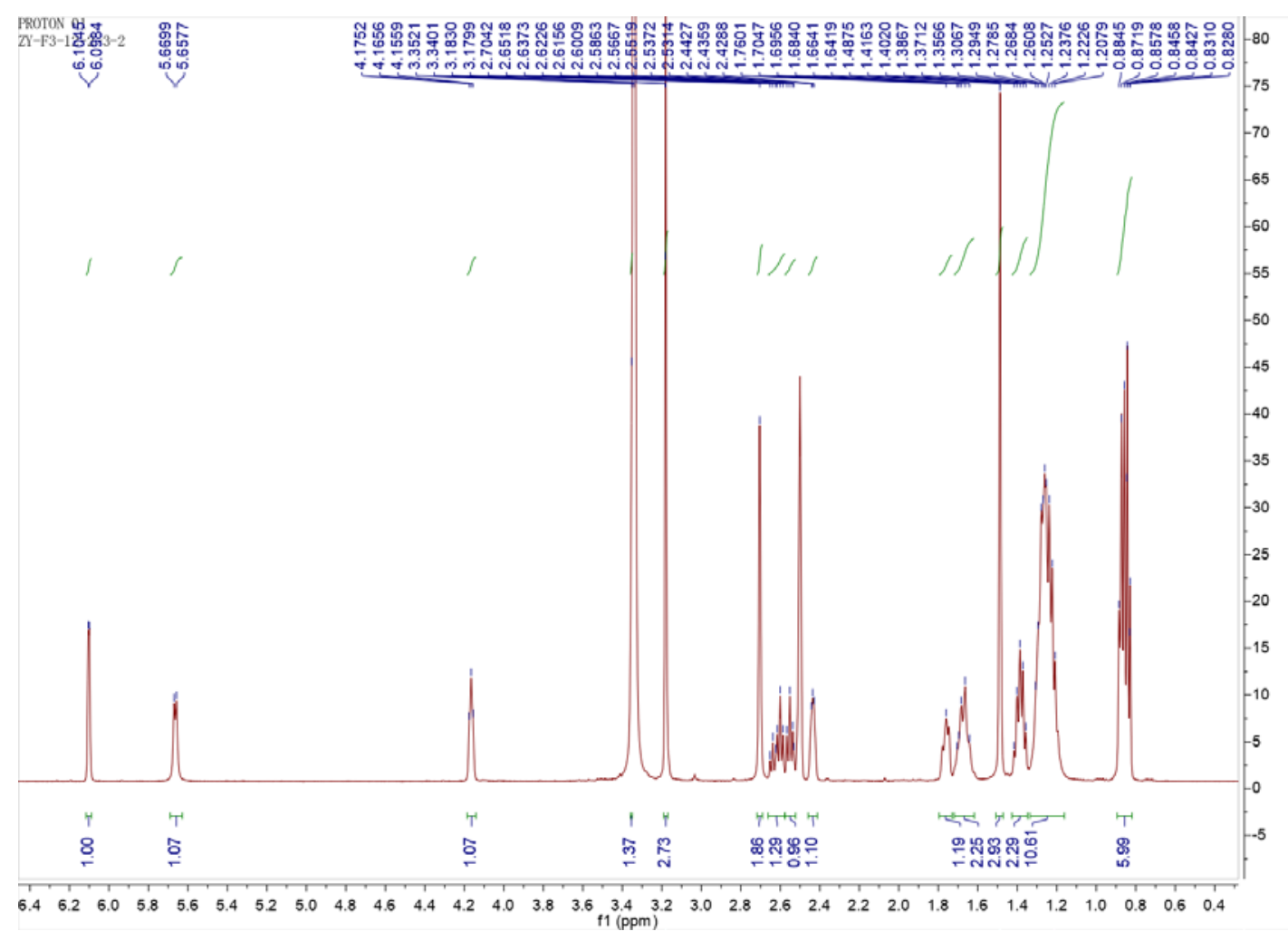

Figure S23 ${ }^{13} \mathrm{C}$ NMR (125 MHz, DMSO- $\left.d_{6}\right)$ spectrum of compound 3.

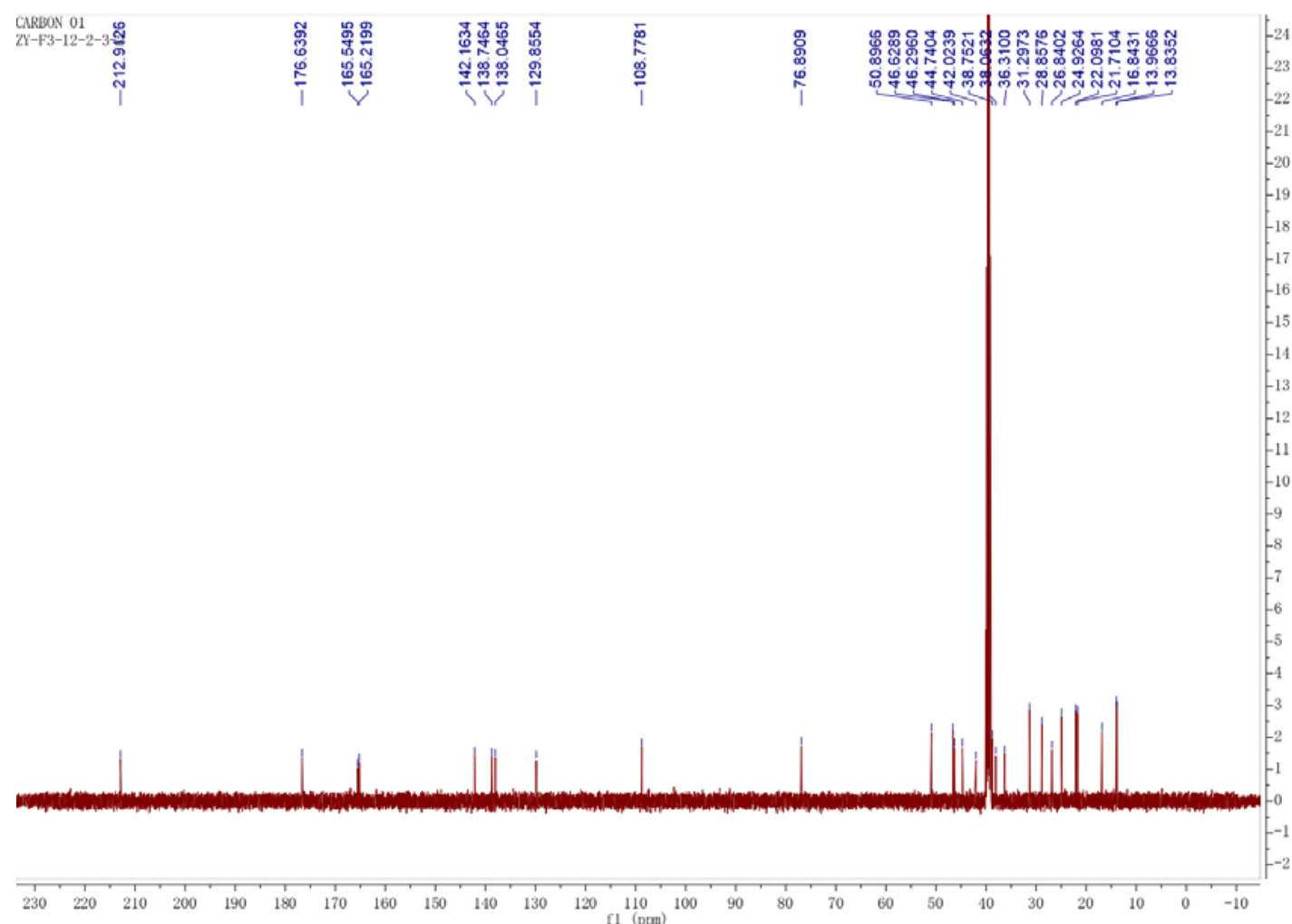


Figure S24 DEPT (125 MHz, DMSO- $d_{6}$ ) spectrum of compound 3.

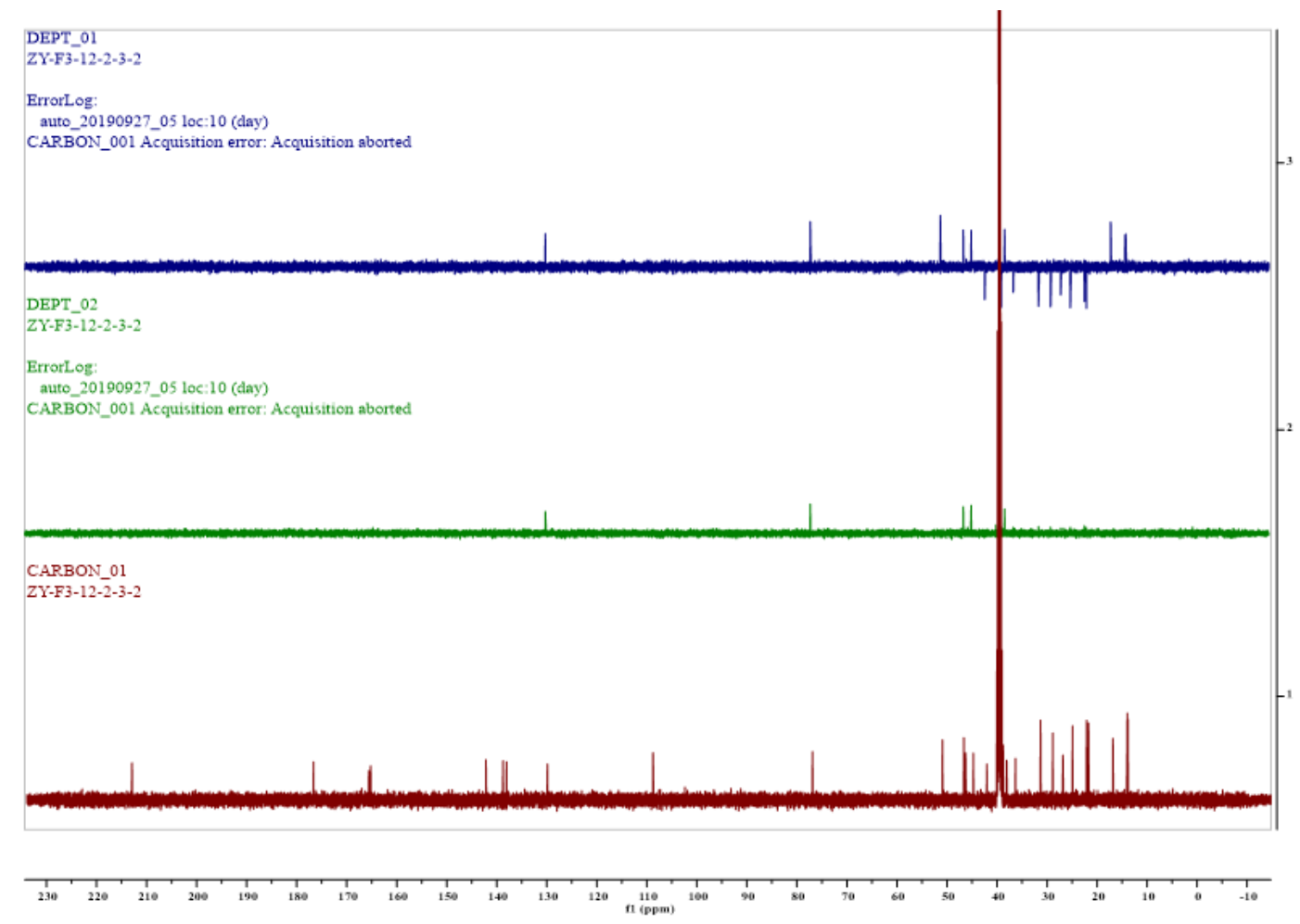

Figure S25 ${ }^{1} \mathrm{H}-{ }^{1} \mathrm{H}$ COSY spectrum of compound 3.

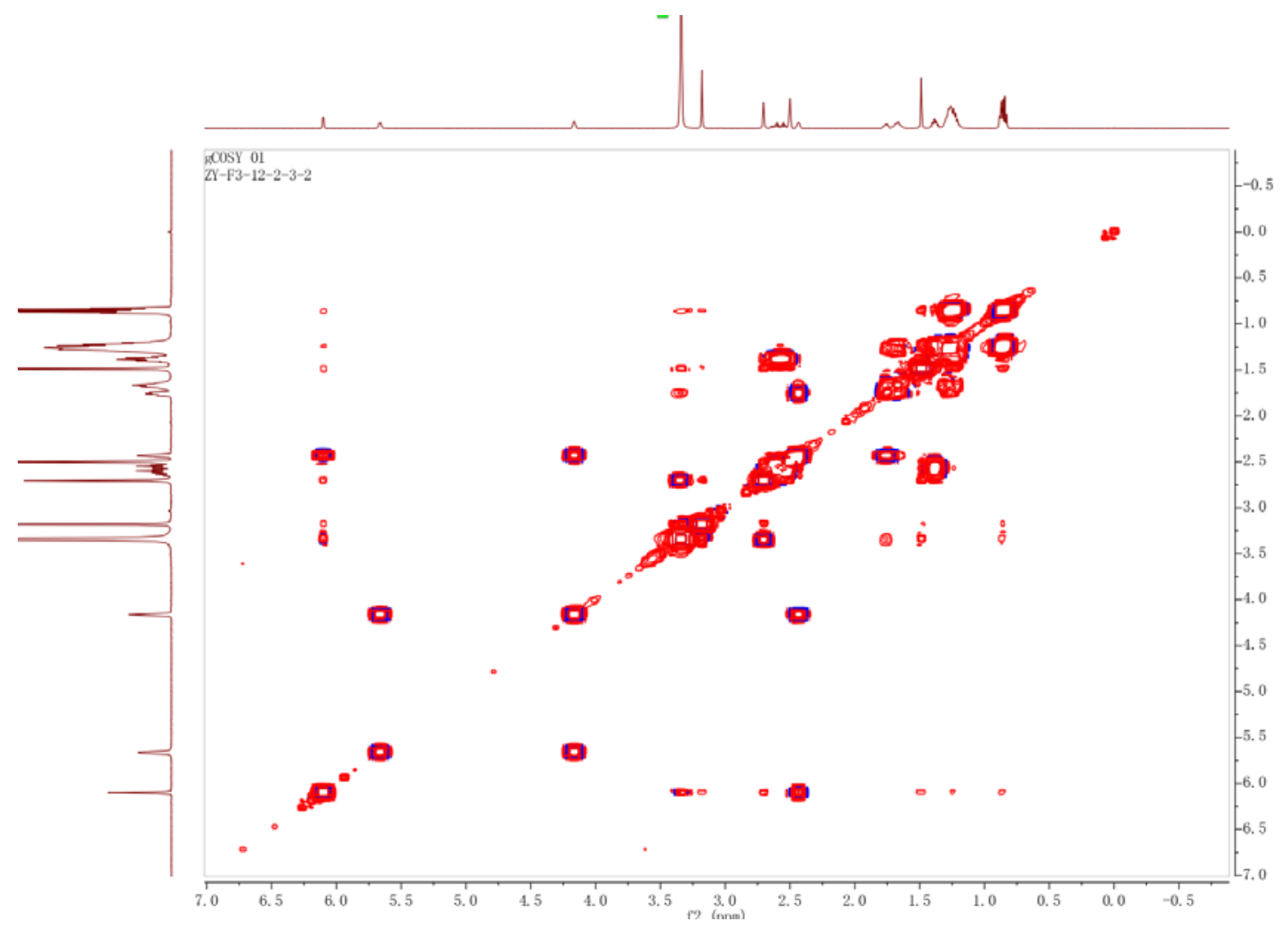


Figure S26 ${ }^{1} \mathrm{H}^{1}{ }^{13} \mathrm{C}$ HSQC spectrum of compound 3.

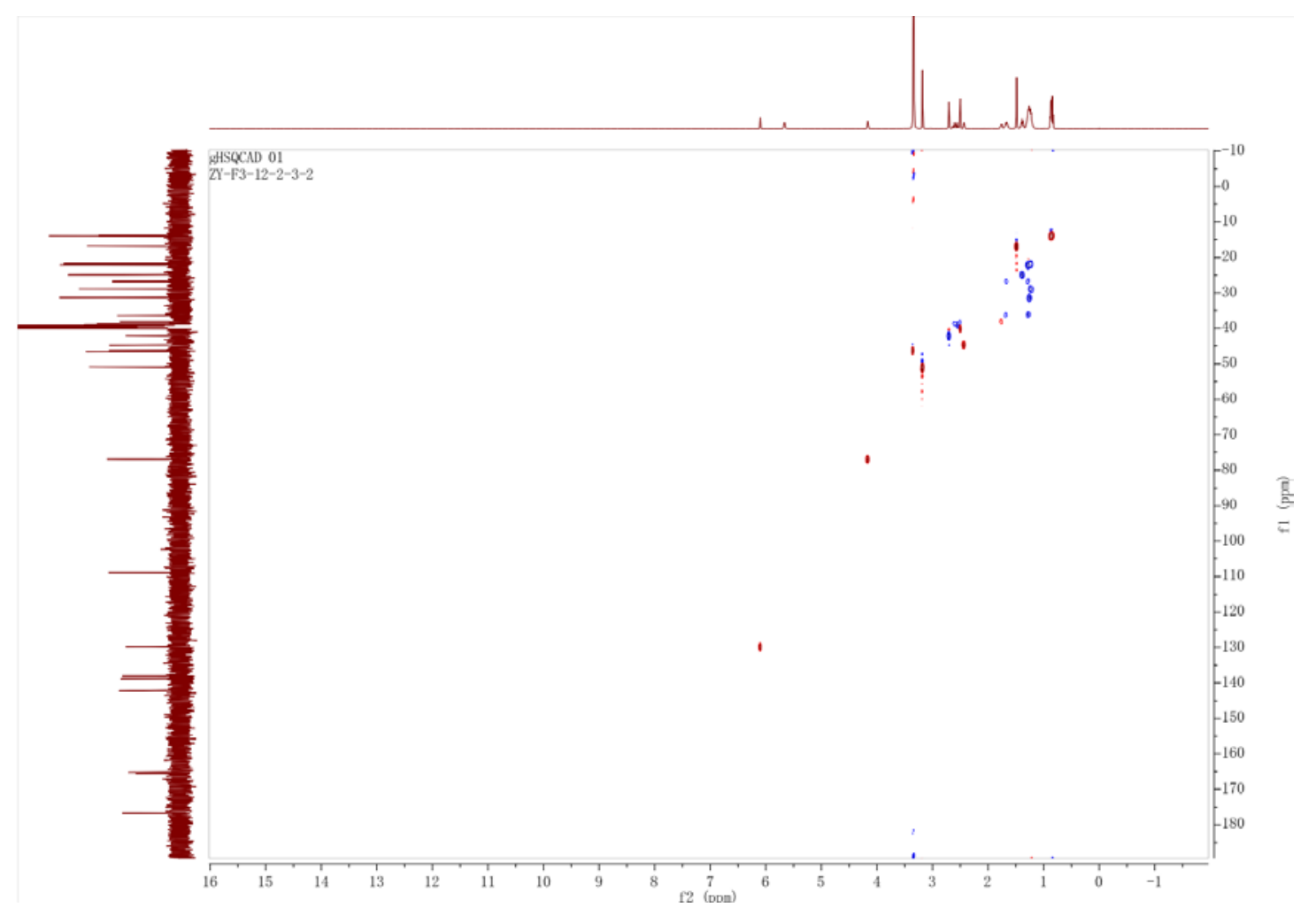

Figure S27 ${ }^{1} \mathrm{H}-{ }^{13} \mathrm{C}$ HMBC spectrum of compound 3.

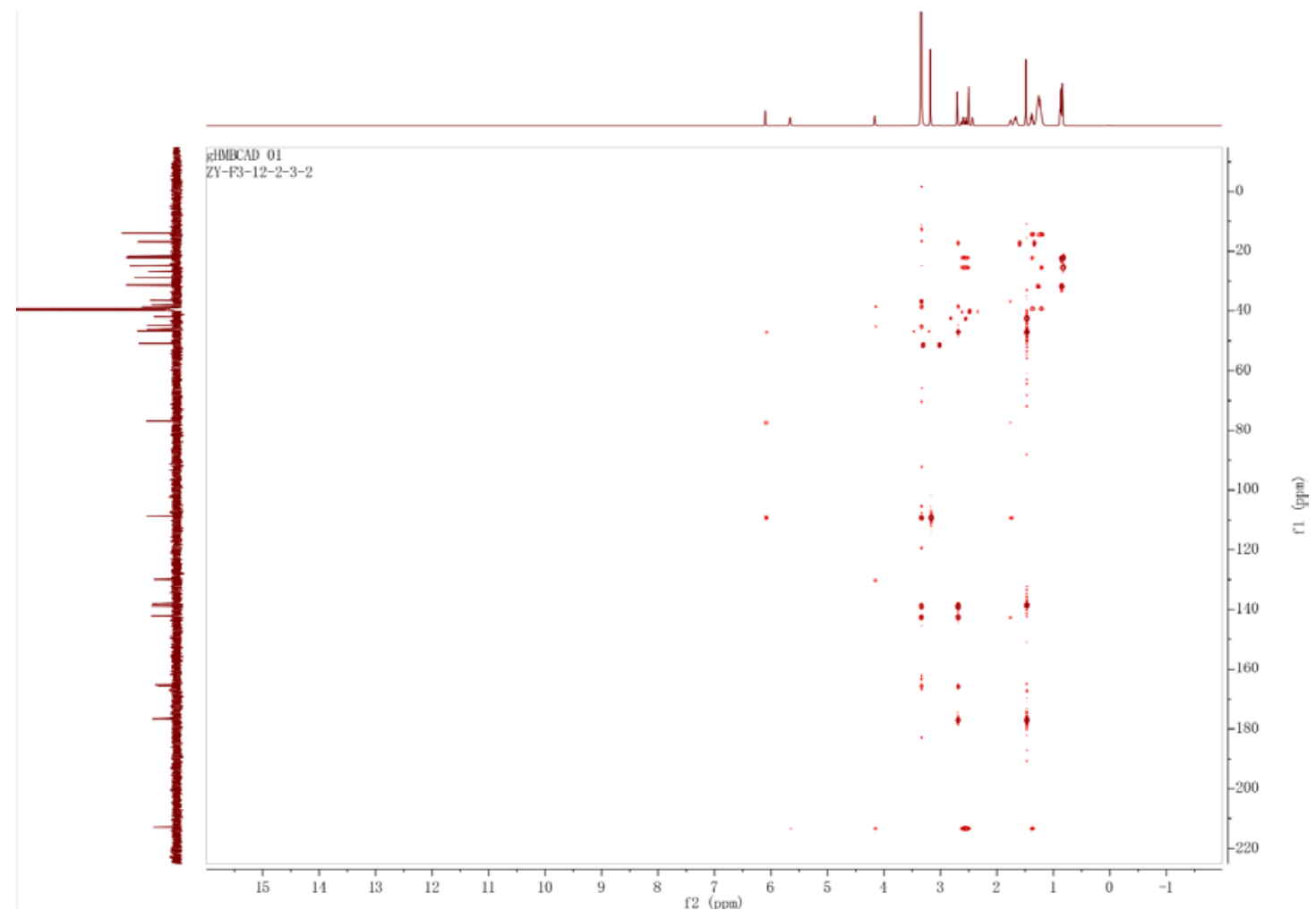


Figure S28 NOESY spectrum of compound 3.

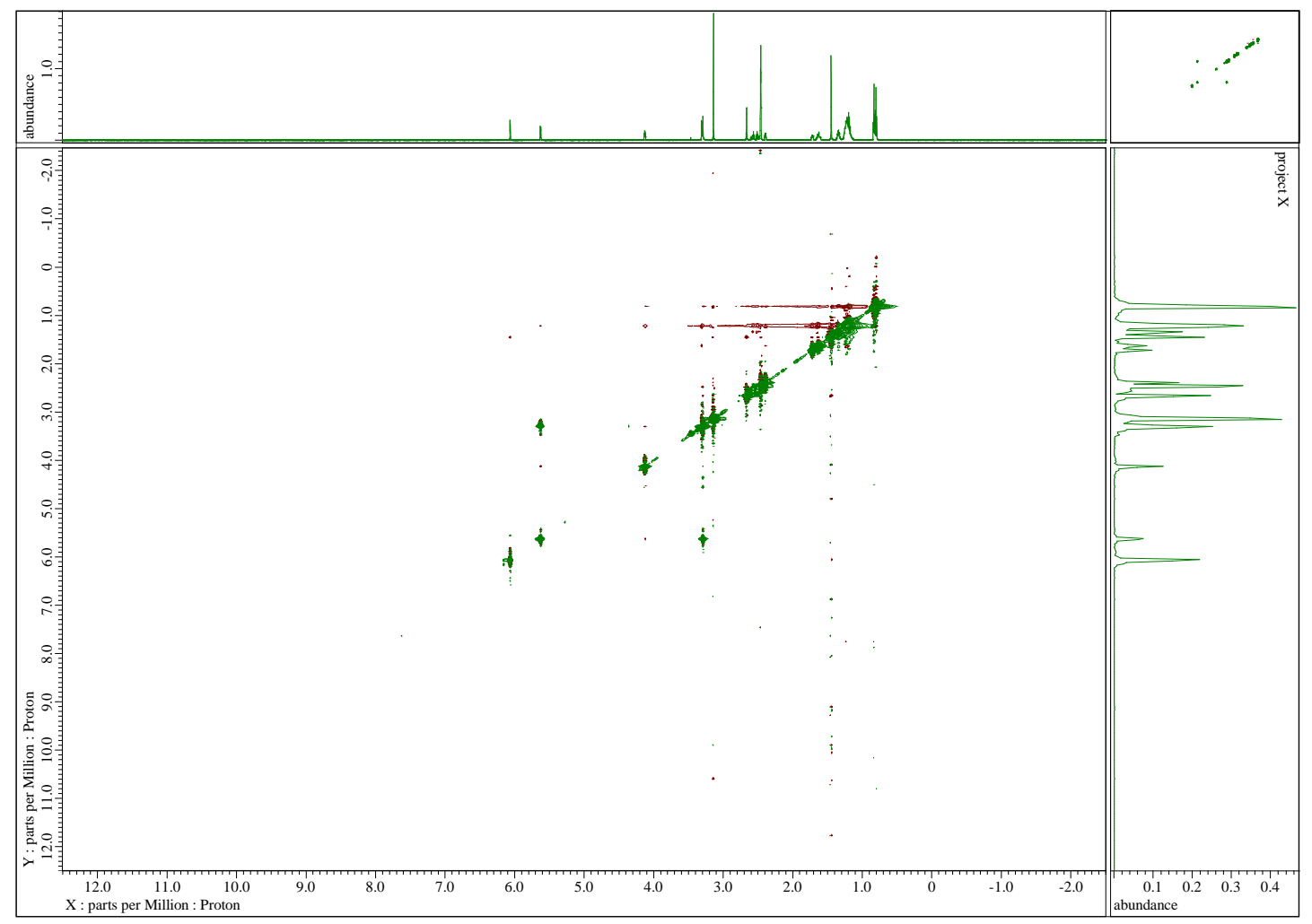

Figure S29 HRESIMS spectrum of compound 3.

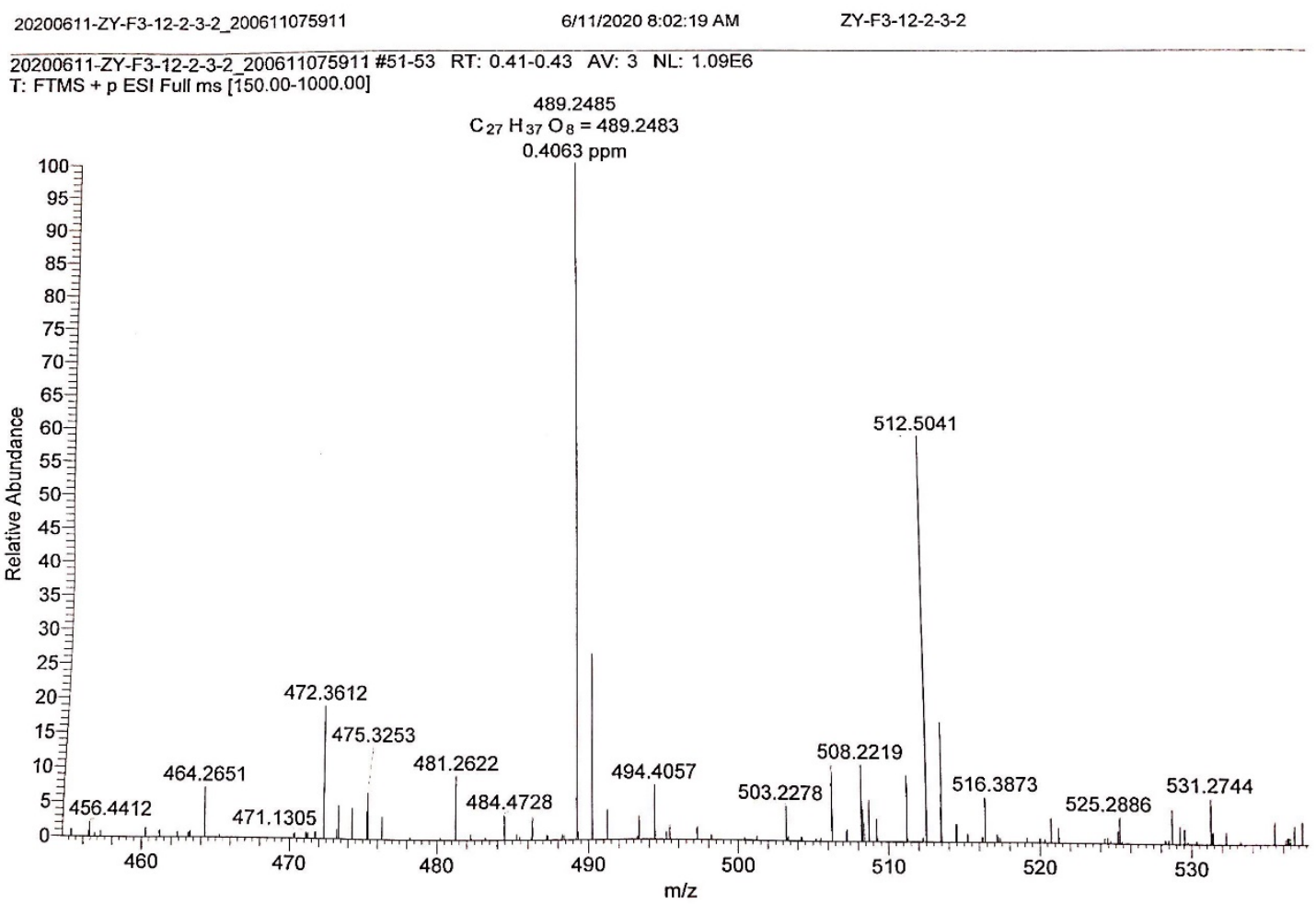


Figure S30 IR spectrum of compound 3.

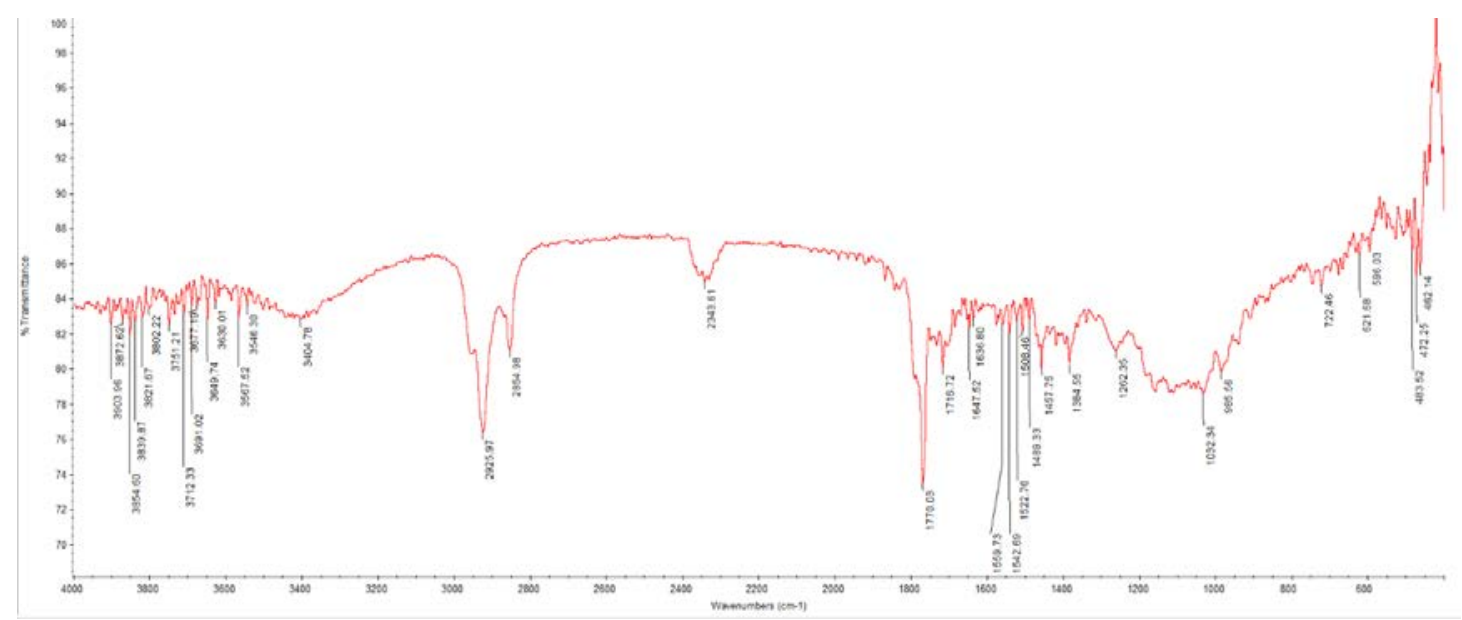

Figure S31 UV spectrum of compound 3.

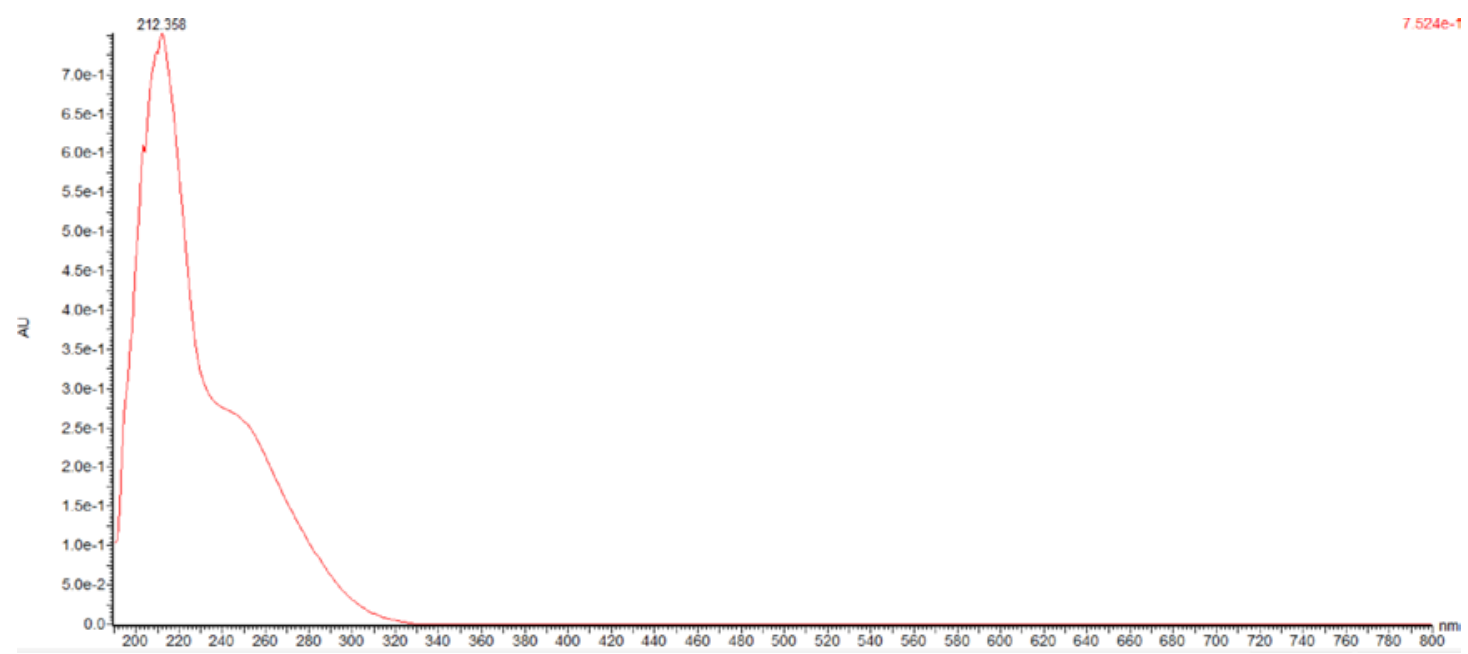


Figure S32 ${ }^{1} \mathrm{H}$ NMR (400 MHz, DMSO-d $)$ spectrum of compound 4.

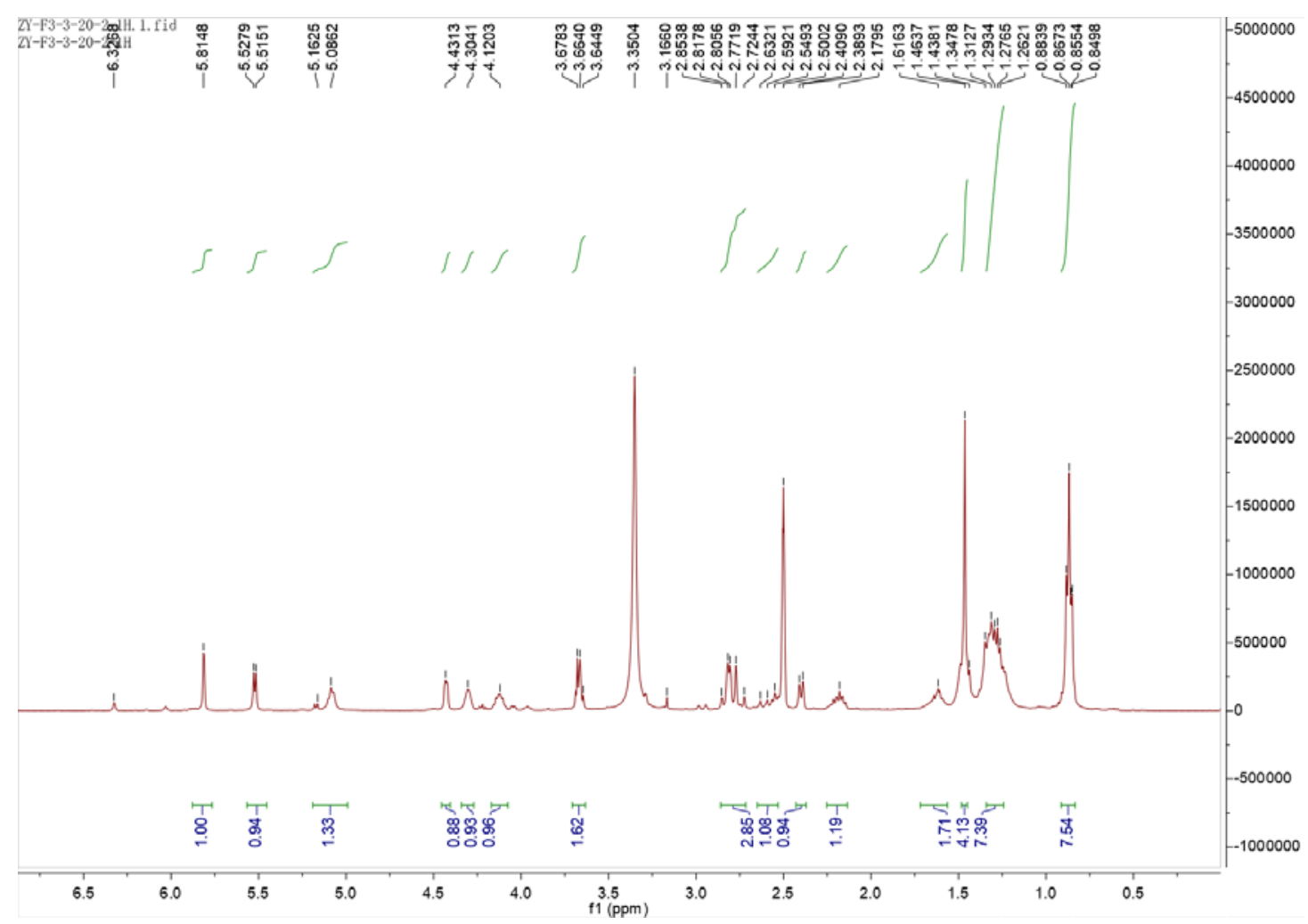

Figure S33 ${ }^{13} \mathrm{C}$ NMR (100 MHz, DMSO- $\left.d_{6}\right)$ spectrum of compound 4.

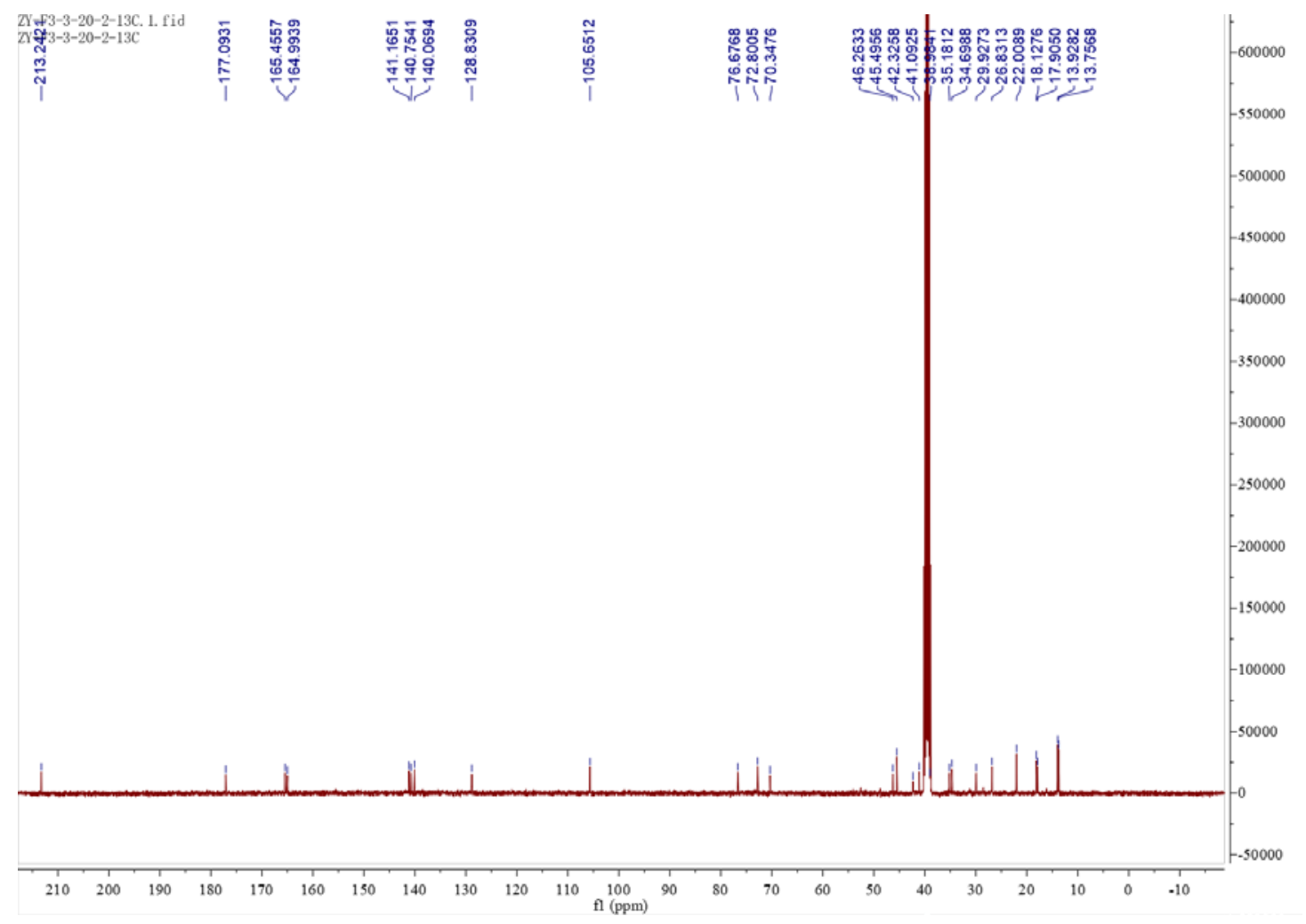


Figure S34 DEPT (100 MHz, DMSO- $d_{6}$ ) spectrum of compound 4.

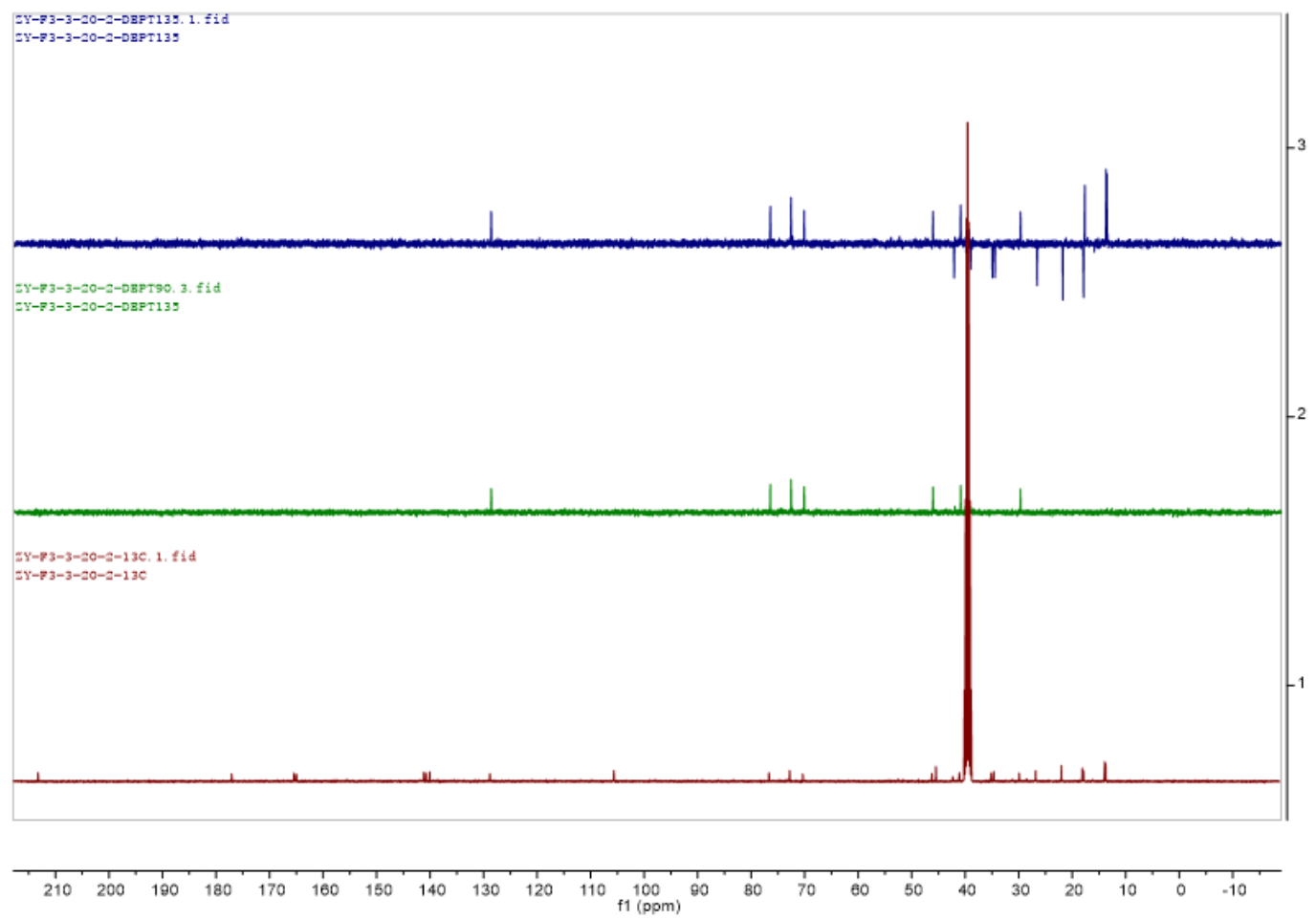

Figure S35 ${ }^{1} \mathrm{H}-{ }^{1} \mathrm{H}$ COSY spectrum of compound 4.

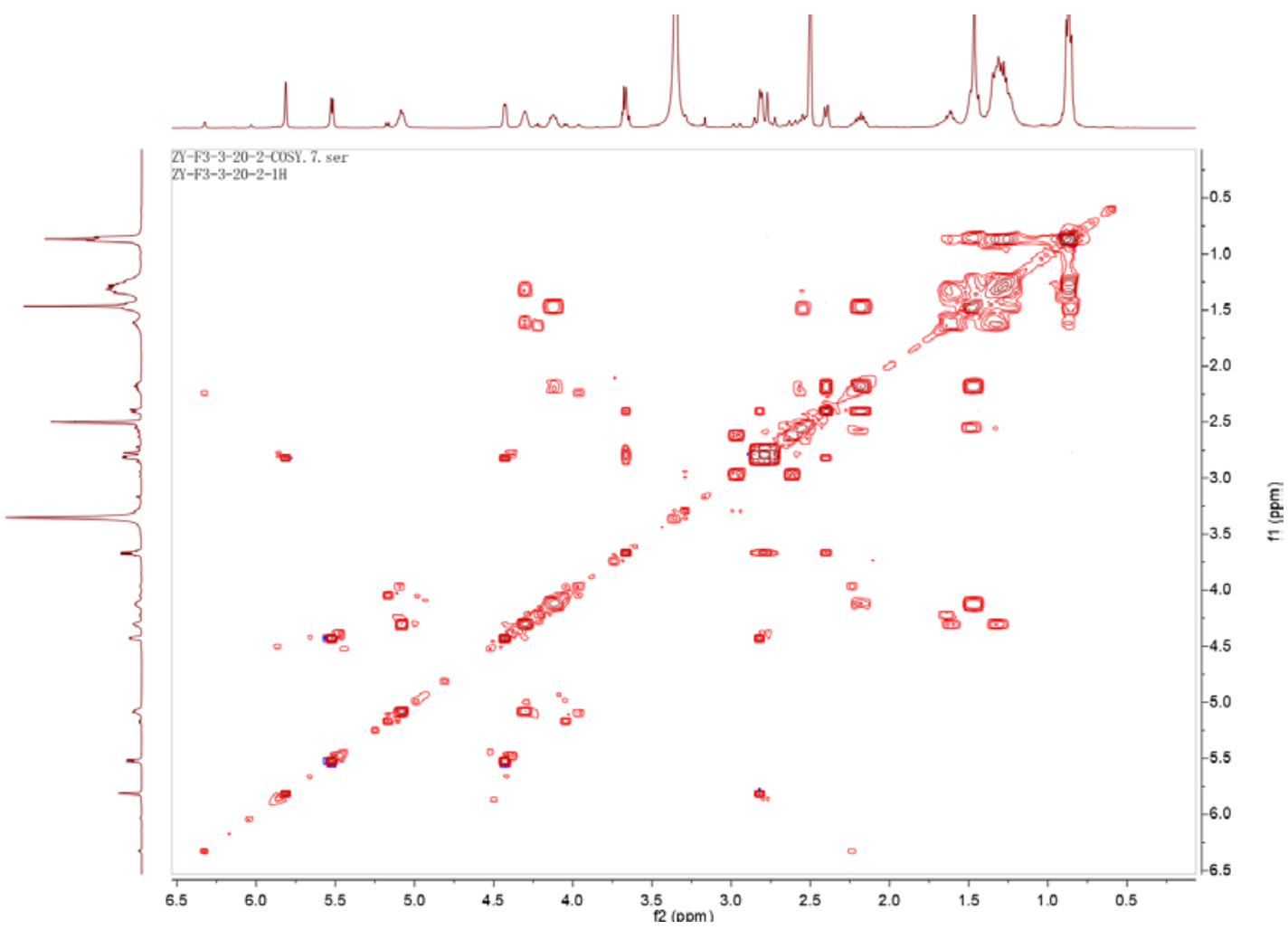


Figure S36 ${ }^{1} \mathrm{H}-{ }^{13} \mathrm{C}$ HSQC spectrum of compound 4 .

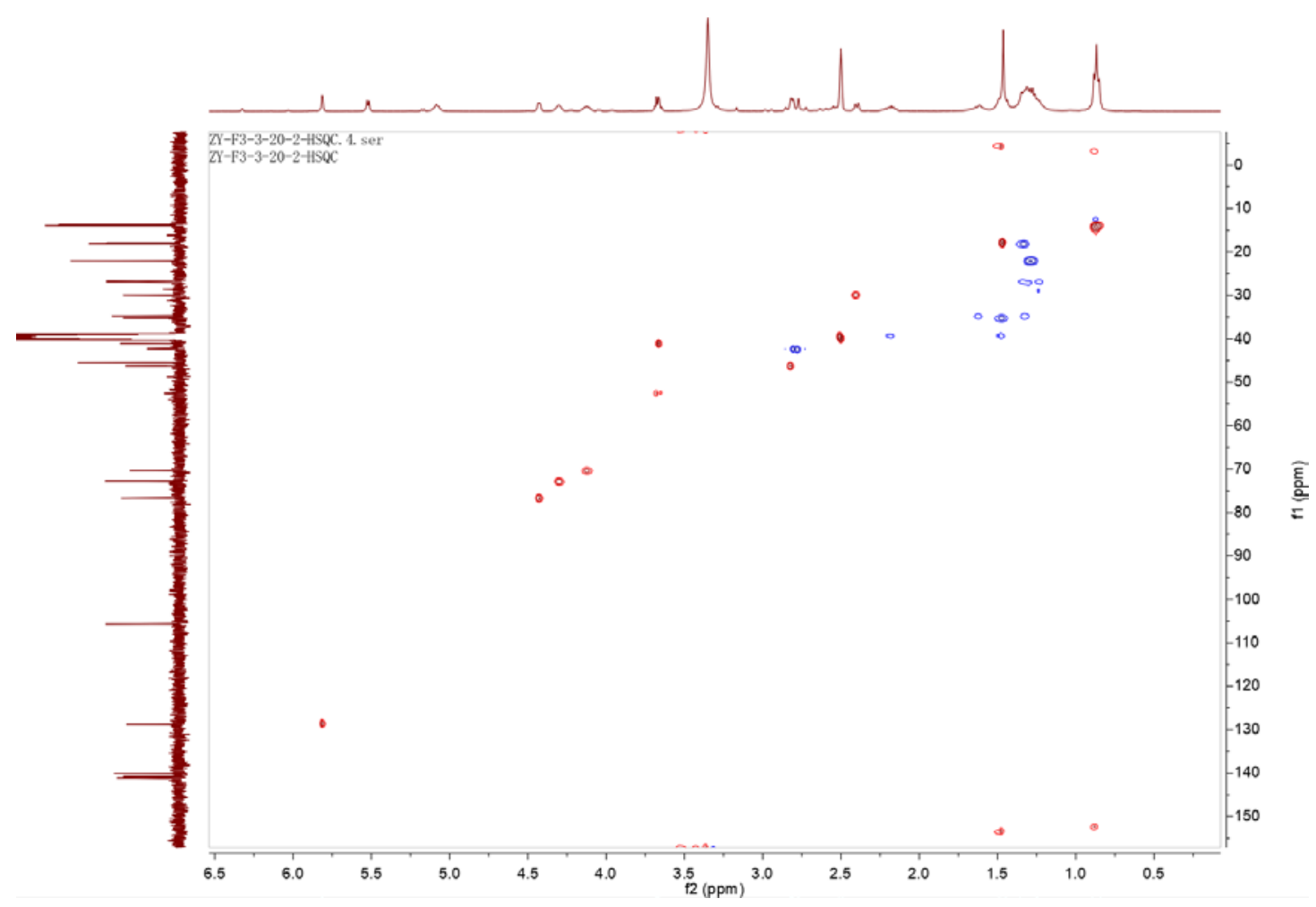

Figure S37 ${ }^{1} \mathrm{H}-{ }^{13} \mathrm{C}$ HMBC spectrum of compound 4 .

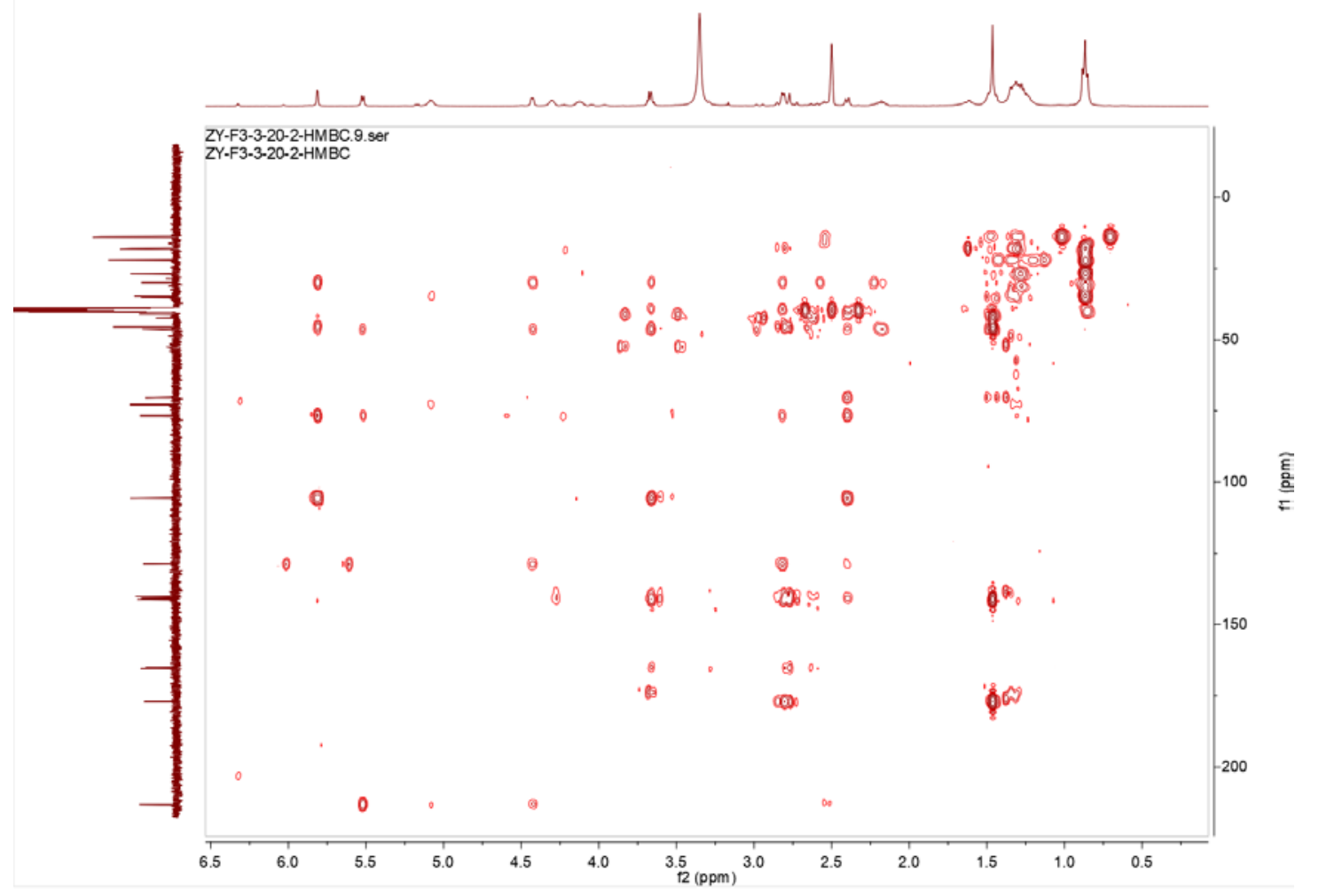


Figure S38 NOESY spectrum of compound 4.

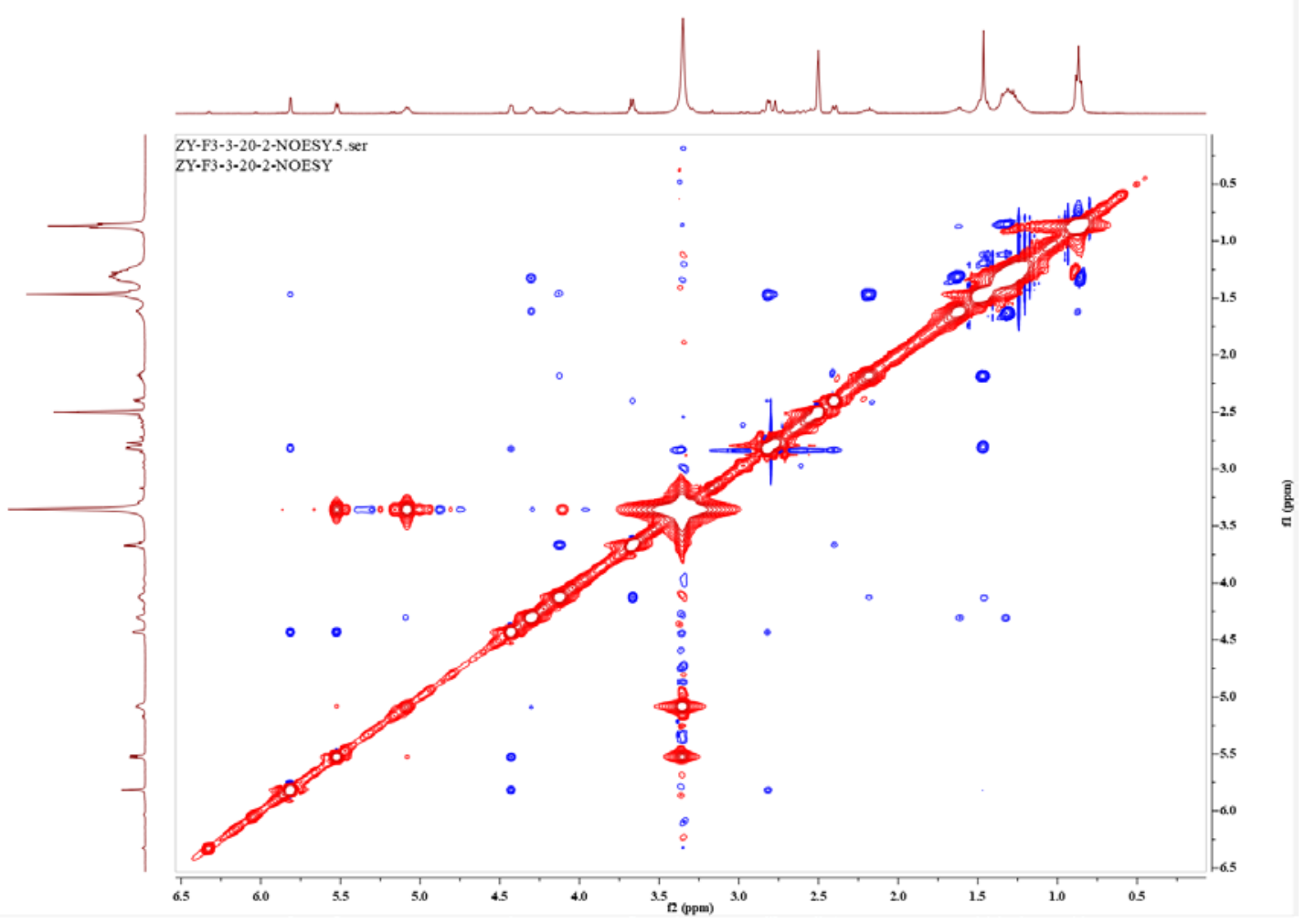

Figure S39 HRESIMS spectrum of compound 4.

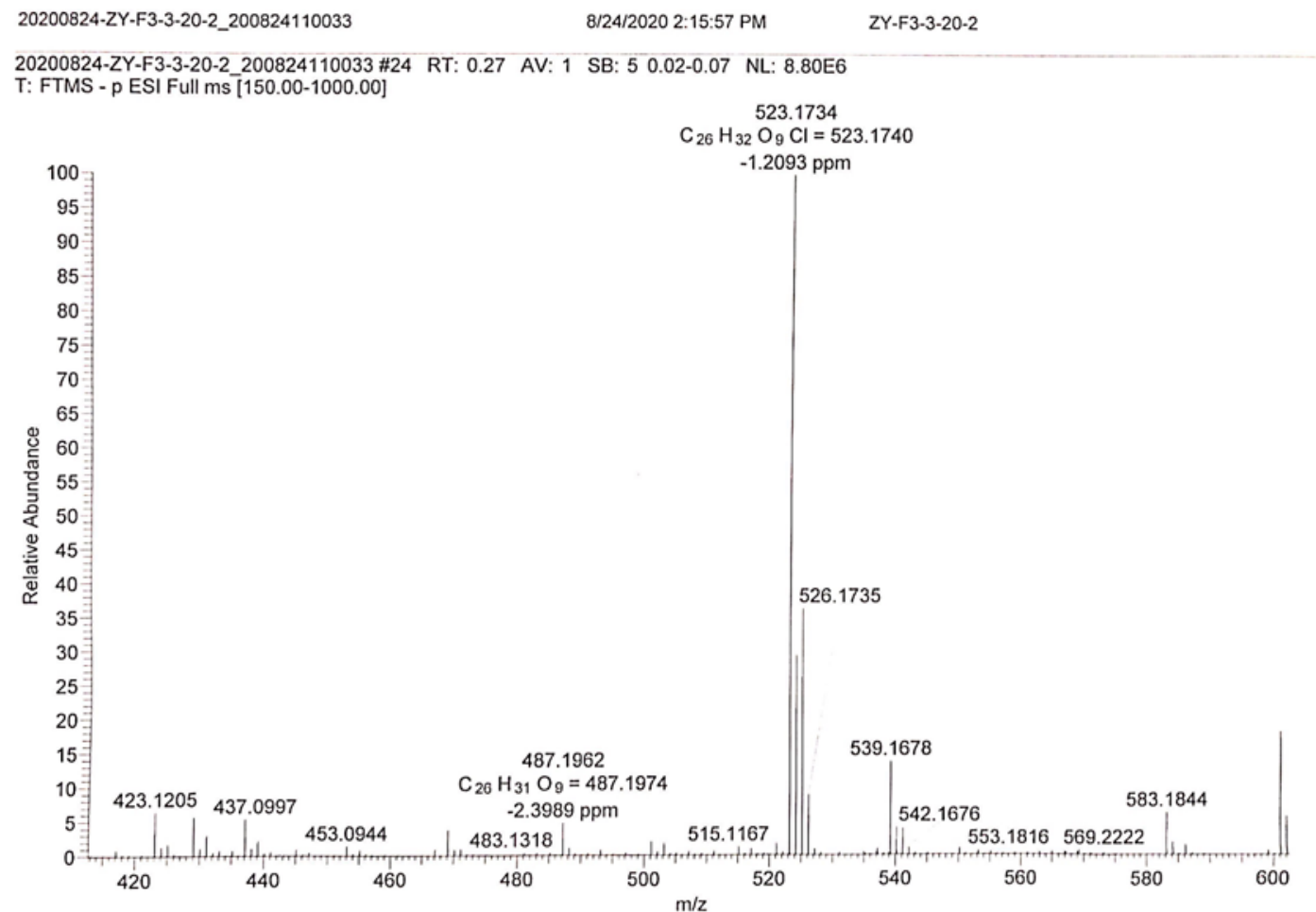


Figure S40 IR spectrum of compound 4.

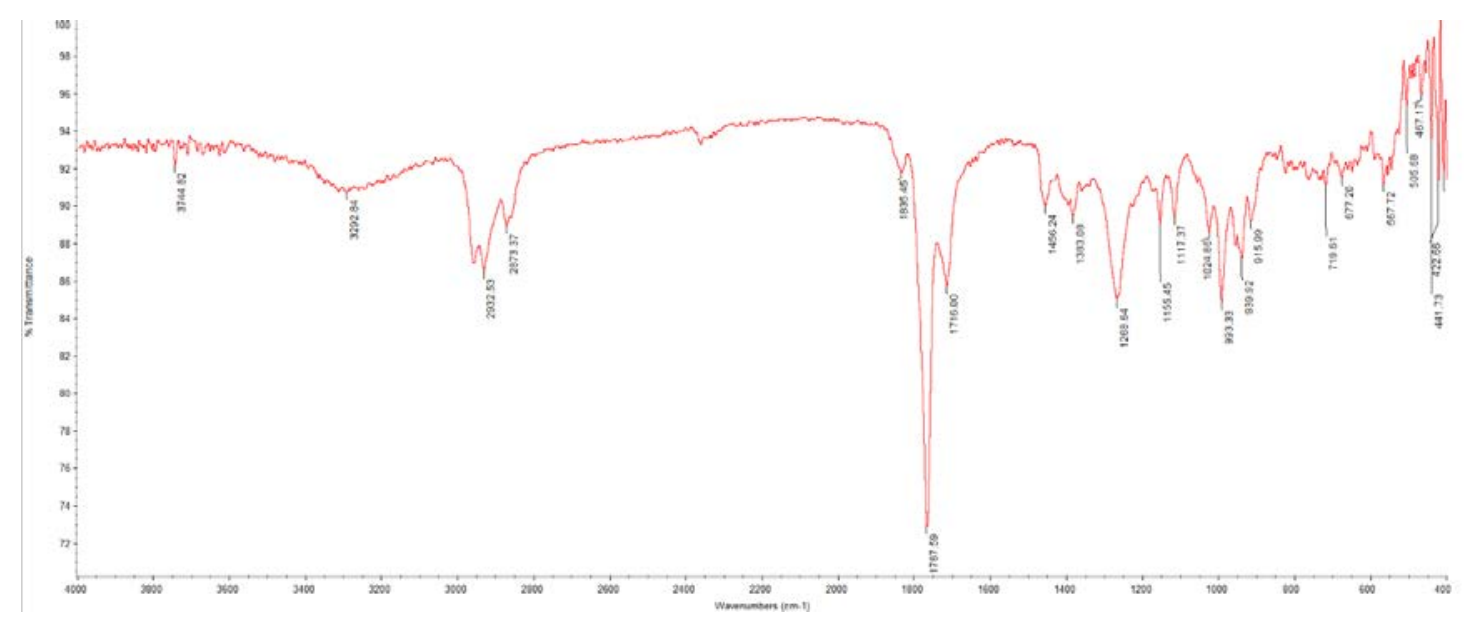

Figure S41 UV spectrum of compound 4.

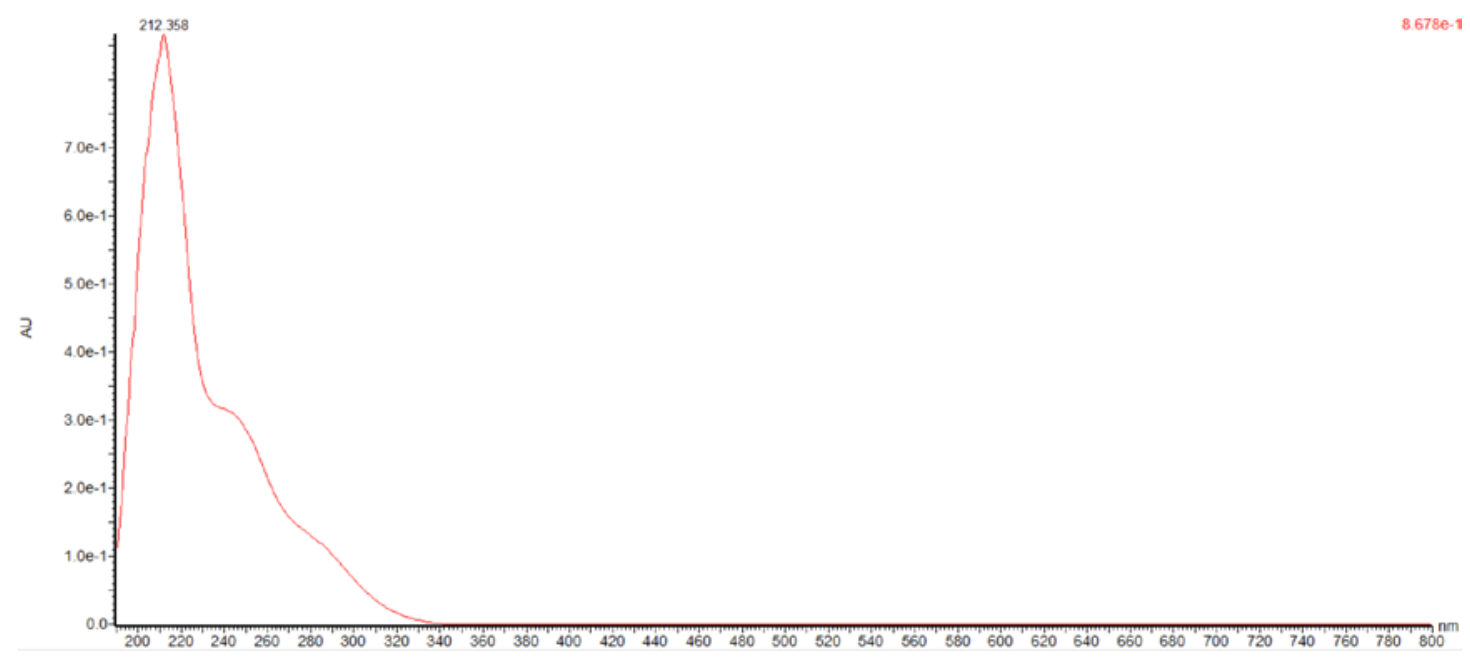


Figure S42 ${ }^{1} \mathrm{H}$ NMR (500 MHz, DMSO- $d_{6}$ ) spectrum of compound 5.

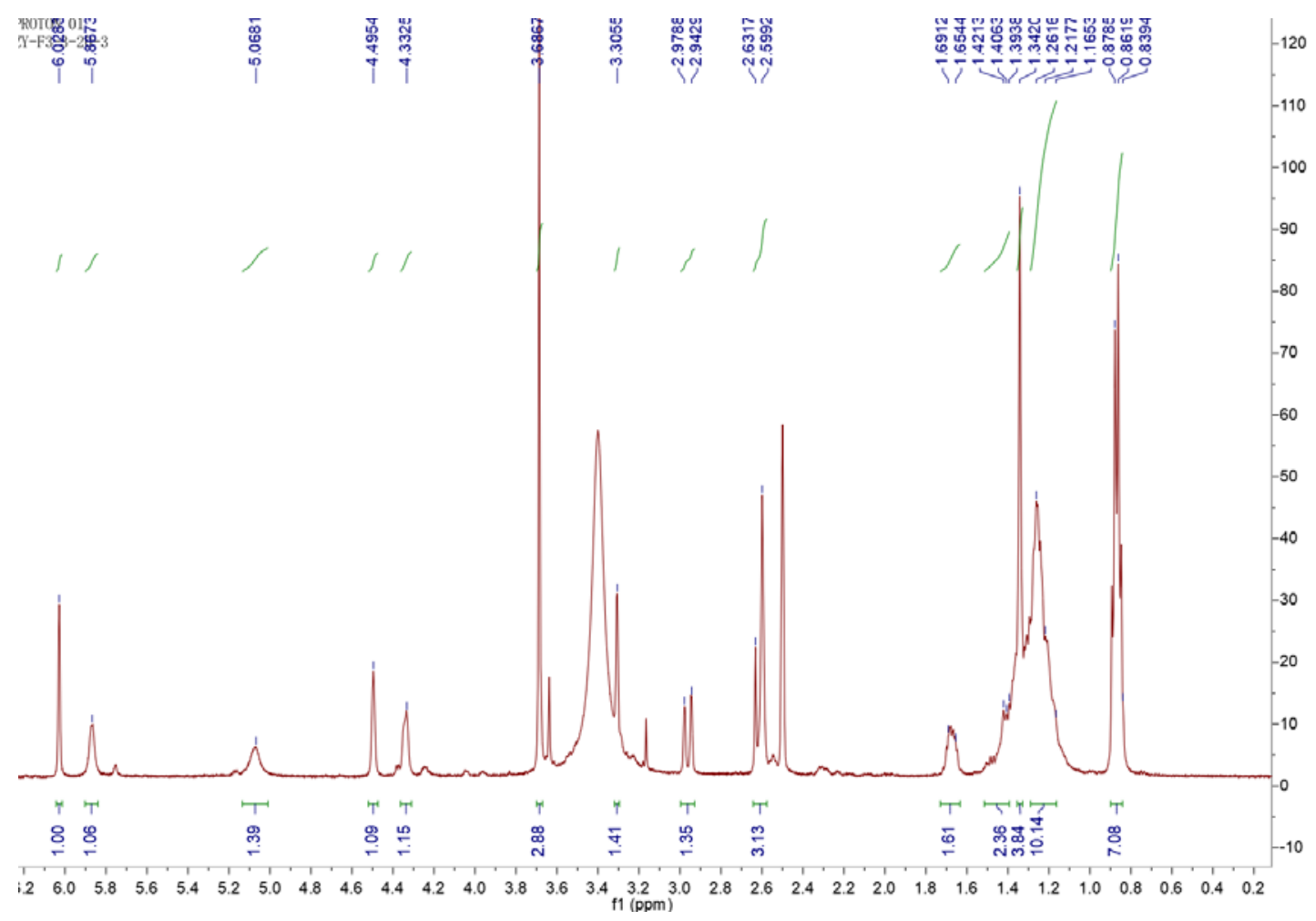

Figure S43 ${ }^{13} \mathrm{C}$ NMR (125 MHz, DMSO- $\left.d_{6}\right)$ spectrum of compound 5.

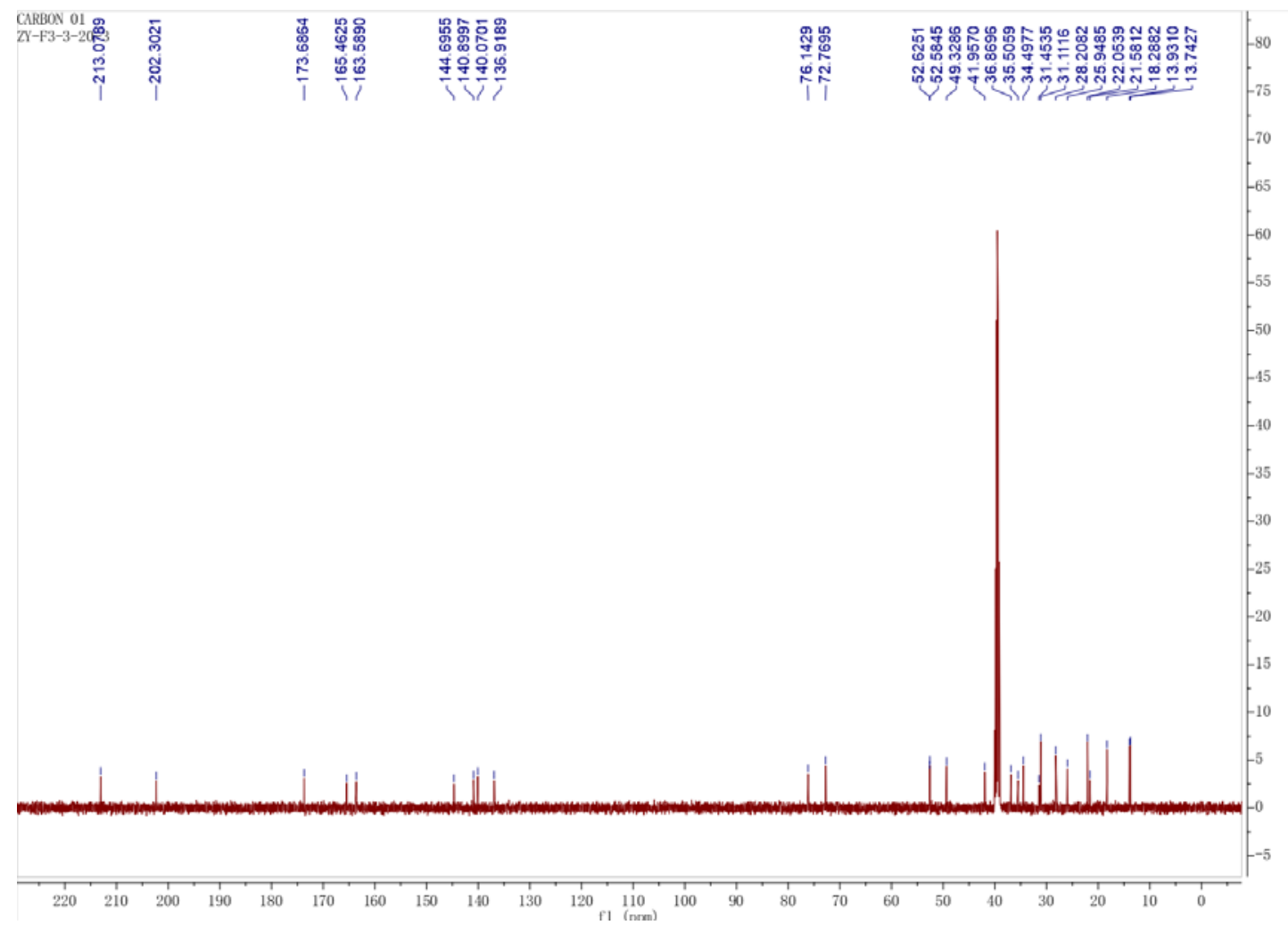


Figure S44 DEPT (125 MHz, DMSO- $d_{6}$ ) spectrum of compound 5.

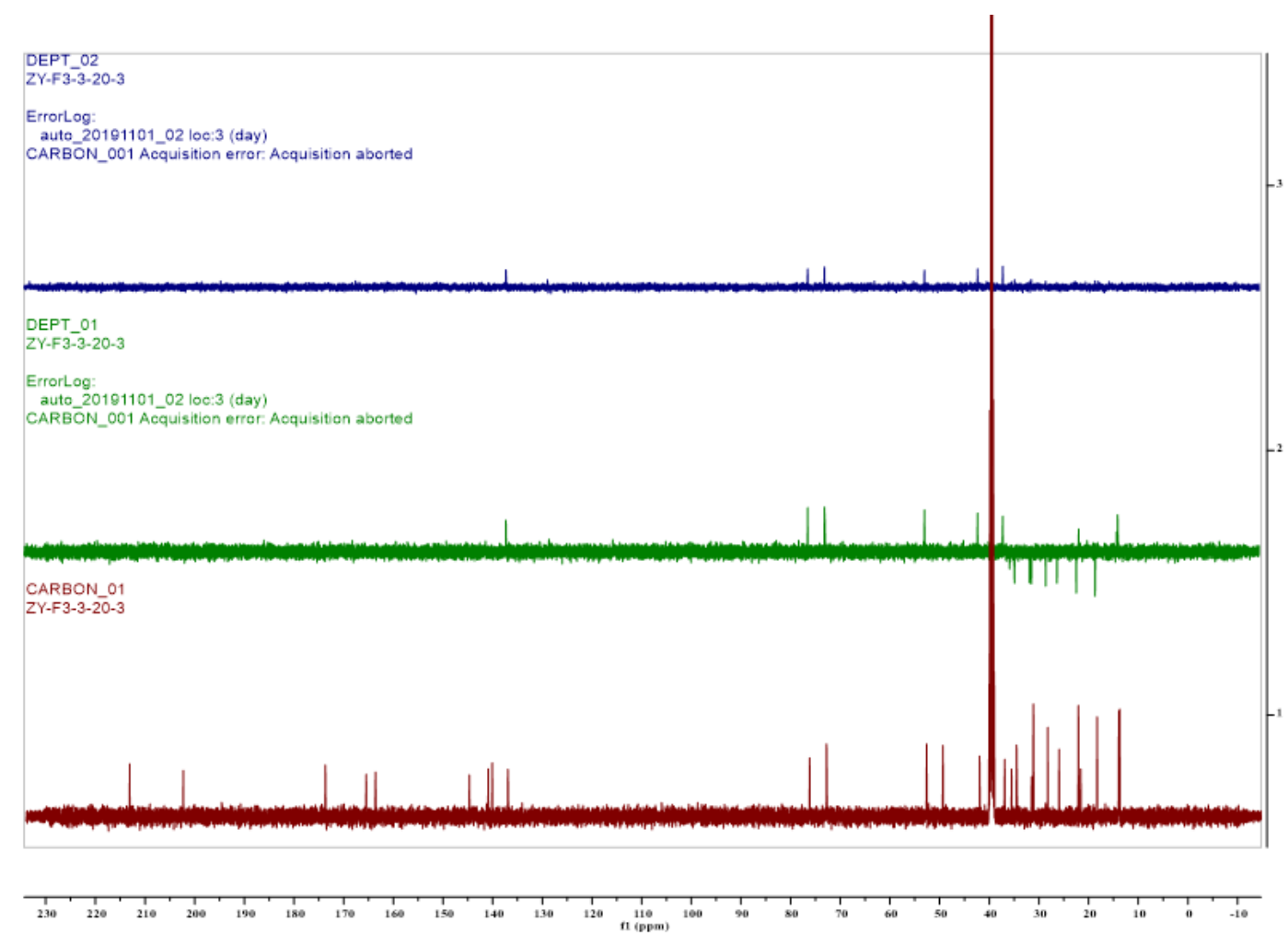

Figure S45 ${ }^{1} \mathrm{H}-{ }^{1} \mathrm{H}$ COSY spectrum of compound 5.

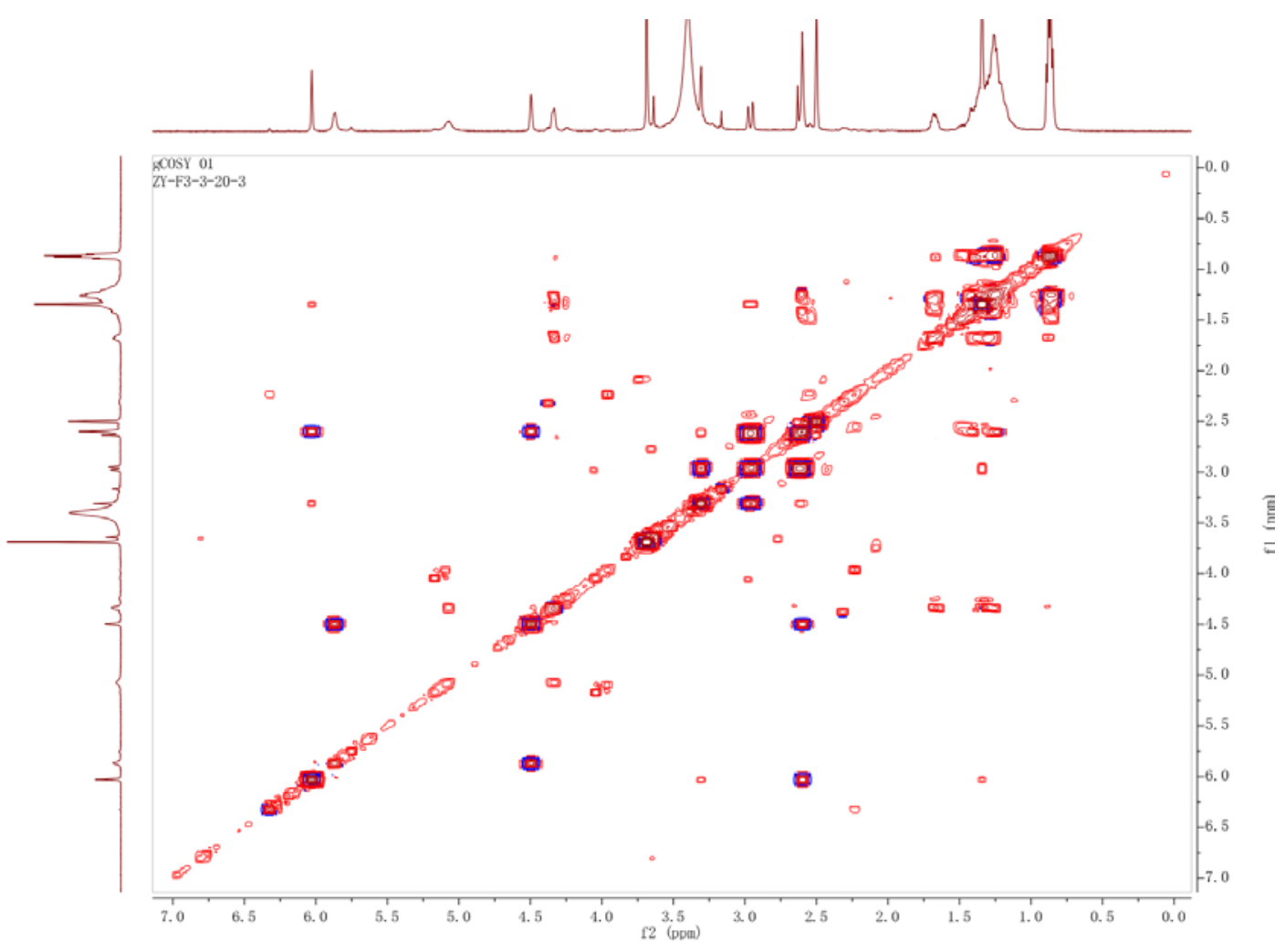


Figure S46 ${ }^{1} \mathrm{H}-{ }^{13} \mathrm{C}$ HSQC spectrum of compound 5 .

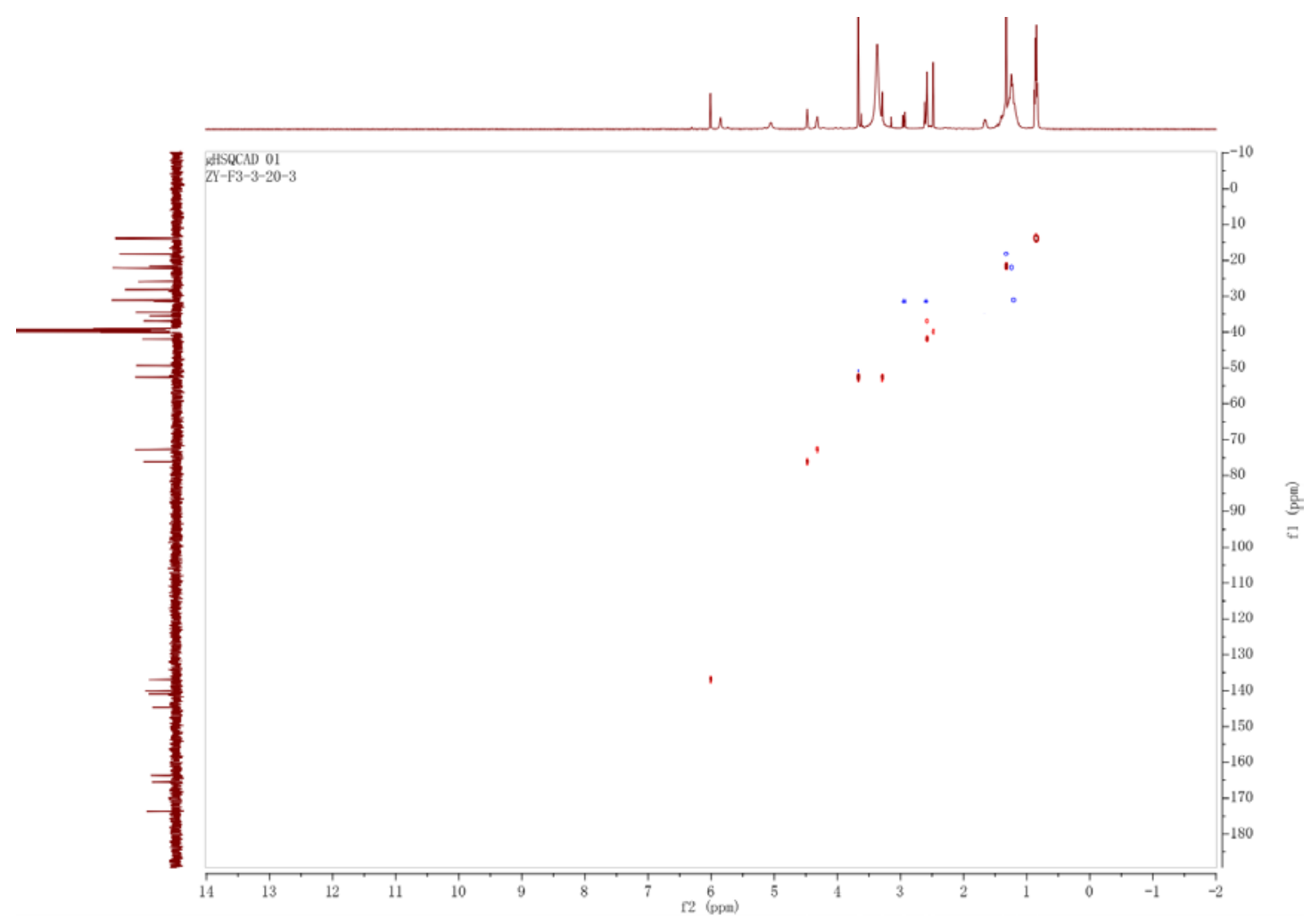

Figure $\mathbf{S 4 7}{ }^{1} \mathrm{H}^{13} \mathrm{C}$ HMBC spectrum of compound 5.

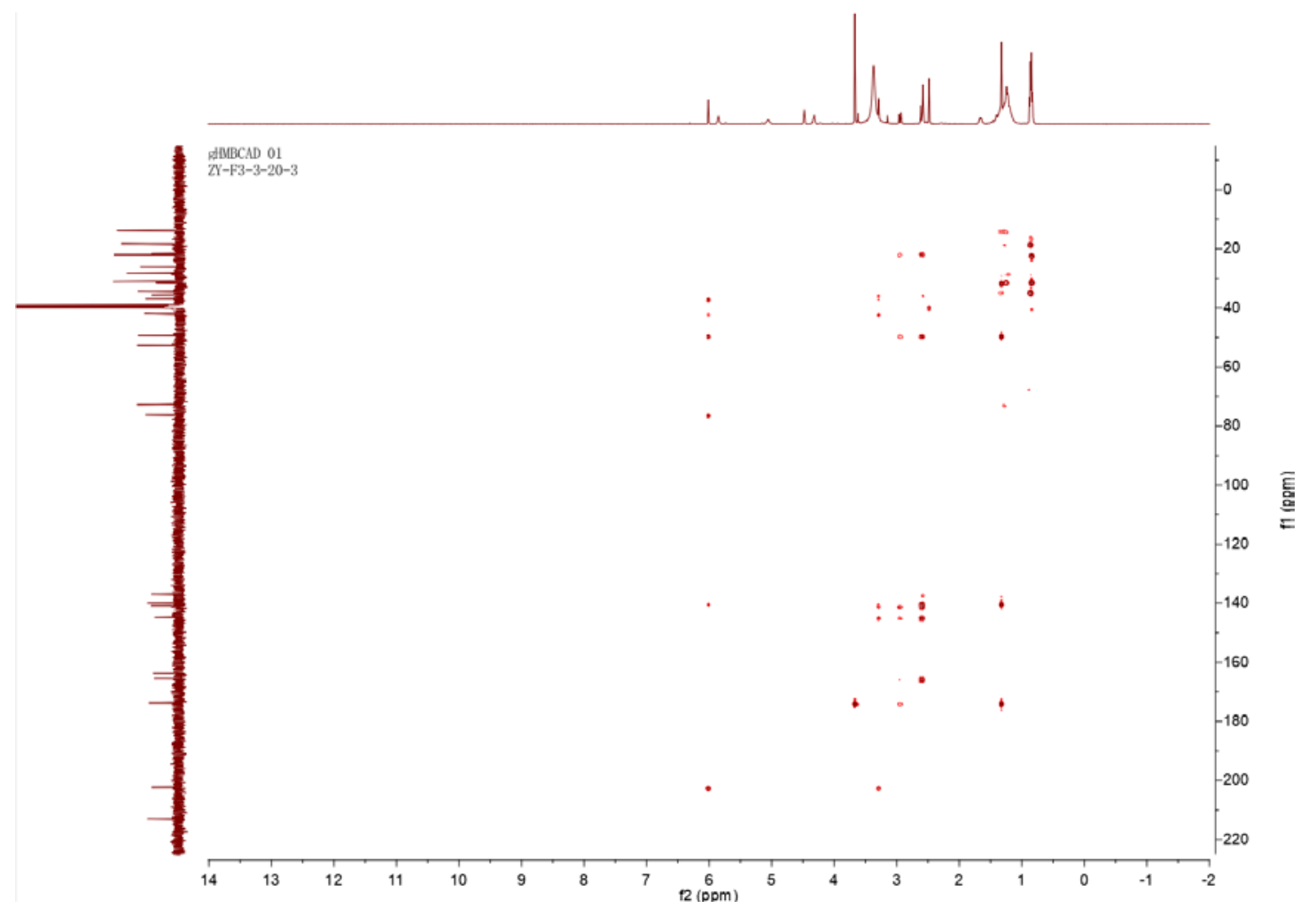


Figure S48 NOESY spectrum of compound 5.

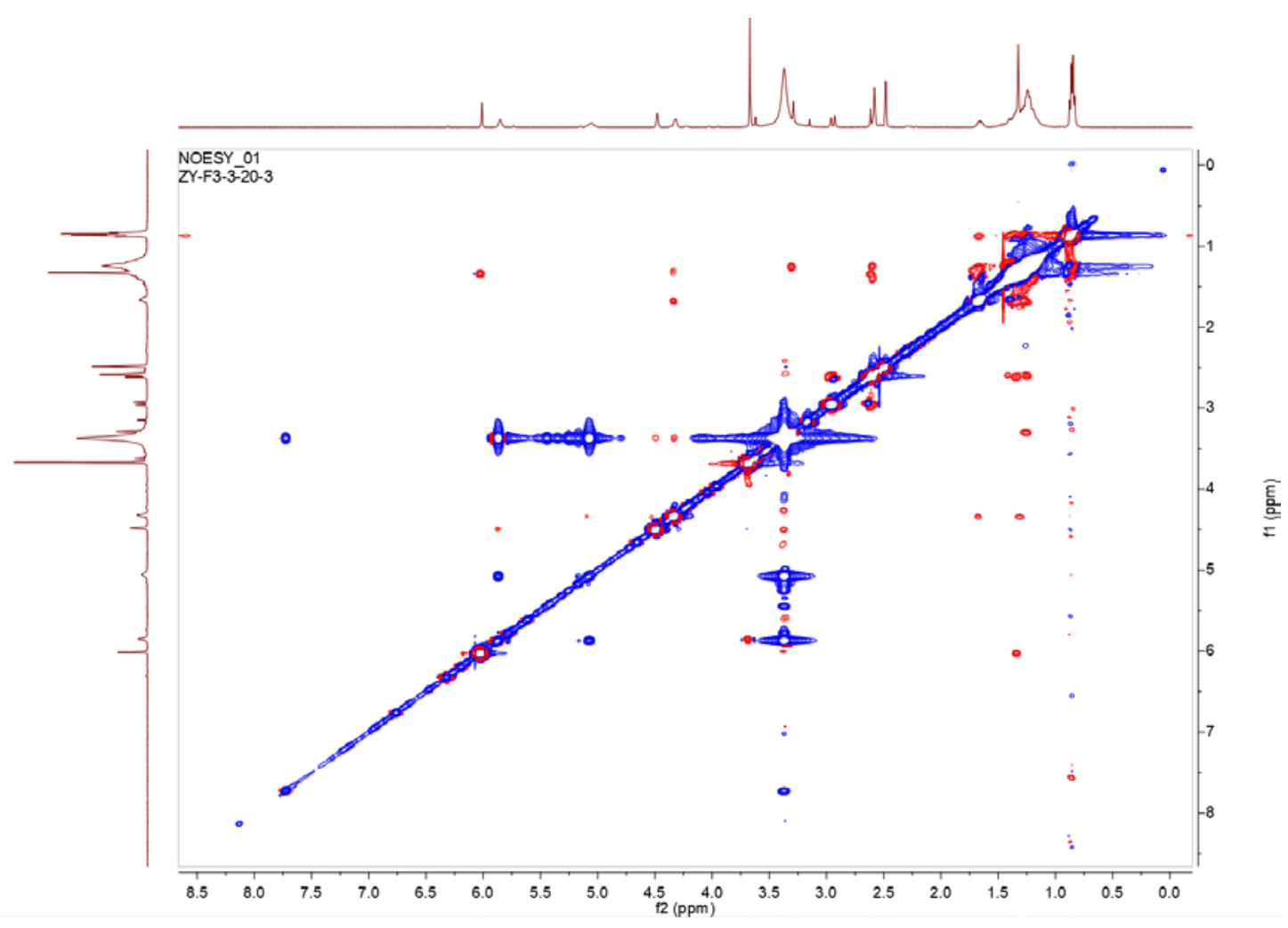

Figure S49 HRESIMS spectrum of compound 5.

20200824-ZY-F3-3-20-3_200824110033

8/24/2020 2:18:57 PM ZY-F3-3-20-3

20200824-ZY-F3-3-20-3_200824110033\#25 RT: 0.35 AV: 1 SB: 6 0.04-0.11 NL: 1.16E6

T: FTMS - p ESI Full ms [150.00-1000.00]

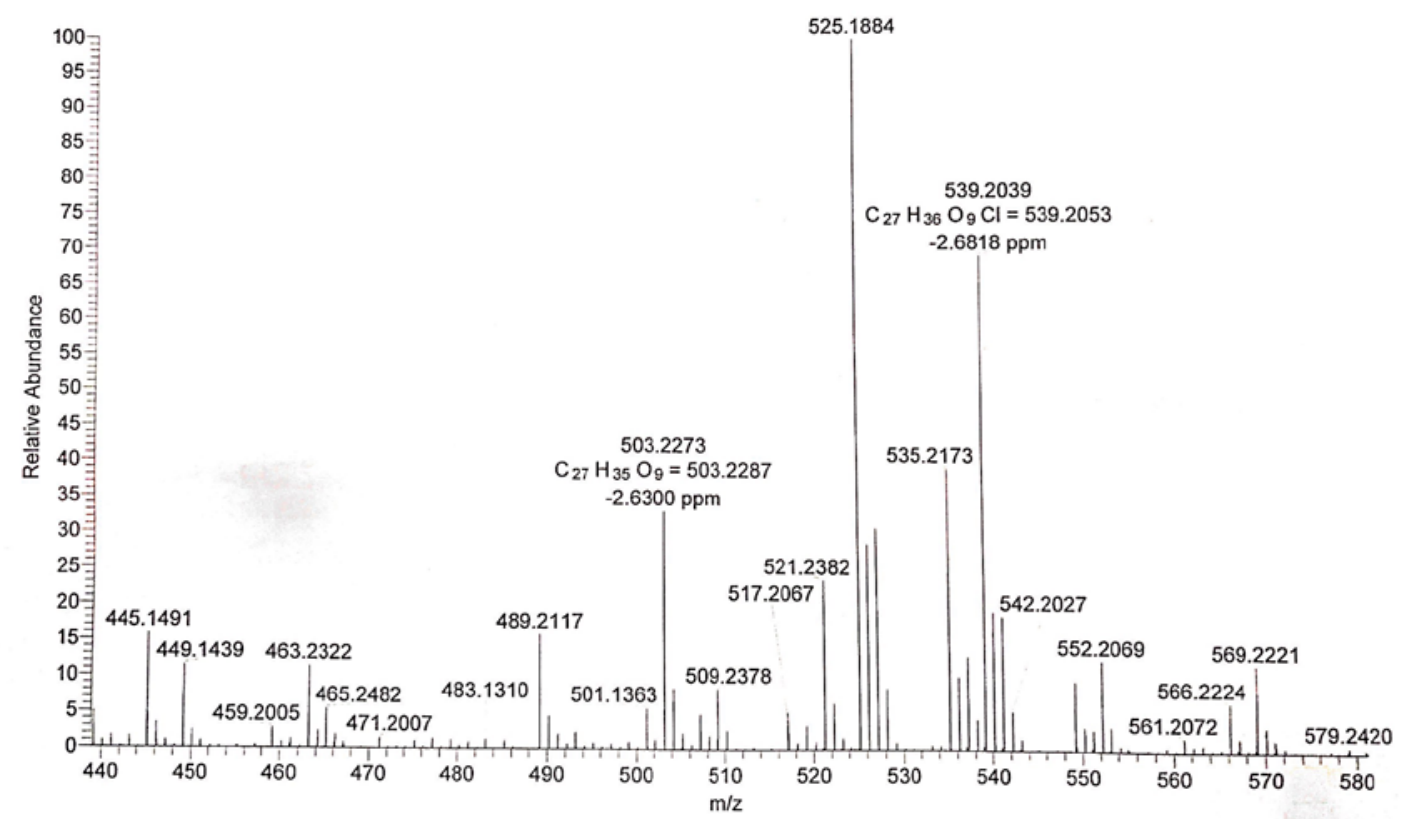


Figure S50 IR spectrum of compound 5.

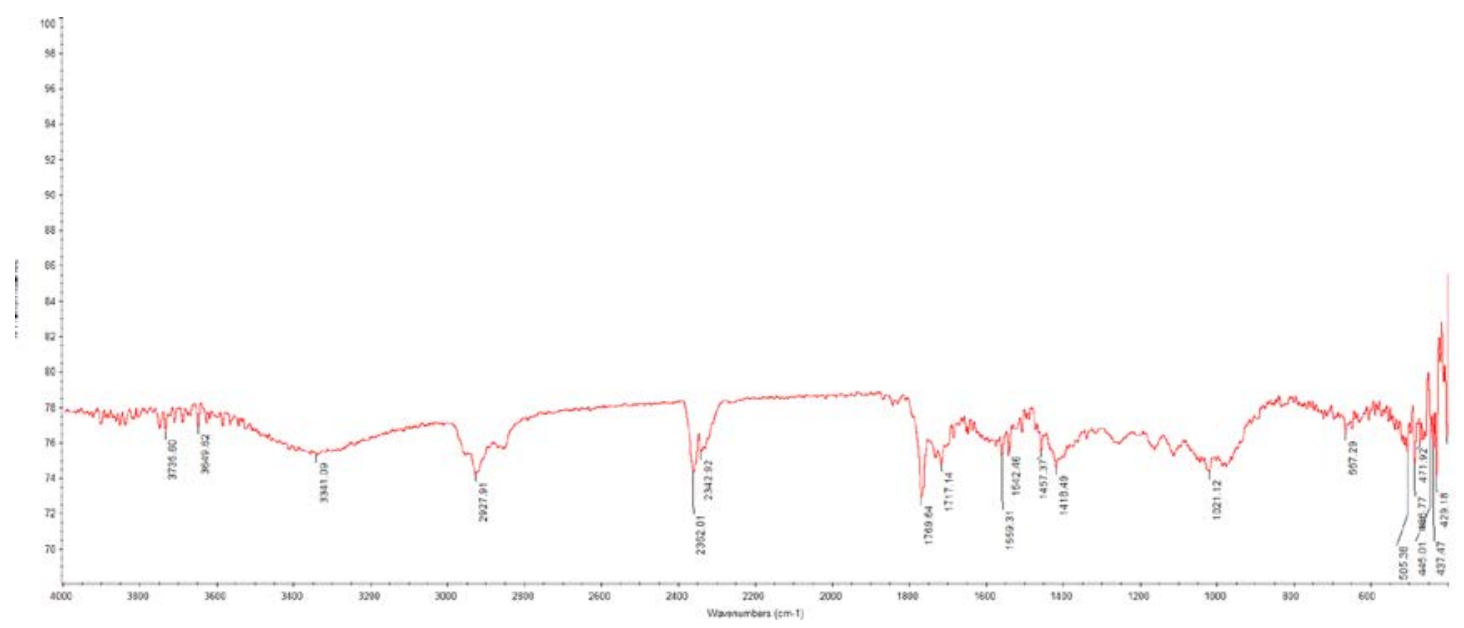

Figure S51 UV spectrum of compound 5.

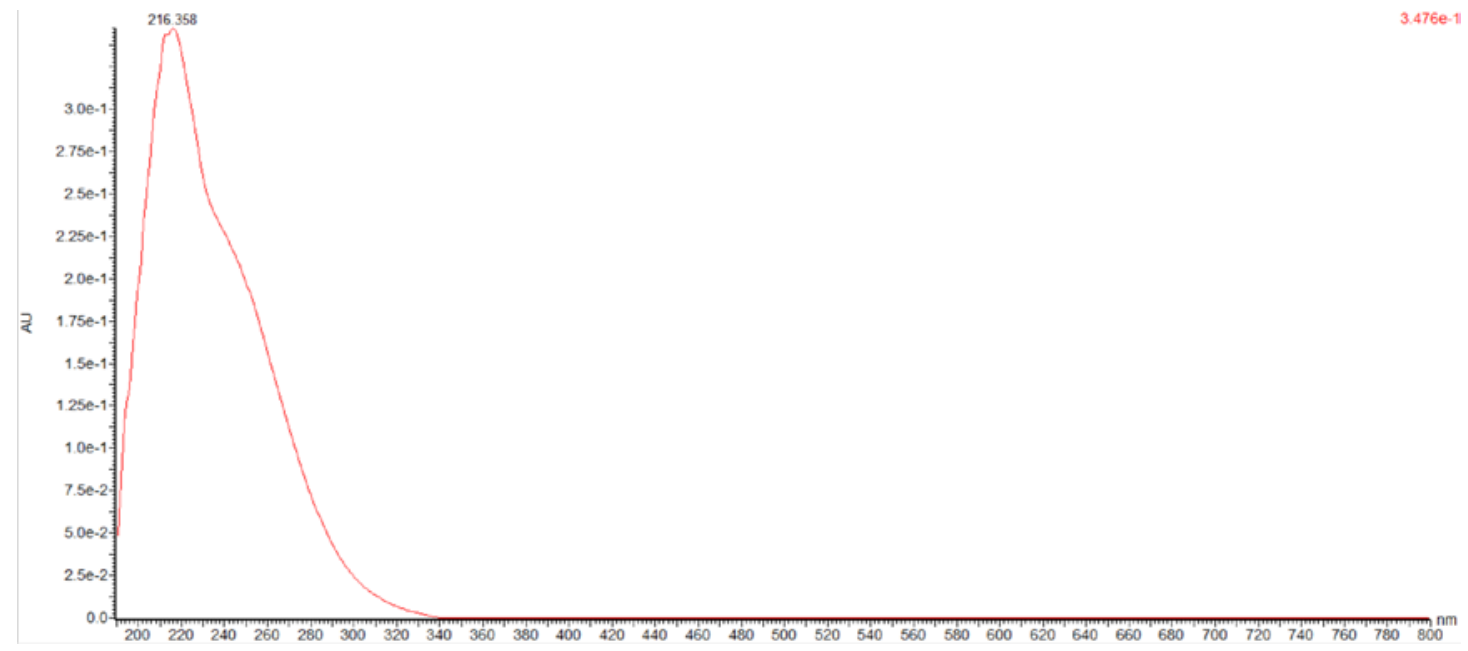


Figure S52 ${ }^{1} \mathrm{H}$ NMR (600 MHz, DMSO- $\left.d_{6}\right)$ spectrum of compound 6.

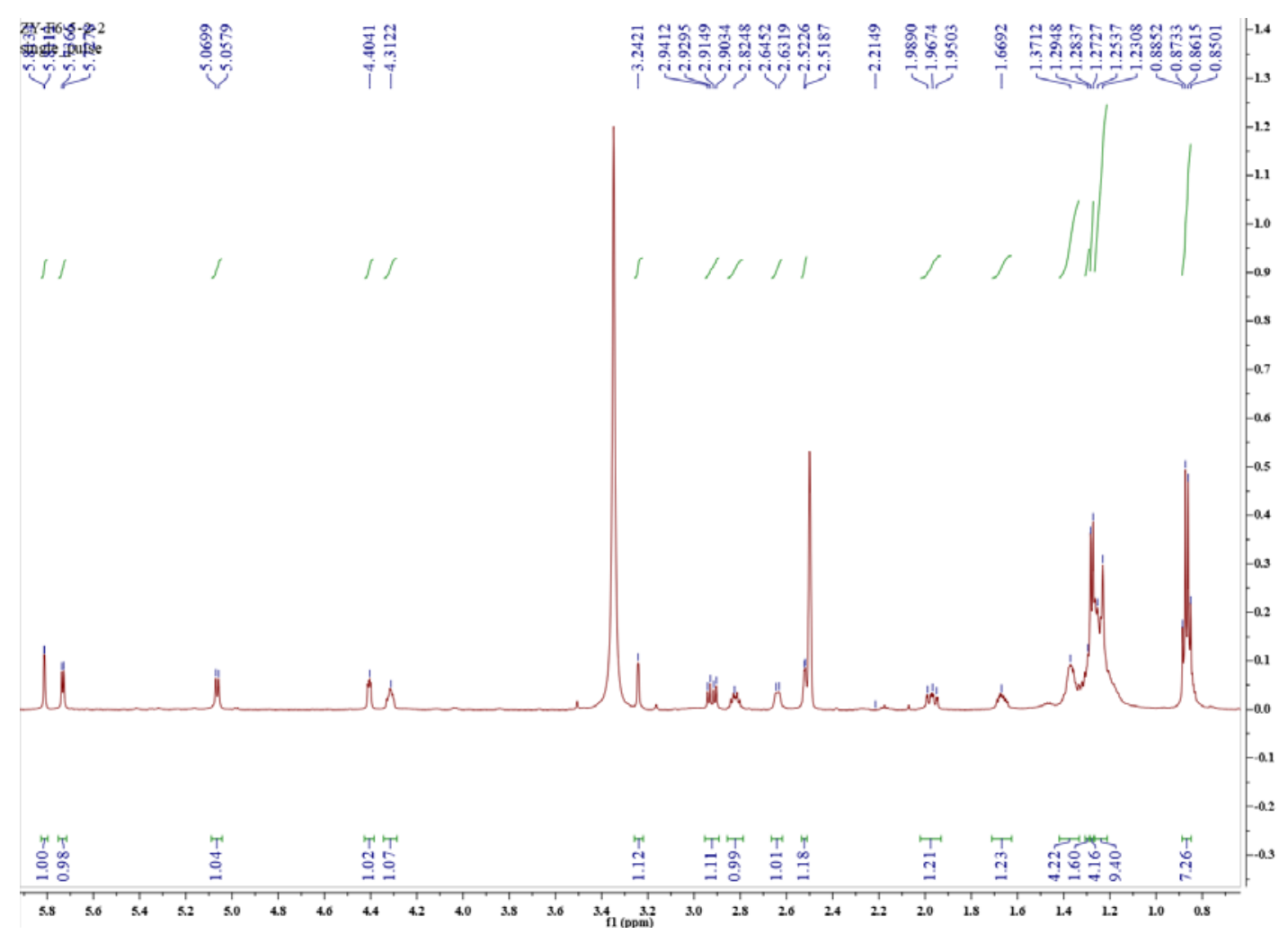

Figure S53 ${ }^{13} \mathrm{C}$ NMR (150 MHz, DMSO- $\left.d_{6}\right)$ spectrum of compound 6. 


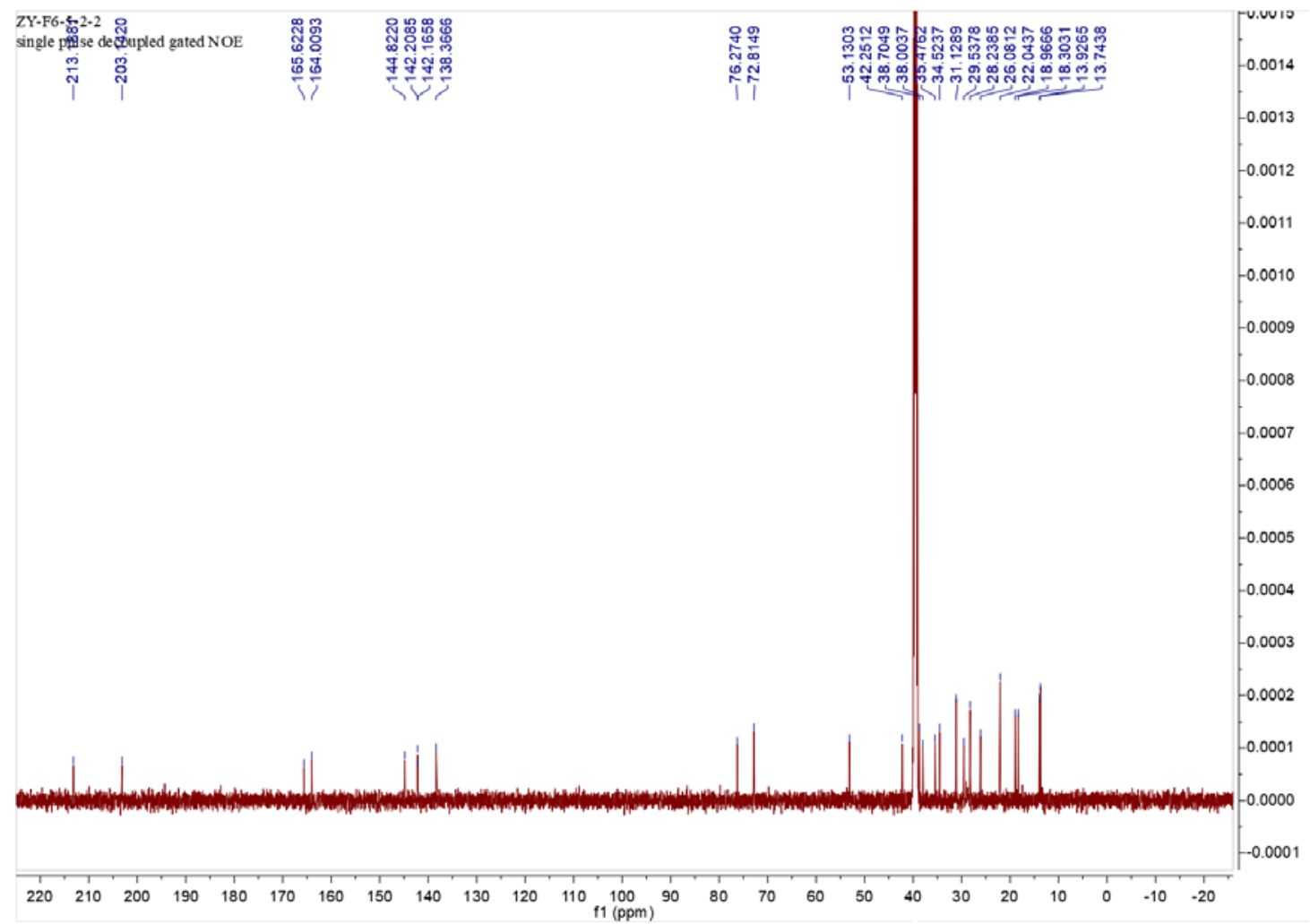

Figure S54 DEPT (150 MHz, DMSO- $d_{6}$ ) spectrum of compound 6.

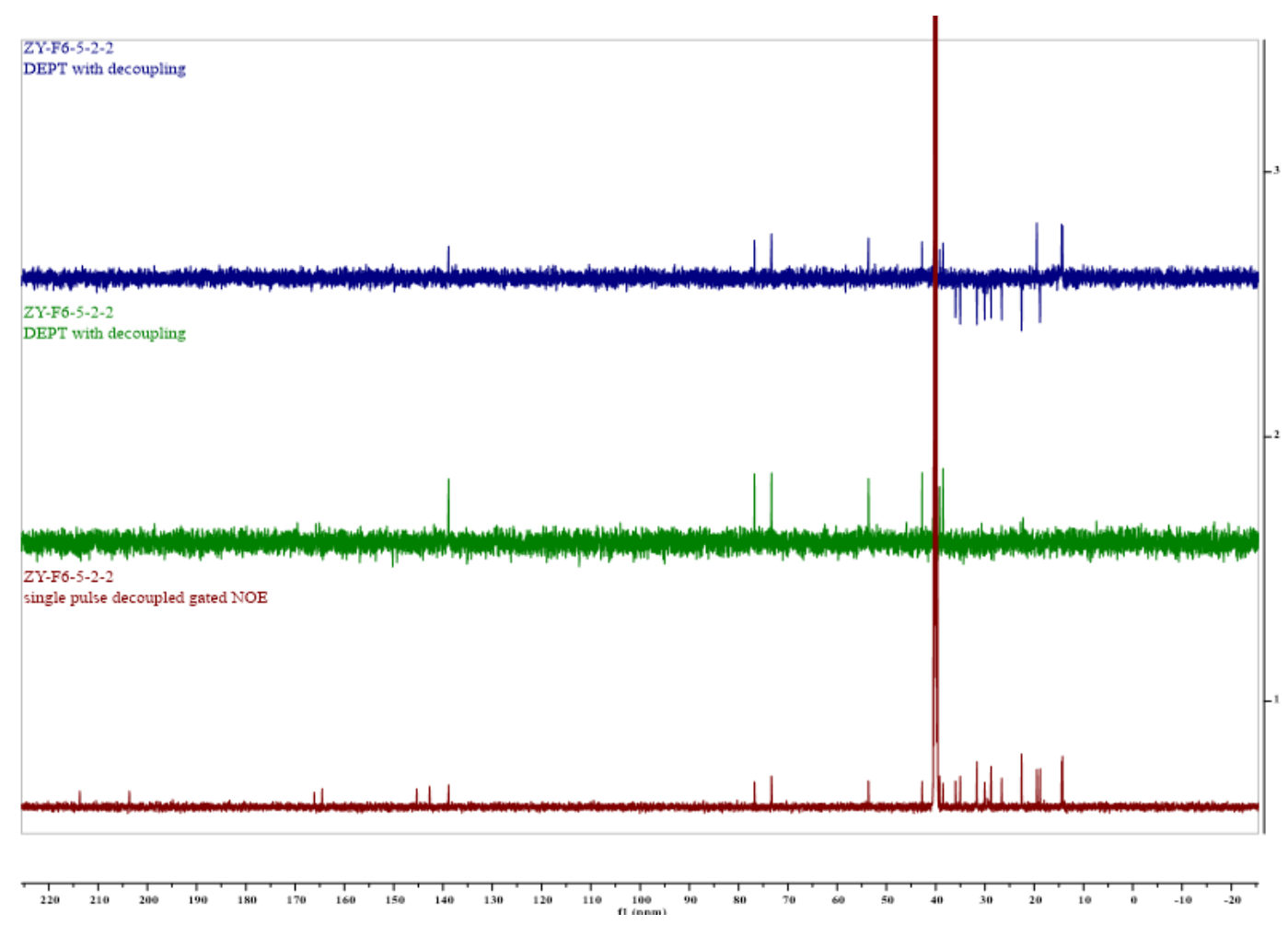

Figure S55 ${ }^{1} \mathrm{H}-{ }^{1} \mathrm{H}$ COSY spectrum of compound 6. 


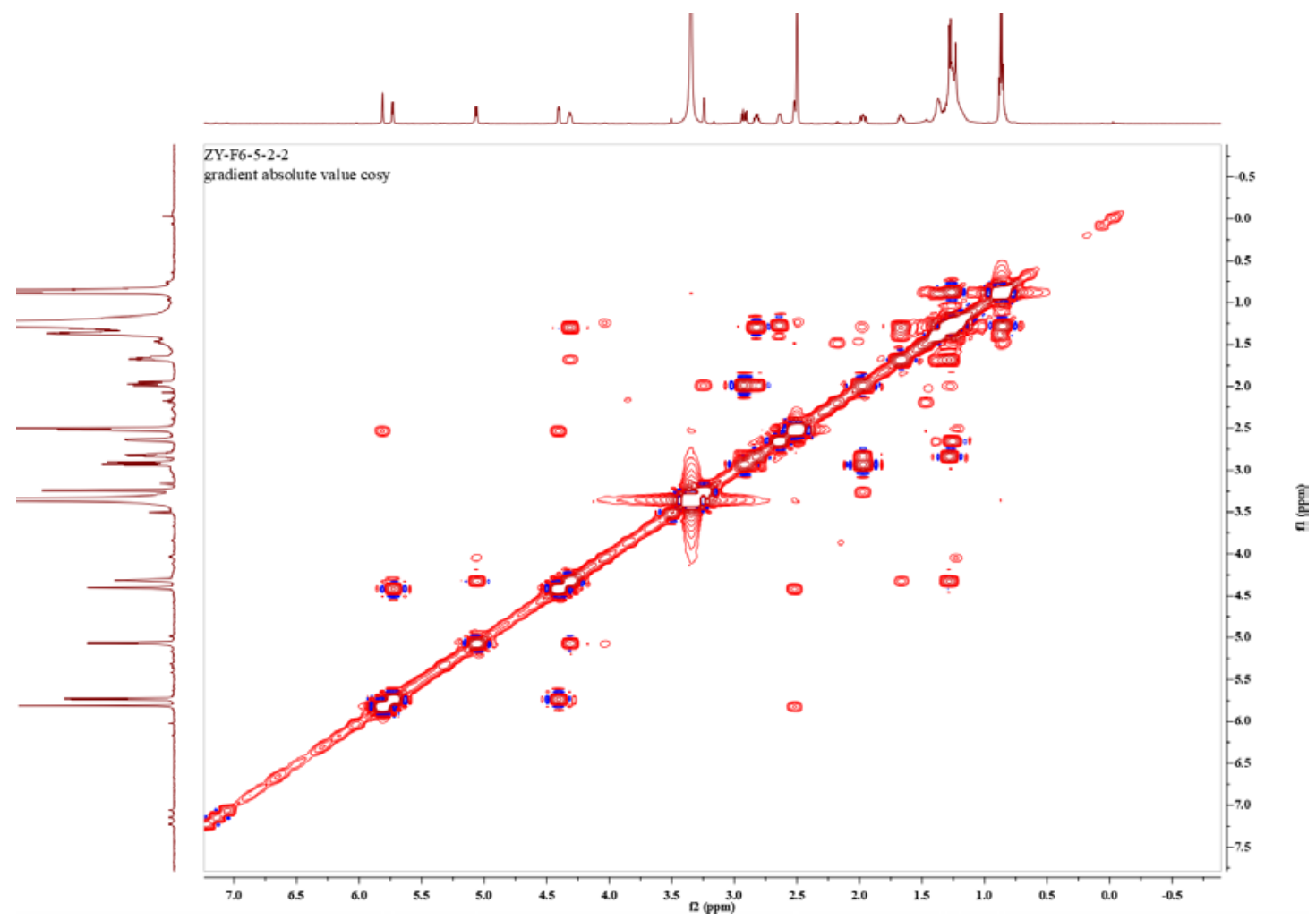

Figure S56 ${ }^{1} \mathrm{H}^{-13} \mathrm{C}$ HSQC spectrum of compound 6.

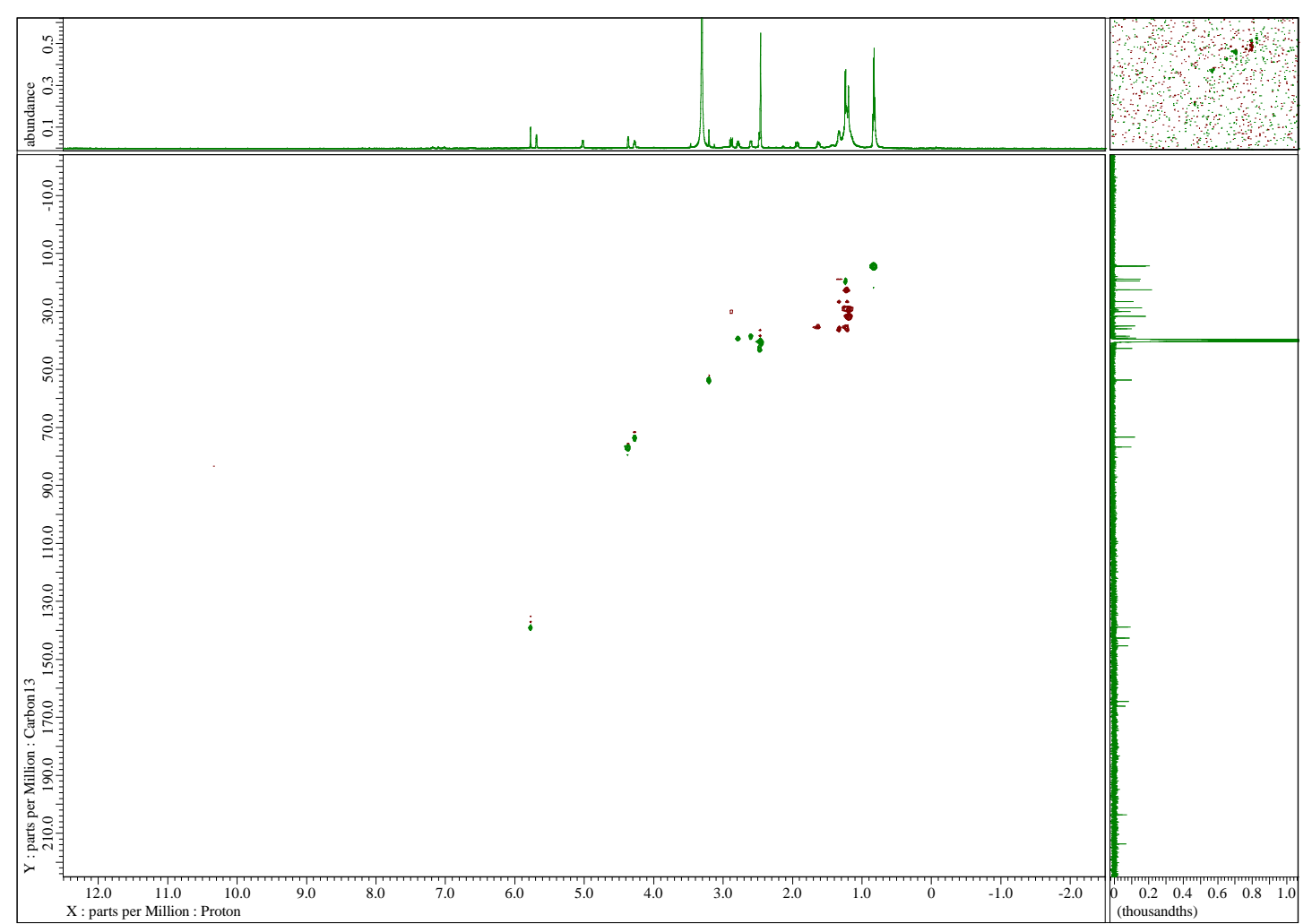

Figure S57 ${ }^{1} \mathrm{H}^{-13} \mathrm{C}$ HMBC spectrum of compound 6. 


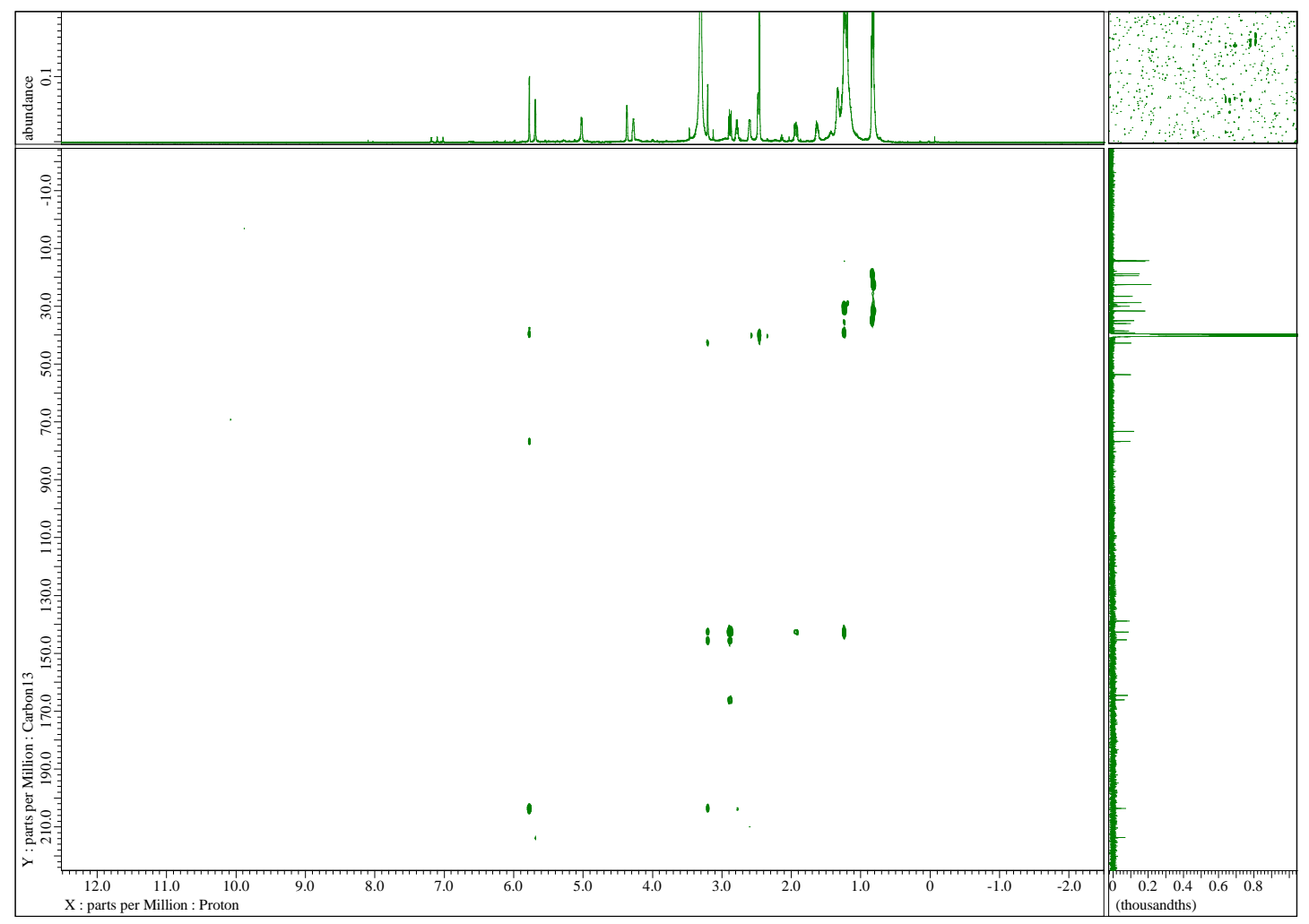

Figure S58 NOESY spectrum of compound 6.

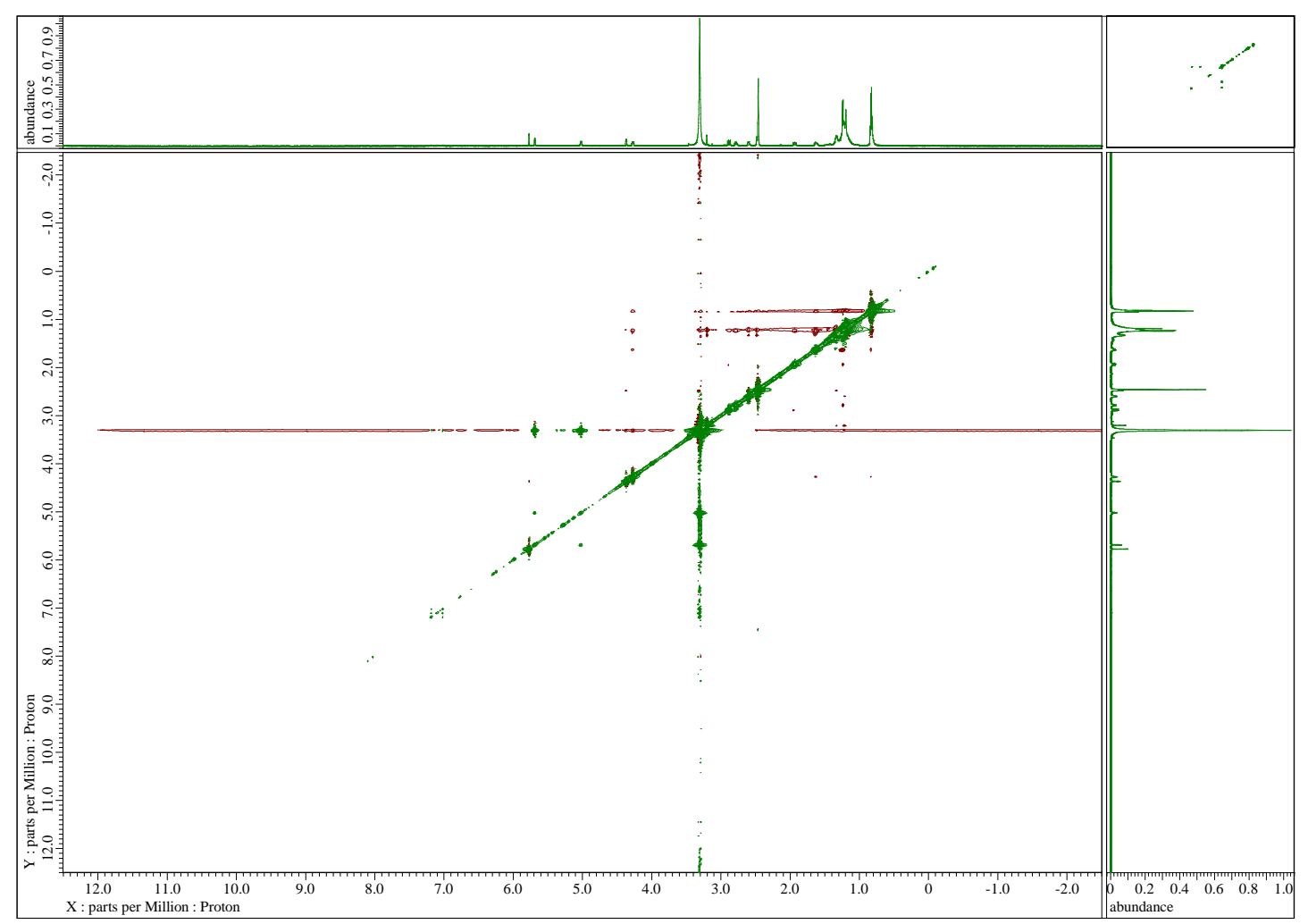

Figure S59 HRESIMS spectrum of compound 6. 


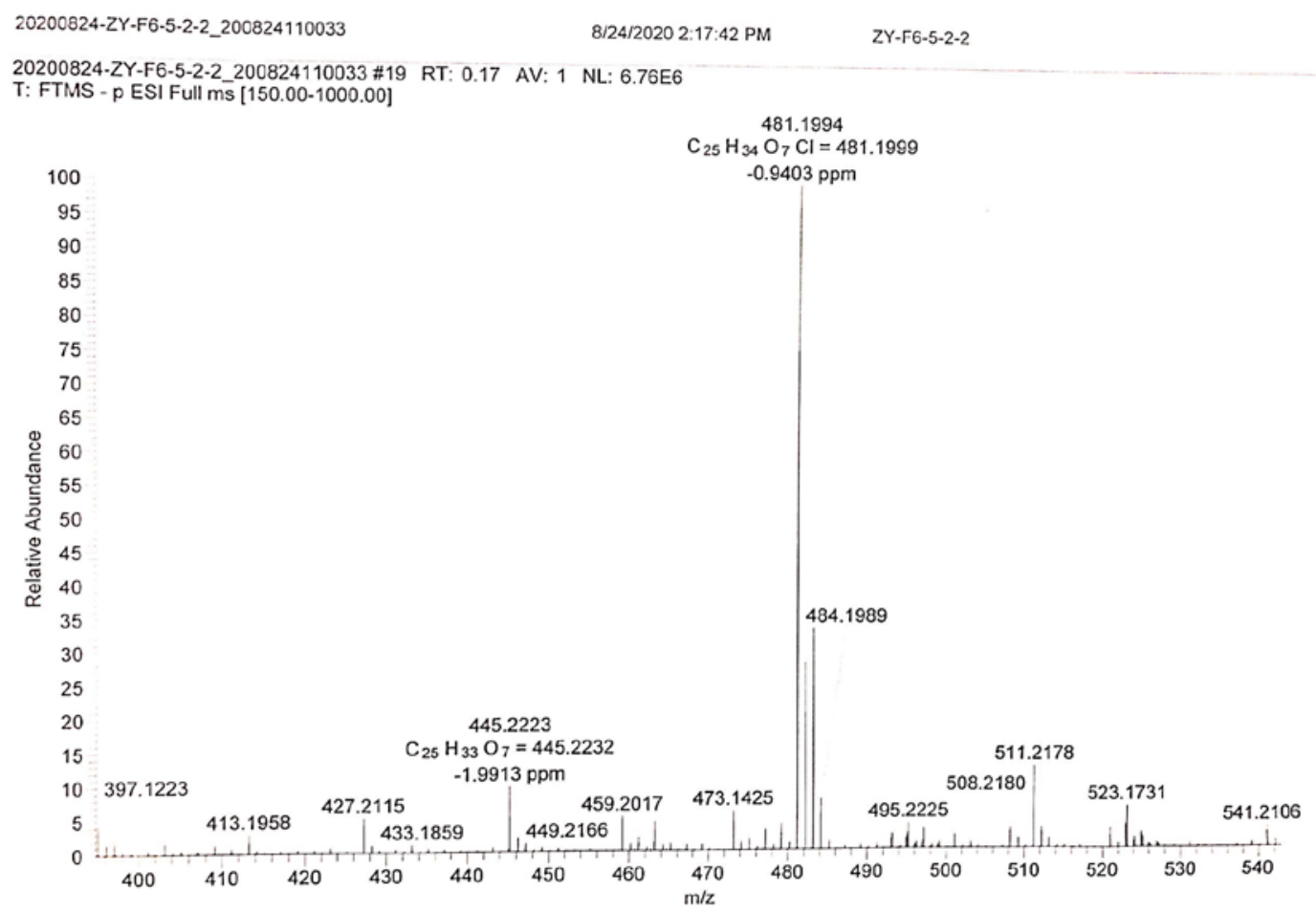

Figure S60 IR spectrum of compound 6.

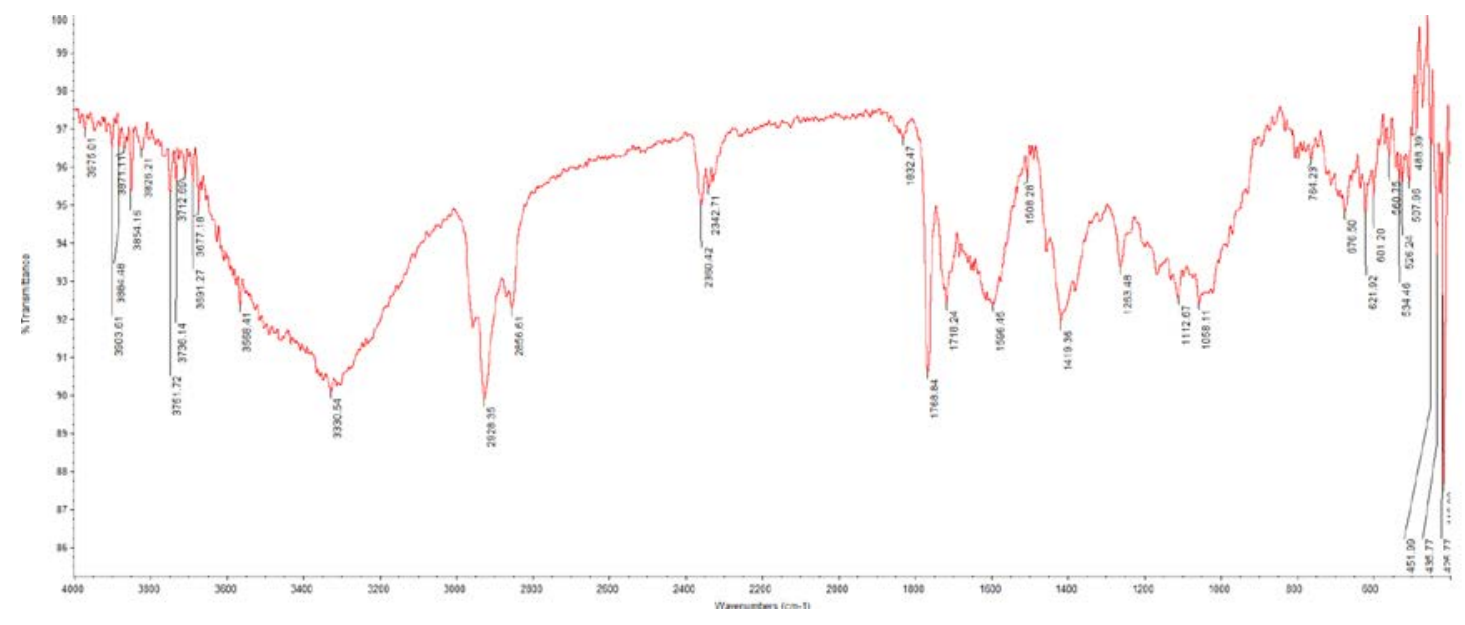

Figure S61 UV spectrum of compound 6. 


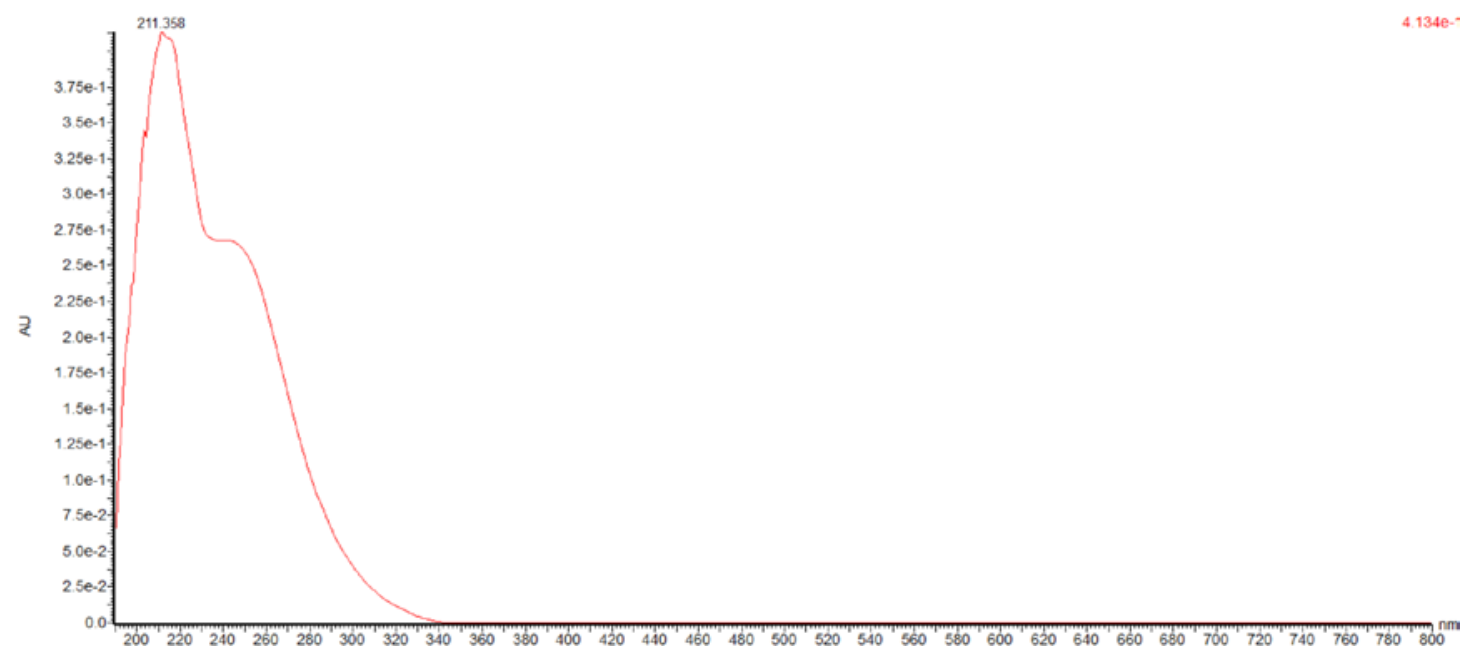

Figure S62 ${ }^{1} \mathrm{H}$ NMR (400 MHz, DMSO-d $)$ spectrum of compound 2g. 


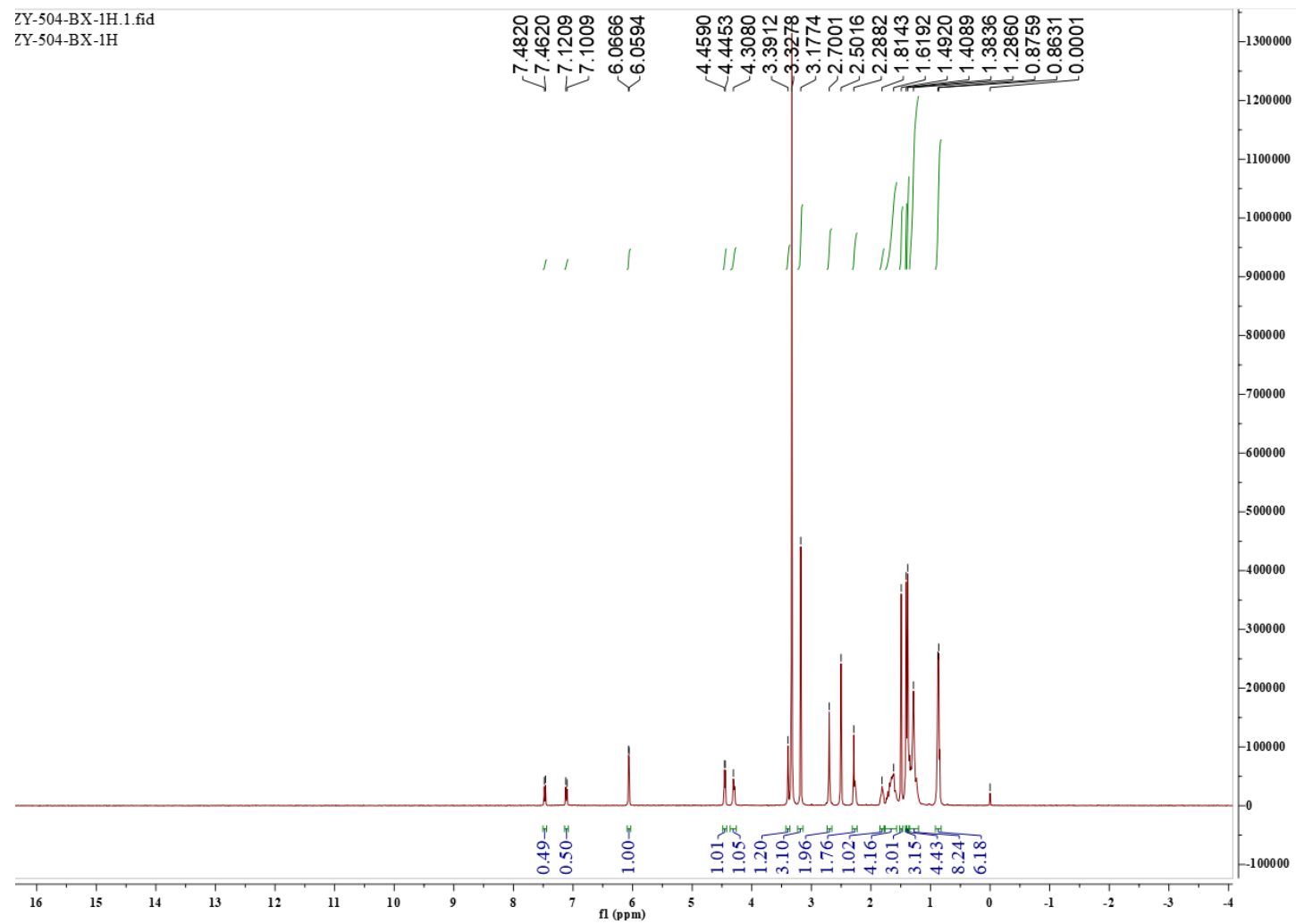

Figure $\mathbf{S 6 3}{ }^{1} \mathrm{H}-{ }^{1} \mathrm{H}$ COSY spectrum of compound $\mathbf{2 g}$.

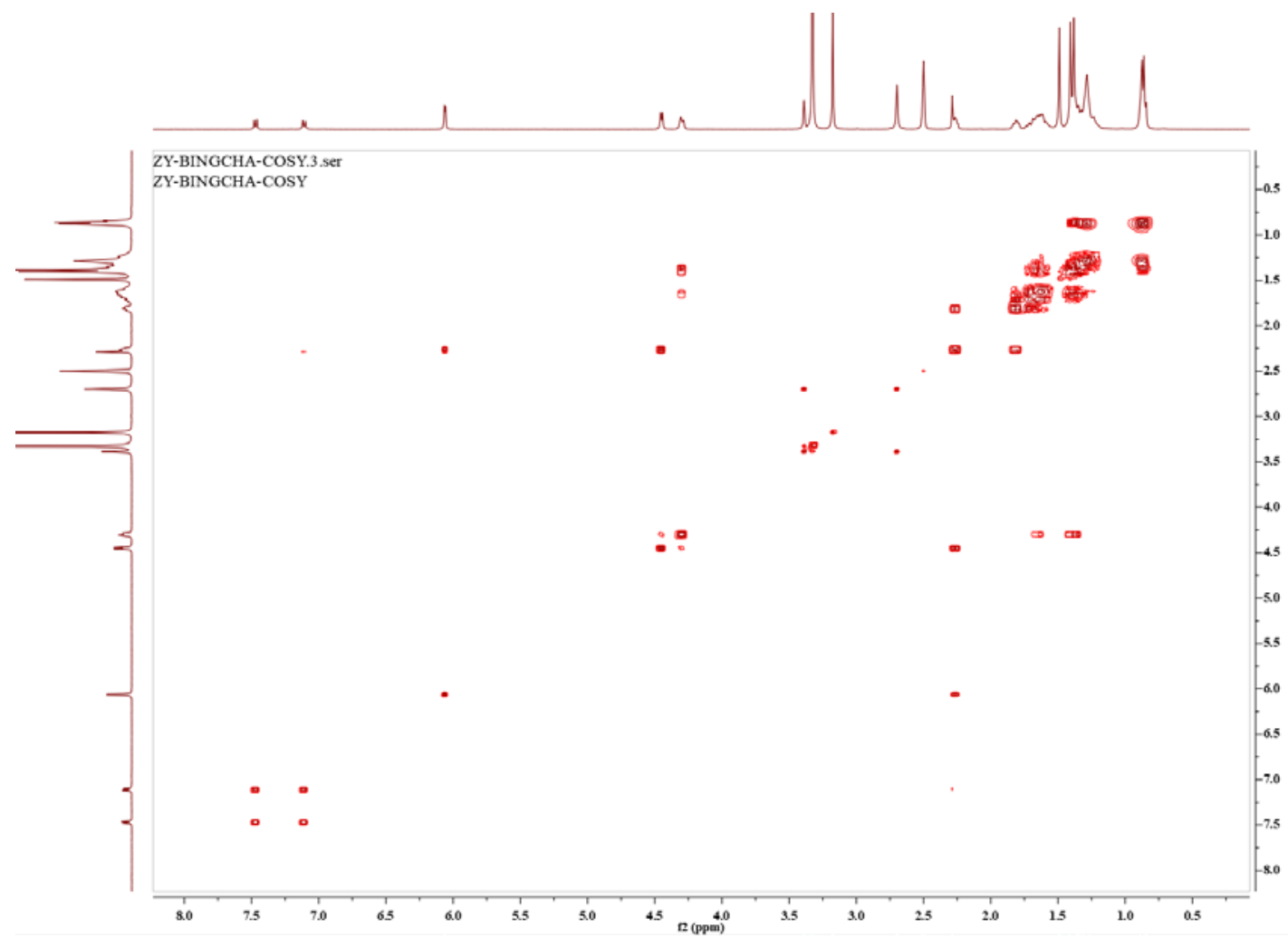

Figure S64 NOESY spectrum of compound 2g. 


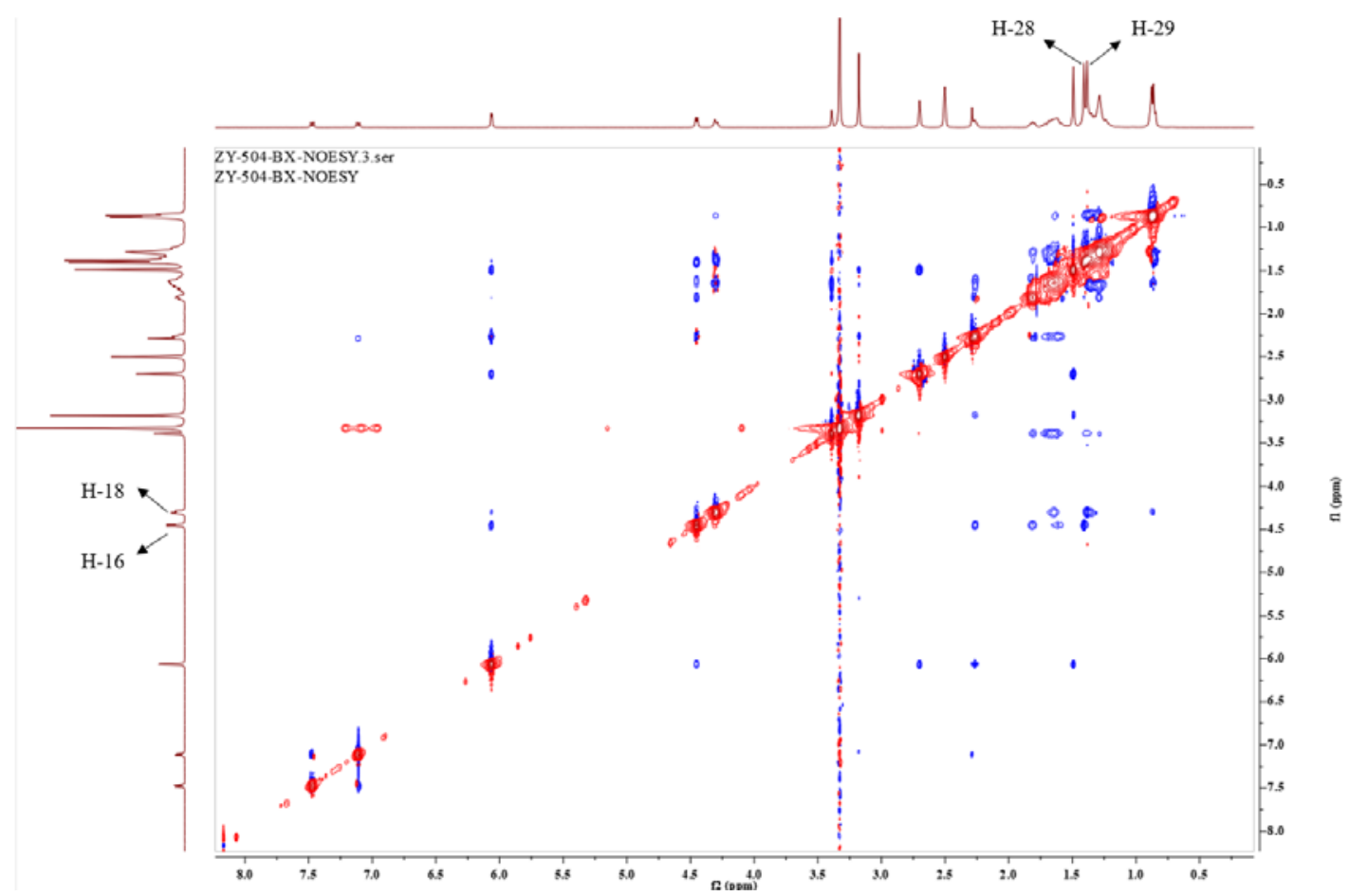

Figure S65 HRESIMS spectrum of compound 2g.

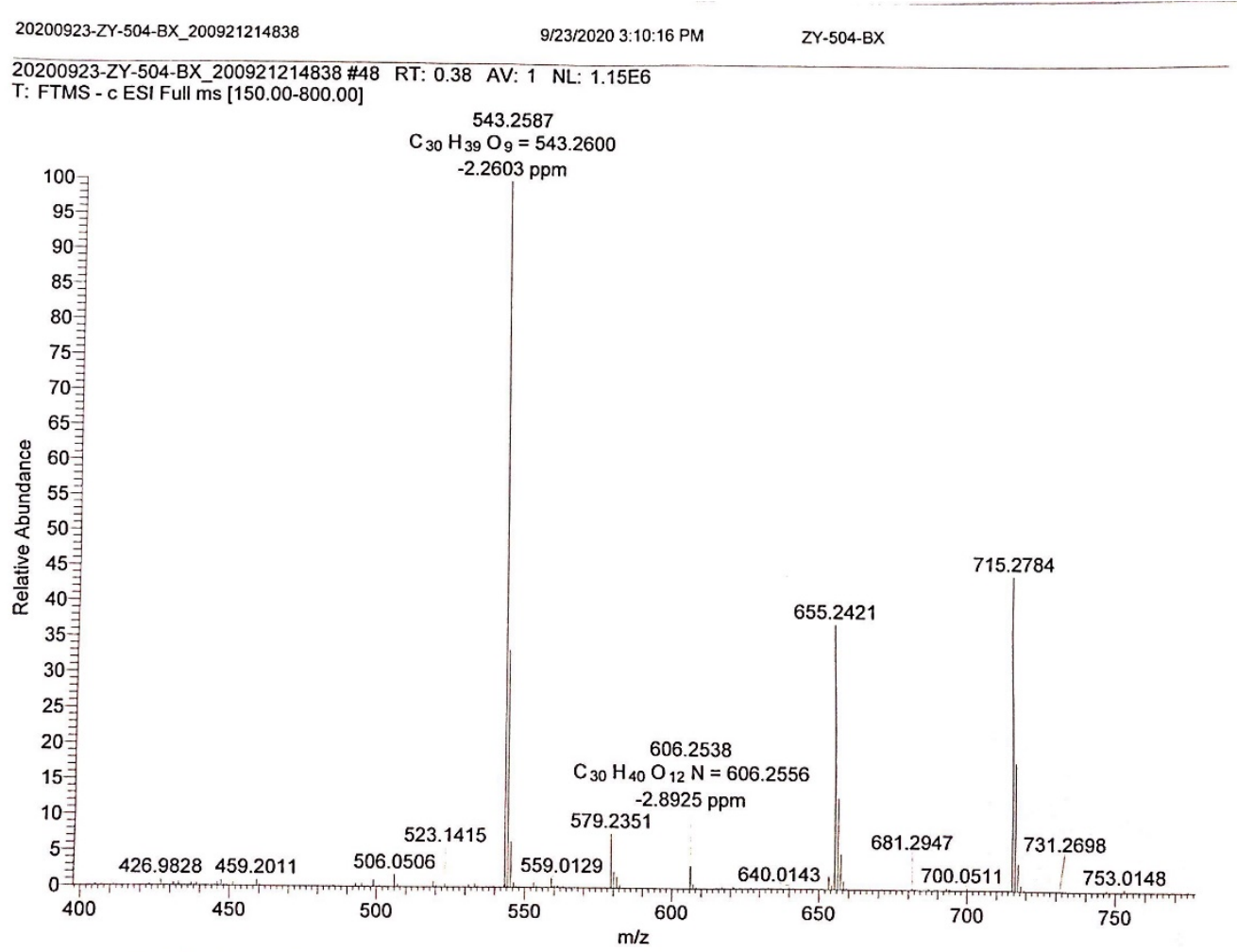

Figure S66 Key NOESY correlations of compound 2g. 

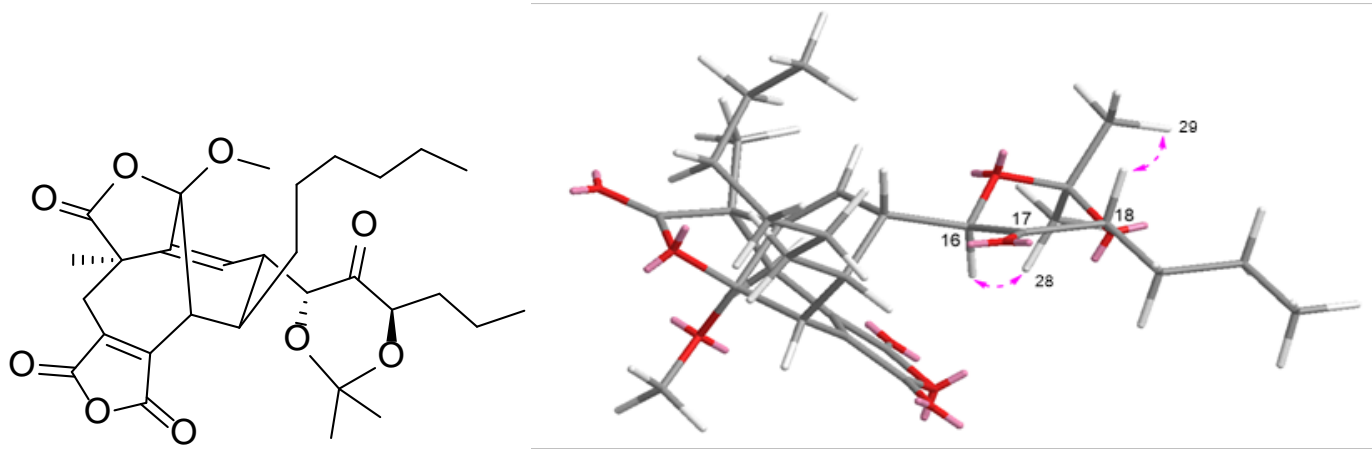

Figure S67. DFT-optimized structures for low-energy conformers of ( $7 R, 8 R, 12 R, 15 R$, 22S)-1a at B3LYP/6-31+G(d) level in methanol (CPCM) (Conformer populations were calculated using the Gibbs free energy and Boltzmann population at $298 \mathrm{~K}$ estimated thereof).

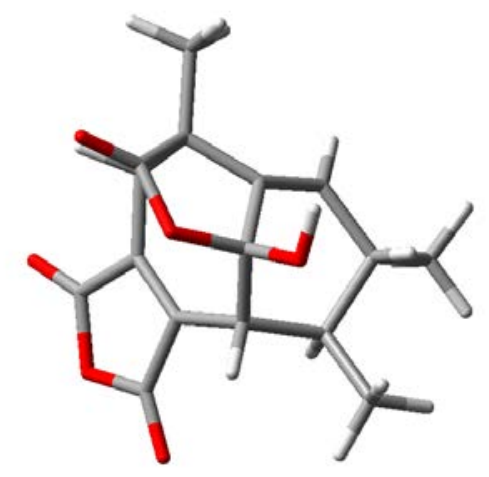

Conf. A $100.0 \%$

Table S1. Harmonic frequencies $\left(\mathrm{cm}^{* *-1}\right)$ of $1 \mathrm{~A}$.

\begin{tabular}{|c|c|c|c|}
\hline \multirow{2}{*}{ Conformations } & \multicolumn{3}{|c|}{ Frequencies } \\
\cline { 2 - 4 } & 1 & 2 & 3 \\
\hline $\mathrm{A}$ & 46.8410 & 62.4641 & 78.3953 \\
\hline
\end{tabular}

Table S2. Important thermodynamic parameters (a.u.) and Boltzmann distributions of the optimized 1a at B3LYP/6-31G+(d) level of theory with PCM solvent model for $\mathrm{MeOH}$.

\begin{tabular}{|c|c|c|c|}
\hline Conformations & E+ZPE & G & \% \\
\hline A & -1070.438916 & -1070.484110 & $100.0 \%$ \\
\hline
\end{tabular}


E+ZPE, G: total energy with zero point energy (ZPE) and Gibbs free energy at B3LYP/6-31G+(d) level of theory with PCM solvent model for MeOH. \%: Boltzmann distributions, using the relative Gibbs free energies as weighting factors

Table S3. Cartesian coordinates of the low-energy reoptimized conformers of $(7 R, 8 R$, $12 R, 15 R, 22 S)-1$ a calculated at B3LYP/6-31+G(d) level of theory with PCM solvent model for $\mathrm{MeOH}$.

\begin{tabular}{|c|c|c|c|c|}
\hline \multicolumn{2}{|c|}{ Conformer A } & \multicolumn{3}{|c|}{$\begin{array}{c}\text { Standard Orientation } \\
\text { (Ångstroms) }\end{array}$} \\
\hline $\mathrm{I}$ & Atom & $\mathrm{X}$ & $\mathrm{Y}$ & $\mathrm{Z}$ \\
\hline 1 & $\mathrm{O}$ & -1.87729 & 1.36103 & -1.15413 \\
\hline 2 & $\mathrm{C}$ & -2.65953 & 0.2485 & -1.093 \\
\hline 3 & $\mathrm{C}$ & -1.83878 & -0.97897 & -0.74035 \\
\hline 4 & $\mathrm{C}$ & -0.46709 & -0.50275 & -1.08141 \\
\hline 5 & $\mathrm{C}$ & -0.51553 & 0.98322 & -1.10876 \\
\hline 6 & $\mathrm{C}$ & -1.96652 & -1.16405 & 0.79528 \\
\hline 7 & $\mathrm{C}$ & -1.36505 & -0.08751 & 1.67178 \\
\hline 8 & $\mathrm{C}$ & -1.69481 & -0.05231 & 3.09916 \\
\hline 9 & $\mathrm{O}$ & -1.05203 & 0.99035 & 3.65543 \\
\hline 10 & $\mathrm{C}$ & -0.32634 & 1.62214 & 2.71476 \\
\hline 11 & $\mathrm{C}$ & -0.51953 & 0.92587 & 1.44121 \\
\hline 12 & $\mathrm{C}$ & 0.19194 & 1.42593 & 0.18928 \\
\hline 13 & $\mathrm{C}$ & 0.69584 & -1.16254 & -0.94281 \\
\hline 14 & $\mathrm{C}$ & 1.6901 & 0.91818 & 0.18164 \\
\hline 15 & $\mathrm{C}$ & 1.95381 & -0.33945 & -0.73833 \\
\hline 16 & $\mathrm{C}$ & 3.07036 & -1.20832 & -0.14939 \\
\hline 17 & $\mathrm{C}$ & 2.63798 & 2.06064 & -0.2117 \\
\hline 18 & $\mathrm{O}$ & 0.13846 & 1.49969 & -2.25054 \\
\hline 19 & $\mathrm{O}$ & -3.87296 & 0.27324 & -1.22928 \\
\hline 20 & $\mathrm{O}$ & 0.38302 & 2.59525 & 2.88472 \\
\hline 21 & $\mathrm{O}$ & -2.41885 & -0.84417 & 3.67185 \\
\hline 22 & $\mathrm{C}$ & -2.29423 & -2.19743 & -1.53138 \\
\hline 23 & $\mathrm{H}$ & -3.03284 & -1.25342 & 1.04547 \\
\hline 24 & $\mathrm{H}$ & -1.50266 & -2.11804 & 1.08141 \\
\hline 25 & $\mathrm{H}$ & 0.17285 & 2.52399 & 0.22092 \\
\hline 26 & $\mathrm{H}$ & 0.72831 & -2.23842 & -0.79001 \\
\hline 27 & $\mathrm{H}$ & 1.96388 & 0.6468 & 1.21135 \\
\hline
\end{tabular}




\begin{tabular}{|c|c|c|c|c|}
\hline 28 & H & 2.29449 & -0.01132 & -1.72974 \\
\hline 29 & H & 3.28709 & -2.0612 & -0.8025 \\
\hline 30 & H & 3.99657 & -0.63612 & -0.03608 \\
\hline 31 & H & 2.79319 & -1.60297 & 0.8347 \\
\hline 32 & H & 2.52119 & 2.91033 & 0.46944 \\
\hline 33 & H & 2.44264 & 2.41352 & -1.22901 \\
\hline 34 & H & 3.6833 & 1.74014 & -0.16084 \\
\hline 35 & H & 0.01276 & 0.86305 & -2.97272 \\
\hline 36 & H & -2.23834 & -2.01609 & -2.6112 \\
\hline 37 & H & -1.68031 & -3.07604 & -1.30528 \\
\hline 38 & H & -3.33511 & -2.4507 & -1.29995 \\
\hline
\end{tabular}

Figure S68. DFT-optimized structures for low-energy conformers of $(7 R, 8 R, 12 R, 15 R$, $16 R, 18 R, 22 S)-4 a$ at B3LYP/6-31+G(d) level in methanol (CPCM) (Conformer populations were calculated using the Gibbs free energy and Boltzmann population at 298 K estimated thereof).

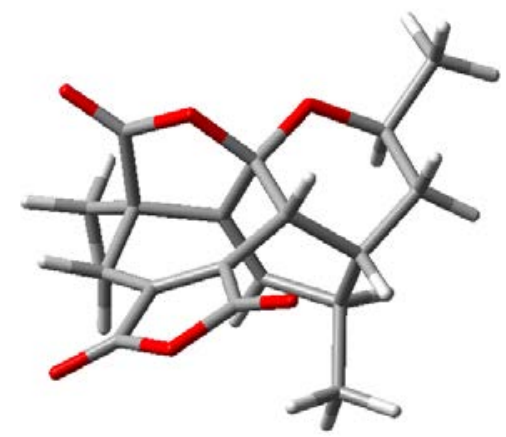

Conf. A $100.0 \%$

Table S4. Harmonic frequencies $\left(\mathrm{cm}^{* *-1}\right)$ of $4 \mathrm{~A}$.

\begin{tabular}{|c|c|c|c|}
\hline \multirow{2}{*}{ Conformations } & \multicolumn{3}{l|}{ Frequencies } \\
\cline { 2 - 4 } & 1 & 2 & 3 \\
\hline $\mathrm{A}$ & 57.5934 & 64.8491 & 85.6864 \\
\hline
\end{tabular}

Table S5. Important thermodynamic parameters (a.u.) and Boltzmann distributions of the optimized 4a at B3LYP/6-31G+(d) level of theory with PCM solvent model for $\mathrm{MeOH}$.

\begin{tabular}{|c|c|c|c|}
\hline Conformations & E+ZPE & G & \% \\
\hline A & -1147.817008 & -1147.862797 & $100.0 \%$ \\
\hline
\end{tabular}


E+ZPE, G: total energy with zero point energy (ZPE) and Gibbs free energy at B3LYP/6-31G+(d) level of theory with PCM solvent model for MeOH. \%: Boltzmann distributions, using the relative Gibbs free energies as weighting factors

Table S6. Cartesian coordinates of the low-energy reoptimized conformers of (7R, $8 R$, $12 R, 15 R, 16 R, 18 R, 22 S)-4 a$ calculated at B3LYP/6-31+G(d) level of theory with PCM solvent model for $\mathrm{MeOH}$.

\begin{tabular}{|c|c|c|c|c|}
\hline \multicolumn{2}{|c|}{ Conformer A } & \multicolumn{3}{|c|}{$\begin{array}{c}\text { Standard Orientation } \\
\text { (Ångstroms) }\end{array}$} \\
\hline $\mathrm{I}$ & Atom & $\mathrm{X}$ & $\mathrm{Y}$ & $\mathrm{Z}$ \\
\hline 1 & $\mathrm{O}$ & -1.92915 & 0.83209 & 1.22879 \\
\hline 2 & $\mathrm{C}$ & -2.50949 & -0.38663 & 1.36309 \\
\hline 3 & $\mathrm{C}$ & -1.69695 & -1.44318 & 0.64714 \\
\hline 4 & $\mathrm{C}$ & -0.93977 & -0.61281 & -0.34372 \\
\hline 5 & $\mathrm{C}$ & -0.98565 & 0.7964 & 0.16319 \\
\hline 6 & $\mathrm{C}$ & -0.70612 & -1.99933 & 1.71609 \\
\hline 7 & $\mathrm{C}$ & 0.41038 & -1.08146 & 2.18645 \\
\hline 8 & $\mathrm{C}$ & 1.26561 & -1.50913 & 3.29747 \\
\hline 9 & $\mathrm{O}$ & 2.17982 & -0.54751 & 3.52227 \\
\hline 10 & $\mathrm{C}$ & 1.99815 & 0.45643 & 2.64564 \\
\hline 11 & $\mathrm{C}$ & 0.86898 & 0.11324 & 1.78185 \\
\hline 12 & $\mathrm{C}$ & 0.43126 & 1.08068 & 0.69241 \\
\hline 13 & $\mathrm{C}$ & 0.06743 & -1.1027 & -1.09844 \\
\hline 14 & $\mathrm{C}$ & 1.35316 & 1.07738 & -0.57002 \\
\hline 15 & $\mathrm{C}$ & 1.32017 & -0.28074 & -1.36474 \\
\hline 16 & $\mathrm{C}$ & 2.56018 & -1.11879 & -1.02169 \\
\hline 17 & $\mathrm{C}$ & -0.5908 & 1.99059 & -1.91943 \\
\hline 18 & $\mathrm{C}$ & 0.85886 & 2.21487 & -1.48623 \\
\hline 19 & $\mathrm{C}$ & -1.13894 & 3.21904 & -2.63661 \\
\hline 20 & $\mathrm{O}$ & -1.44076 & 1.727 & -0.80865 \\
\hline 21 & $\mathrm{O}$ & -3.48388 & -0.59619 & 2.06923 \\
\hline 22 & $\mathrm{O}$ & 2.66227 & 1.47195 & 2.56177 \\
\hline 23 & $\mathrm{O}$ & 1.16449 & -2.56305 & 3.89599 \\
\hline 24 & $\mathrm{C}$ & -2.59148 & -2.5104 & 0.03315 \\
\hline 25 & $\mathrm{H}$ & -0.23327 & -2.90839 & 1.31891 \\
\hline
\end{tabular}




\begin{tabular}{|c|c|c|c|c|}
\hline 26 & $\mathrm{H}$ & -1.28144 & -2.31483 & 2.59767 \\
\hline 27 & $\mathrm{H}$ & 0.43025 & 2.08859 & 1.13162 \\
\hline 28 & $\mathrm{H}$ & 0.12158 & -2.16758 & -1.32149 \\
\hline 29 & $\mathrm{H}$ & 2.38346 & 1.31579 & -0.27702 \\
\hline 30 & $\mathrm{H}$ & 1.37416 & -0.08509 & -2.44329 \\
\hline 31 & $\mathrm{H}$ & 2.58265 & -2.04245 & -1.61129 \\
\hline 32 & $\mathrm{H}$ & 3.47607 & -0.56323 & -1.2508 \\
\hline 33 & $\mathrm{H}$ & 2.59165 & -1.39979 & 0.03516 \\
\hline 34 & $\mathrm{H}$ & -0.66129 & 1.14921 & -2.61733 \\
\hline 35 & $\mathrm{H}$ & 0.9398 & 3.16171 & -0.9361 \\
\hline 36 & $\mathrm{H}$ & 1.50672 & 2.30545 & -2.3664 \\
\hline 37 & $\mathrm{H}$ & -0.5419 & 3.46373 & -3.52035 \\
\hline 38 & $\mathrm{H}$ & -1.15465 & 4.08842 & -1.96996 \\
\hline 39 & $\mathrm{H}$ & -2.17408 & 3.04679 & -2.95114 \\
\hline 40 & $\mathrm{H}$ & -3.30738 & -2.07233 & -0.67215 \\
\hline 41 & $\mathrm{H}$ & -2.00759 & -3.26468 & -0.5052 \\
\hline 42 & $\mathrm{H}$ & -3.17249 & -3.02907 & 0.80418 \\
\hline
\end{tabular}

Figure S69. DFT-optimized structures for low-energy conformers of $(7 R, 8 R, 12 R, 15 R$, 16R, 18R)-5a at B3LYP/6-31+G(d) level in methanol (CPCM) (Conformer populations were calculated using the Gibbs free energy and Boltzmann population at $298 \mathrm{~K}$ estimated thereof).

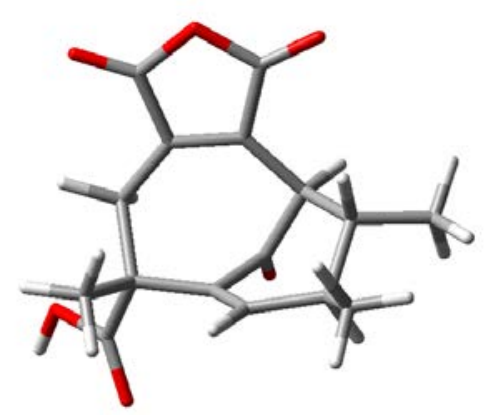

Conf. A $23.57 \%$

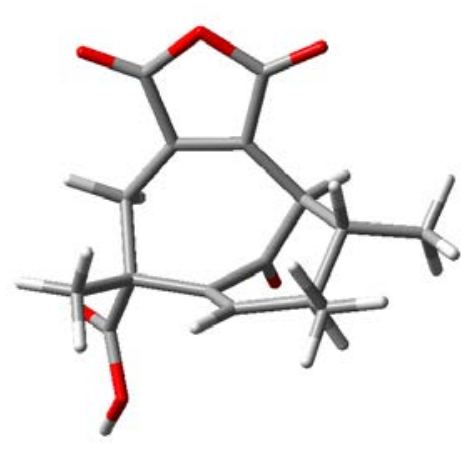


Table S7. Harmonic frequencies $\left(\mathrm{cm}^{* *-1}\right)$ of 5 A.

\begin{tabular}{|c|c|c|c|}
\hline \multirow{2}{*}{ Conformations } & \multicolumn{3}{|c|}{ Frequencies } \\
\cline { 2 - 4 } & 1 & 2 & 3 \\
\hline A & 27.4711 & 44.4727 & 50.9488 \\
\hline B & 39.9717 & 42.2403 & 50.6799 \\
\hline
\end{tabular}

Table S8. Important thermodynamic parameters (a.u.) and Boltzmann distributions of the optimized 5a at B3LYP/6-31G+(d) level of theory with PCM solvent model for $\mathrm{MeOH}$.

\begin{tabular}{|c|c|c|c|}
\hline Conformations & E+ZPE & G & \% \\
\hline A & -1070.317273 & -1070.362245 & $23.57 \%$ \\
\hline B & -1070.435243 & -1070.483131 & $76.43 \%$ \\
\hline
\end{tabular}

E+ZPE, G: total energy with zero point energy (ZPE) and Gibbs free energy at B3LYP/6-31G+(d) level of theory with PCM solvent model for MeOH. \%: Boltzmann distributions, using the relative Gibbs free energies as weighting factors 
Table S9. Cartesian coordinates of the low-energy reoptimized conformers of ( $7 R, 8 R$, $12 R, 15 R, 16 R, 18 R)-5 a$ calculated at B3LYP/6-31+G(d) level of theory with PCM solvent model for $\mathrm{MeOH}$.

\begin{tabular}{|c|c|c|c|c|}
\hline \multicolumn{2}{|c|}{ Conformer A } & \multicolumn{3}{|c|}{$\begin{array}{c}\text { Standard Orientation } \\
\text { (Ångstroms) }\end{array}$} \\
\hline $\mathrm{I}$ & Atom & $\mathrm{X}$ & $\mathrm{Y}$ & $\mathrm{Z}$ \\
\hline 1 & $\mathrm{O}$ & -3.17111 & -2.57249 & -1.4982 \\
\hline 2 & $\mathrm{C}$ & -1.86135 & -2.29734 & -1.65998 \\
\hline 3 & $\mathrm{C}$ & -1.19979 & -1.69322 & -0.41989 \\
\hline 4 & $\mathrm{C}$ & -0.11896 & -0.74211 & -0.89184 \\
\hline 5 & $\mathrm{C}$ & -0.59422 & 0.63731 & -1.19774 \\
\hline 6 & $\mathrm{C}$ & -2.23268 & -0.8985 & 0.46281 \\
\hline 7 & $\mathrm{C}$ & -1.68047 & 0.17551 & 1.37384 \\
\hline 8 & $\mathrm{C}$ & -2.04003 & 0.2562 & 2.78822 \\
\hline 9 & $\mathrm{O}$ & -1.43866 & 1.34288 & 3.31051 \\
\hline 10 & $\mathrm{C}$ & -0.71932 & 1.96209 & 2.35526 \\
\hline 11 & $\mathrm{C}$ & -0.85453 & 1.20079 & 1.11711 \\
\hline 12 & $\mathrm{C}$ & -0.15914 & 1.63848 & -0.15543 \\
\hline 13 & $\mathrm{C}$ & 1.21654 & -0.81333 & -0.7541 \\
\hline 14 & $\mathrm{C}$ & 1.40389 & 1.6219 & -0.08316 \\
\hline 15 & $\mathrm{C}$ & 2.06453 & 0.43617 & -0.87223 \\
\hline 16 & $\mathrm{C}$ & 3.48797 & 0.16149 & -0.3755 \\
\hline 17 & $\mathrm{C}$ & 1.95138 & 2.96402 & -0.59029 \\
\hline 18 & $\mathrm{O}$ & -1.39123 & 0.8652 & -2.09659 \\
\hline 19 & $\mathrm{O}$ & -1.30462 & -2.61752 & -2.69893 \\
\hline 20 & $\mathrm{O}$ & -0.06157 & 2.97617 & 2.48884 \\
\hline 21 & $\mathrm{O}$ & -2.75041 & -0.53041 & 3.38385 \\
\hline 22 & $\mathrm{C}$ & -0.64328 & -2.86766 & 0.40703 \\
\hline 23 & $\mathrm{H}$ & -3.43759 & -2.95728 & -2.36136 \\
\hline 24 & $\mathrm{H}$ & -2.81451 & -1.61705 & 1.05558 \\
\hline 25 & $\mathrm{H}$ & -2.97912 & -0.41053 & -0.18075 \\
\hline 26 & $\mathrm{H}$ & -0.53584 & 2.62689 & -0.44425 \\
\hline 27 & $\mathrm{H}$ & 1.69914 & -1.73805 & -0.44864 \\
\hline 28 & $\mathrm{H}$ & 1.70731 & 1.53986 & 0.96963 \\
\hline 29 & $\mathrm{H}$ & 2.13462 & 0.69094 & -1.93888 \\
\hline 30 & $\mathrm{H}$ & 3.93804 & -0.67392 & -0.92397 \\
\hline 31 & $\mathrm{H}$ & 4.13574 & 1.03115 & -0.52011 \\
\hline 32 & $\mathrm{H}$ & 3.49765 & -0.09482 & 0.6899 \\
\hline 33 & $\mathrm{H}$ & 1.70548 & 3.11667 & -1.64663 \\
\hline
\end{tabular}




\begin{tabular}{|c|c|c|c|c|}
\hline 34 & H & 3.03834 & 3.02096 & -0.48238 \\
\hline 35 & H & 1.52426 & 3.79571 & -0.01947 \\
\hline 36 & H & 0.0522 & -3.48097 & -0.17841 \\
\hline 37 & H & -0.11903 & -2.51904 & 1.30407 \\
\hline 38 & H & -1.44961 & -3.53613 & 0.73209 \\
\hline
\end{tabular}

\begin{tabular}{|c|c|c|c|c|}
\hline \multicolumn{2}{|c|}{ Conformer B } & \multicolumn{3}{|c|}{ Standard Orientation } \\
\hline I & Atom & X & Y & Z \\
\hline 1 & O & -0.56765 & -3.55355 & -1.51022 \\
\hline 2 & C & -1.48502 & -2.99606 & -0.6936 \\
\hline 3 & C & -0.91833 & -1.92116 & 0.23534 \\
\hline 4 & C & 0.00852 & -1.01003 & -0.54147 \\
\hline 5 & C & -0.67396 & 0.06621 & -1.31234 \\
\hline 6 & C & -2.10802 & -1.06758 & 0.81544 \\
\hline 7 & C & -1.79141 & 0.33438 & 1.28456 \\
\hline 8 & C & -2.2188 & 0.83222 & 2.5907 \\
\hline 9 & O & -1.84337 & 2.12243 & 2.68876 \\
\hline 10 & C & -1.20513 & 2.49225 & 1.5623 \\
\hline 11 & C & -1.14833 & 1.3381 & 0.66991 \\
\hline 12 & C & -0.48417 & 1.42751 & -0.68844 \\
\hline 13 & C & 1.32555 & -0.78427 & -0.39152 \\
\hline 14 & C & 1.05141 & 1.72586 & -0.64248 \\
\hline 15 & C & 1.95404 & 0.47712 & -0.94712 \\
\hline 16 & C & 3.36567 & 0.66244 & -0.38005 \\
\hline 17 & C & 1.37893 & 2.86278 & -1.62155 \\
\hline 18 & O & -1.41727 & -0.1804 & -2.25086 \\
\hline 19 & O & -2.63522 & -3.40637 & -0.70323 \\
\hline 20 & O & -0.74472 & 3.59145 & 1.31996 \\
\hline 21 & O & -2.8001 & 0.18459 & 3.43961 \\
\hline 22 & C & -0.21723 & -2.64524 & 1.39967 \\
\hline 23 & H & -1.08281 & -4.1876 & -2.05294 \\
\hline 24 & H & -2.57926 & -1.6318 & 1.63141 \\
\hline 25 & H & -2.90289 & -0.97112 & 0.0613 \\
\hline 26 & H & -1.01881 & 2.16746 & -1.29574 \\
\hline 27 & H & 1.93931 & -1.44149 & 0.21893 \\
\hline 28 & H & 1.30937 & 2.09479 & 0.35961 \\
\hline 29 & H & 2.05416 & 0.34587 & -2.03357 \\
\hline 30 & H & 3.99015 & -0.21233 & -0.59465 \\
\hline 31 & H & 3.86156 & 1.53209 & -0.82134 \\
\hline H & H & 3.34541 & 0.79949 & 0.70701 \\
\hline 34 & 2.43334 & 3.14859 & -1.56639 \\
\hline
\end{tabular}




\begin{tabular}{|c|c|c|c|c|}
\hline 35 & $\mathrm{H}$ & 0.78726 & 3.75483 & -1.38889 \\
\hline 36 & $\mathrm{H}$ & 0.60283 & -3.28145 & 1.04616 \\
\hline 37 & $\mathrm{H}$ & 0.19146 & -1.9367 & 2.12905 \\
\hline 38 & $\mathrm{H}$ & -0.91548 & -3.30354 & 1.93058 \\
\hline
\end{tabular}

Figure S70. DFT-optimized structures for low-energy conformers of (7R, 8R, 12S, 15R, 16R, 18R)-6a at B3LYP/6-31+G(d) level in methanol (CPCM) (Conformer populations were calculated using the Gibbs free energy and Boltzmann population at $298 \mathrm{~K}$ estimated thereof).

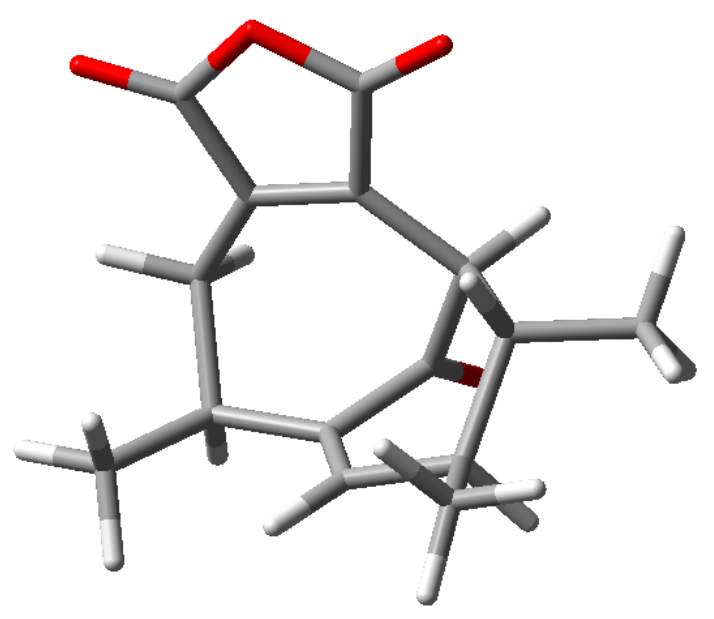

Conf. A 100.0\%

Table S10. Harmonic frequencies $\left(\mathrm{cm}^{* *-1}\right)$ of $6 \mathrm{~A}$.

\begin{tabular}{|c|c|c|c|}
\hline \multirow{2}{*}{ Conformations } & \multicolumn{3}{|c|}{ Frequencies } \\
\cline { 2 - 4 } & 1 & 2 & 3 \\
\hline $\mathrm{A}$ & 39.5743 & 51.8208 & 71.5614 \\
\hline
\end{tabular}

Table S11. Important thermodynamic parameters (a.u.) and Boltzmann distributions of the optimized 6a at B3LYP/6-31G+(d) level of theory with PCM solvent model for $\mathrm{MeOH}$.

\begin{tabular}{|c|c|c|c|}
\hline Conformations & E+ZPE & G & \% \\
\hline A & -881.872737 & -881.916701 & $100.0 \%$ \\
\hline
\end{tabular}

E+ZPE, G: total energy with zero point energy (ZPE) and Gibbs free energy at B3LYP/6-31G+(d) level of theory with PCM solvent model for MeOH. \%: Boltzmann 
distributions, using the relative Gibbs free energies as weighting factors

Table S12. Cartesian coordinates of the low-energy reoptimized conformers of (7R, $8 R$, $12 S, 15 R, 16 R, 18 R)-6 a$ calculated at B3LYP/6-31+G(d) level of theory with PCM solvent model for $\mathrm{MeOH}$.

\begin{tabular}{|c|c|c|c|c|}
\hline \multicolumn{2}{|c|}{ Conformer A } & \multicolumn{3}{|c|}{$\begin{array}{c}\text { Standard Orientation } \\
\text { (Ångstroms) }\end{array}$} \\
\hline I & Atom & $\mathrm{X}$ & $\mathrm{Y}$ & $\mathrm{Z}$ \\
\hline 1 & $\mathrm{C}$ & -1.59635 & -1.74878 & -0.67837 \\
\hline 2 & $\mathrm{C}$ & -0.44897 & -0.88378 & -1.13273 \\
\hline 3 & $\mathrm{C}$ & -0.79435 & 0.54755 & -1.36296 \\
\hline 4 & $\mathrm{C}$ & -2.53924 & -0.94169 & 0.27683 \\
\hline 5 & $\mathrm{C}$ & -1.89193 & 0.04797 & 1.21496 \\
\hline 6 & $\mathrm{C}$ & -2.23307 & 0.10292 & 2.63536 \\
\hline 7 & $\mathrm{O}$ & -1.53597 & 1.11167 & 3.19369 \\
\hline 8 & $\mathrm{C}$ & -0.77471 & 1.70546 & 2.25516 \\
\hline 9 & $\mathrm{C}$ & -0.98557 & 1.01038 & 0.98889 \\
\hline 10 & $\mathrm{C}$ & -0.26785 & 1.44638 & -0.27103 \\
\hline 11 & $\mathrm{C}$ & 0.87494 & -1.08419 & -1.01877 \\
\hline 12 & $\mathrm{C}$ & 1.28866 & 1.28577 & -0.22147 \\
\hline 13 & $\mathrm{C}$ & 1.83207 & 0.08891 & -1.0817 \\
\hline 14 & $\mathrm{C}$ & 3.22914 & -0.33922 & -0.61991 \\
\hline 15 & $\mathrm{C}$ & 1.95077 & 2.59843 & -0.6649 \\
\hline 16 & $\mathrm{O}$ & -1.53824 & 0.90144 & -2.26669 \\
\hline 17 & $\mathrm{O}$ & -0.0318 & 2.6539 & 2.42184 \\
\hline 18 & $\mathrm{O}$ & -3.00796 & -0.63925 & 3.2076 \\
\hline 19 & $\mathrm{C}$ & -1.15274 & -3.04316 & 0.01566 \\
\hline 20 & $\mathrm{H}$ & -2.17895 & -2.0392 & -1.56239 \\
\hline 21 & $\mathrm{H}$ & -3.15919 & -1.64782 & 0.8434 \\
\hline 22 & $\mathrm{H}$ & -3.25456 & -0.37858 & -0.33954 \\
\hline 23 & $\mathrm{H}$ & -0.55629 & 2.47858 & -0.50304 \\
\hline 24 & $\mathrm{H}$ & 1.27174 & -2.06034 & -0.75327 \\
\hline 25 & $\mathrm{H}$ & 1.59295 & 1.12008 & 0.82121 \\
\hline 26 & $\mathrm{H}$ & 1.91574 & 0.39383 & -2.13413 \\
\hline 27 & $\mathrm{H}$ & 3.59651 & -1.18121 & -1.21773 \\
\hline 28 & $\mathrm{H}$ & 3.95178 & 0.47506 & -0.72755 \\
\hline 29 & $\mathrm{H}$ & 3.22516 & -0.65206 & 0.43032 \\
\hline 30 & $\mathrm{H}$ & 1.71015 & 2.82895 & -1.70824 \\
\hline 31 & $\mathrm{H}$ & 3.03936 & 2.55142 & -0.56925 \\
\hline
\end{tabular}




\begin{tabular}{|c|c|c|c|c|}
\hline 32 & $\mathrm{H}$ & 1.60595 & 3.43342 & -0.04535 \\
\hline 33 & $\mathrm{H}$ & -2.02239 & -3.64562 & 0.30055 \\
\hline 34 & $\mathrm{H}$ & -0.53873 & -3.65842 & -0.65111 \\
\hline 35 & $\mathrm{H}$ & -0.57608 & -2.83882 & 0.92468 \\
\hline
\end{tabular}

Figure S71. The experimental ECD spectra for compound $\mathbf{5}$ and the calculated ones using the truncated model compounds (5a and $\mathbf{5 b}$ ).

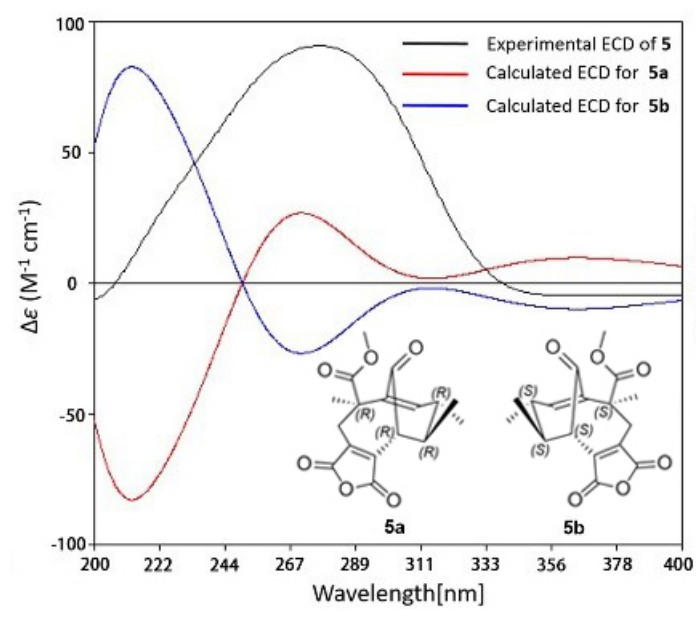

Figure S72. ITS rRNA gene sequence of HDN1820200.

GGCTACGGGTCGGGTTCACGAGCCCAACCTCCCACCCGTGTTTACCGTGAC CGCGTTGCCTCGGCGGGCCCACTGGGGCCTGGCCCCGGTCGCCGGGGGGC ATCTGCCCCCGGGCCCGCGCCCGCCGAAGCGCCCTAGAACCCTGTCTGAA CAGTGAGTCTGAGTGAATGATTCAATCATTAAAACTTTCAACAACGGATCT CTTGGTTCCGGCATCGATGAAGAACGCAGCGAAATGCGATAATTAATGTGA ATTGCAGAATTCCGTGAATCATCGAGTTTTTGAACGCACATTGCGCCCCCTG GCATTCCGGGGGGCATGCCTGTCCGAGCGTCATTTCTGCCCTCCAGCACGG CTGGGTGTTGGGCGCTGTCCCCCCGGGGACACGCCCCAAAGGCAGTGGCG GCGCCGCATCGGGTCCTCGAGCGTATGGGGCTTTGTCACCCGCTCGGGAGG GACTCGTCGGCGCTGGTCTTCCCCCAGGCGACCCTTCGGGGCTCGTCTTCT 
TCCGGTTGACCTCGGATCAGGTAGGGTTACCCGCTGAACTTAAGCATATCA

ATAAGCGGAGGAA

Figure S73. HPLC-UV profile of Talaromyces sp. HDN1820200.

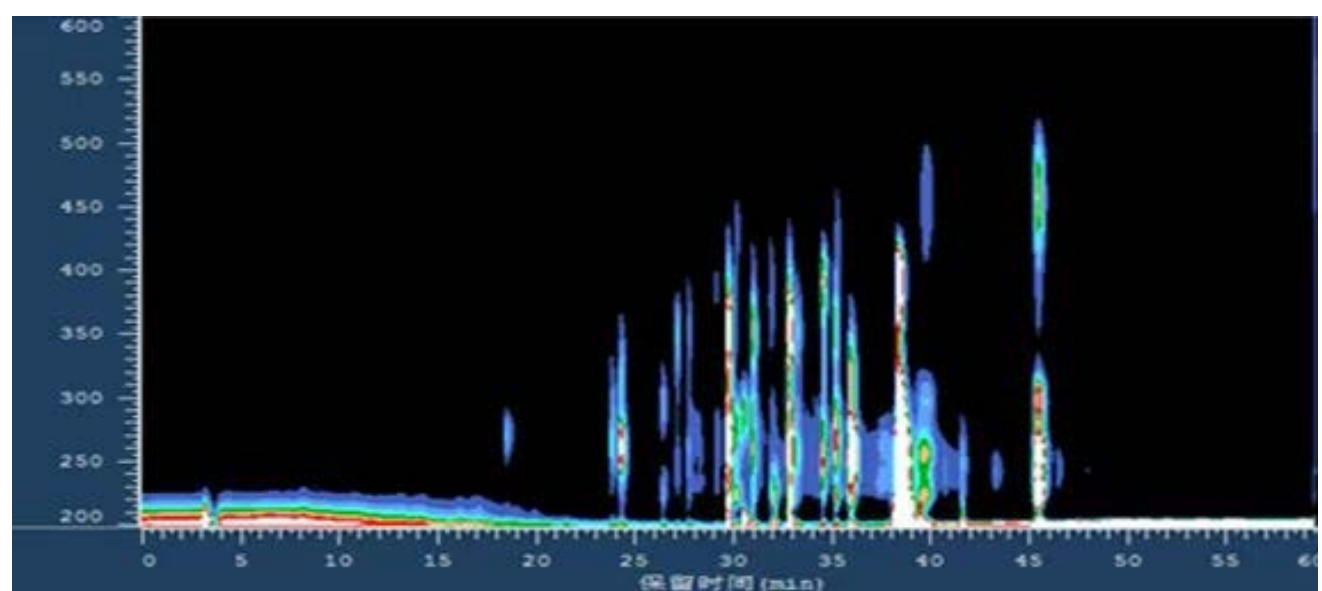

